University of Louisville

ThinkIR: The University of Louisville's Institutional Repository

Electronic Theses and Dissertations

$12-2014$

\title{
Predictors of lifestyle behaviors, trust of health care provider, and utilization of health services among adolescents living in a rural area.
}

Heather Karolyne Hardin

University of Louisville

Follow this and additional works at: https://ir.library.louisville.edu/etd

Part of the Nursing Commons

\section{Recommended Citation}

Hardin, Heather Karolyne, "Predictors of lifestyle behaviors, trust of health care provider, and utilization of health services among adolescents living in a rural area." (2014). Electronic Theses and Dissertations. Paper 1742.

https://doi.org/10.18297/etd/1742

This Doctoral Dissertation is brought to you for free and open access by ThinkIR: The University of Louisville's Institutional Repository. It has been accepted for inclusion in Electronic Theses and Dissertations by an authorized administrator of ThinkIR: The University of Louisville's Institutional Repository. This title appears here courtesy of the author, who has retained all other copyrights. For more information, please contact thinkir@louisville.edu. 


\title{
PREDICTORS OF LIFESTYLE BEHAVIORS, TRUST OF HEALTH CARE PROVIDER, AND UTILIZATION OF HEALTH SERVICES AMONG ADOLESCENTS LIVING IN A RURAL AREA
}

\author{
By \\ Heather Karolyne Hardin \\ BSN, Indiana University Southeast, 2007 \\ MSN, University of Louisville, 2012

\begin{abstract}
A Dissertation
Submitted to the Faculty of the

School of Nursing of the University of Louisville in Partial Fulfillment of the Requirements for the Degree of
\end{abstract}

Doctor of Philosophy

School of Nursing University of Louisville

Louisville, Kentucky

December 2014 
Copyright 2014 by Heather Karolyne Hardin

All rights reserved 

PREDICTORS OF LIFESTYLE BEHAVIORS, TRUST OF HEALTH CARE PROVIDER, AND UTILIZATION OF HEALTH SERVICES AMONG ADOLESCENTS LIVING IN A RURAL AREA

\author{
By \\ Heather Karolyne Hardin \\ BSN, Indiana University Southeast, 2007 \\ MSN, University of Louisville, 2012 \\ A Dissertation Approved on
}

September 29, 2014

By the following Dissertation Committee:

Barbara J. Speck, PhD, RN, Dissertation Director

S. Lee Ridner, PhD, FNP-BC, Committee Member

Valerie Lander McCarthy, PhD, RN, Committee Member

Timothy Crawford, PhD, MPH, Committee Member

M. Susan Jones, PhD, RN, CNE, ANEF Committee Member 


\section{ACKNOWLEDGMENTS}

While my name appears on the cover of this dissertation, several people have contributed significantly to its completion. As with all dissertations, this process was a long process and the result of the guidance, support, and friendship of several individuals. I am grateful to all those who have helped me finish this project.

I would first like to thank my dissertation chair, Dr. Barbara J. Speck. Dr. Speck encouraged me to produce this dissertation while balancing my family and work demands. In addition, Dr. Speck was very gracious in continuing to mentor me, even after her retirement. In addition, I would like to show my appreciation to my dissertation committee members: Dr. Lee Ridner, Dr. Susan Jones, Dr. Valerie Lander McCarthy, and Dr. Timothy Crawford. Thank you for your rigorous scholarship and your patient guidance!

I would also like to express my appreciation to members of my community and especially my research participants. Without your support and thoughtful responses, this work would not have been possible. In the same way, I thank the administrators, faculty, and staff at the high school for allowing me access to the students and for your gracious assistance. Thank you to my friend, Dr. David Winton, for your shared concern for rural adolescents and in encouraging me to the finish. In addition, I would like to thank the Rural Nurses Organization for partial funding of this dissertation study.

Several friends have been instrumental in encouraging me when this dissertation seemed too much to bear. I owe a debt of gratitude to my "PhD sisters" Lisa Carter- 
Harris, Sheila Steinbrenner, Xiaorong Wang, Glenda Adams, Luz Huntington-Moskos, Maryam Alaradi, and Irene Yang. I appreciate your endless camaraderie and hugs. Your friendship and encouragement kept me going when I wanted to quit. For this, I am truly grateful!

Finally, I would like to show the utmost appreciation to my family and closest friends. Thank you to my parents, brothers, and sisters for cheering me on, particularly with our ongoing discussion of the value of pie charts and Venn diagrams. Thank you to my closest friend, Dr. Whitney Goldsberry, for sharing with me the experience of doctoral education. Most of all, thank you to my husband, Joshua. There were many days where there seemed to be no light at the end of this $\mathrm{PhD}$ tunnel; however, you walked beside me, held my hand, and used a flashlight to illuminate my path. Thank you for relieving me of stress and inspiring courage when I needed it most. 


\section{ABSTRACT \\ PREDICTORS OF LIFESTYLE BEHAVIORS, TRUST OF HEALTH CARE PROVIDER, AND UTILIZATION OF HEALTH SERVICES AMONG ADOLESCENTS LIVING IN A RURAL AREA}

Heather K. Hardin

December 18, 2014

Background: Adolescents have elevated morbidity and mortality rates associated with risk-taking behaviors, but utilize health services at low levels. There is little evidence concerning health behavior, trust of health care provider, or utilization of health services among adolescents living in rural areas.

Purpose: The purpose of this study was to examine individual characteristic variables and determine the extent to which these variables influence lifestyle behaviors, trust of health care provider (HCP), and utilization of health services among adolescents attending public high school in rural Indiana.

Methods: This study used a cross-sectional, quantitative design. Instruments used in this study were the Wake Forest Interpersonal Trust in Physician scale, Adolescent Lifestyle Questionnaire, the Stanford Health Care Utilization Questionnaire, and an investigatordeveloped individual characteristic survey. Hierarchical multiple regression evaluated individual characteristic variables as predicting lifestyle behaviors and trust of HCP, while negative binomial regression predicted number of HCP visits and number of emergency room visits in the past 12 months. 
Results: Correlations, analysis of variance, and Kruskal-Wallis tests evaluated relationships between variables. Trust of HCP was predicted by usual source of care, health insurance, lifestyle behavior, and transportation difficulty. Lifestyle behavior was predicted by self-rated health, age, trust of HCP, and sex. Predictors of number of HCP visits were sex, household income, self-rated health, self-perceived need, health insurance, and number of ER visits, while household income and number of HCP visits predicted number of ER visits.

Conclusion: This study adds to the evidence regarding health services utilization and lifestyle behavior, while providing an initial reliable quantitative measurement of trust of HCPs among American adolescents living in a rural area. Results of this study demonstrate the importance of having a $\mathrm{HCP}$ as a usual source of care and the need for school-based health services in rural areas. Future research should test the Wake Forest Trust in Physician scale among diverse adolescent samples, measure intention to seek health services beliefs, and evaluate informal sources of health information among rural adolescents. Additionally, research should evaluate the risk for or existence of chronic health conditions using biological markers among adolescents living in a rural area, along with behavior interventions to prevent or self-manage identified chronic health conditions. With approximately $22 \%$ of American adolescents living in rural areas and therefore at risk for poor outcomes, it is imperative that the research community place greater attention on the health of rural dwelling adolescents. 


\section{TABLE OF CONTENTS}

ABSTRACT

CHAPTER I: RESEARCH PROBLEM ............................................................. 1

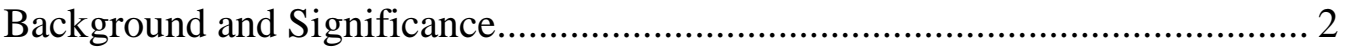

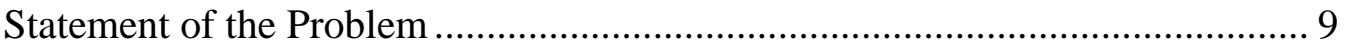

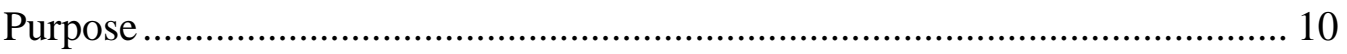

Andersen's Behavioral Model of Health Services Use.................................. 10

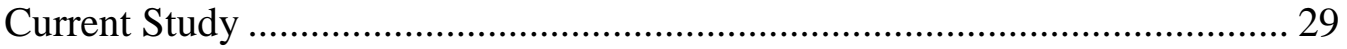

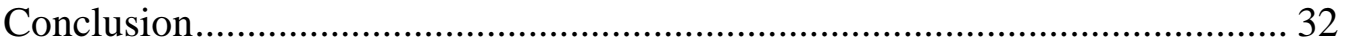

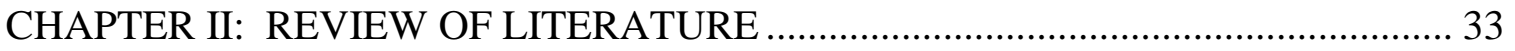

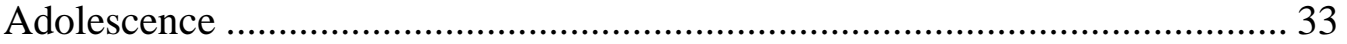

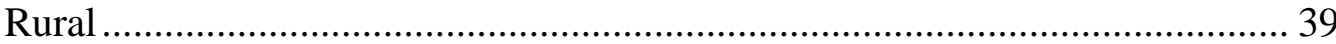

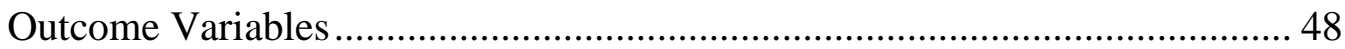

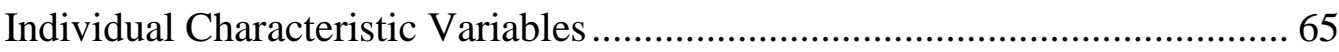

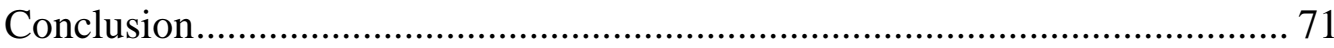

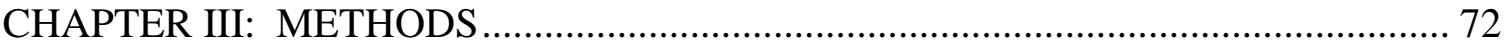

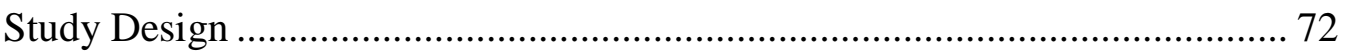


Human Subjects Protection

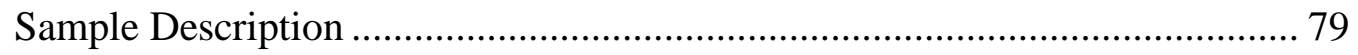

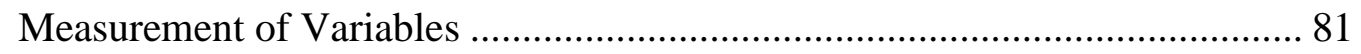

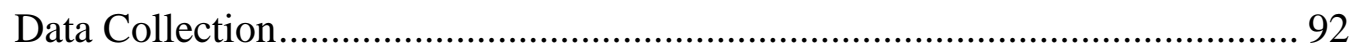

Data Management Procedures.................................................................... 92

Ethical Considerations......................................................................... 108

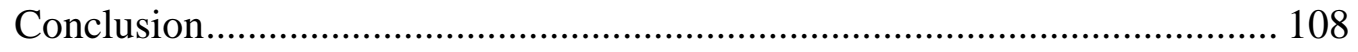

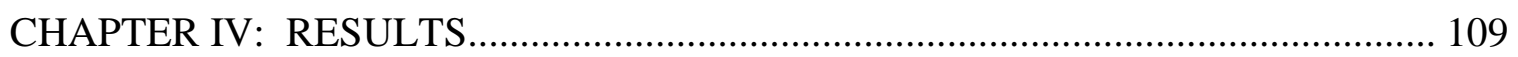

Predisposing Individual Characteristics ................................................ 109

Enabling Individual Characteristics ..................................................... 112

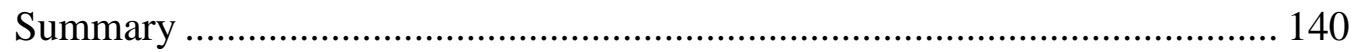

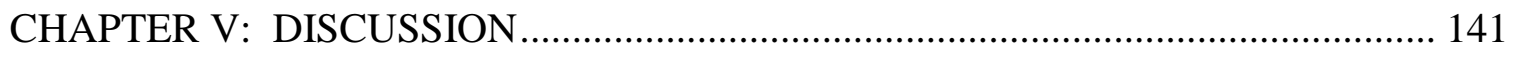

Andersen's Behavioral Model of Health Services Use.............................. 141

Research Questions .................................................................. 142

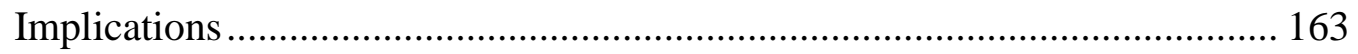

Recommendations for Future Research ............................................... 165

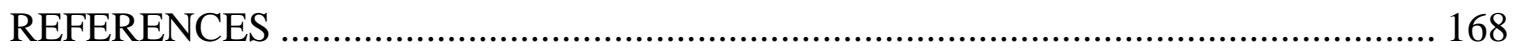

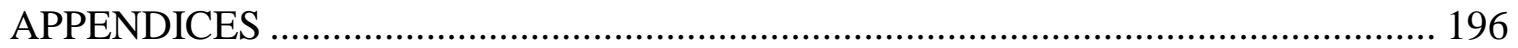

A. Parental Passive Consent Letter .......................................................... 196

B. Institutional Review Board Approval Letter ........................................ 197

C. Minor's Survey Informational Cover Sheet .......................................... 199 
D. Adult Participant Passive Consent Letter and Coversheet

E. Wake Forest Interpersonal Trust in Physician Scale .............................. 201

F. Adolescent Lifestyle Questionnaire ........................................................ 202

G. Stanford Health Care Utilization Questionnaire ..................................... 205

H. Demographic and Individual Characteristic Survey ............................. 206

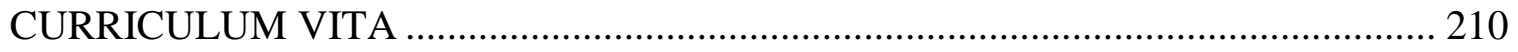




\section{LIST OF TABLES}

\section{TABLE}

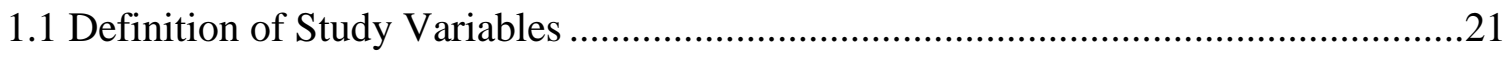

3.1 Normality Statistics for Continuous Outcome Variables......................................96

4.1 Predisposing Individual Characteristics of Sample ............................................111

4.2 Enabling Individual Characteristics of the Sample............................................113

4.3 Need Individual Characteristics of the Sample ...............................................115

4.4 Descriptive Statistics for Outcome Variables ....................................................116

4.5 Tobacco Use and Body Mass Index of the Sample ............................................117

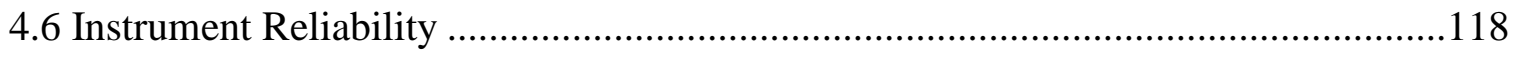

4.7 Correlations between Independent Variables and Dependent Variables ..................121

4.8 One-way Analysis of Variance with Categorical Independent Variables ................123

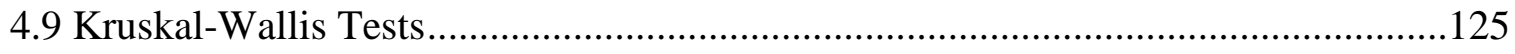

4.10 Correlations between ALQ Subscales and Variables .......................................128

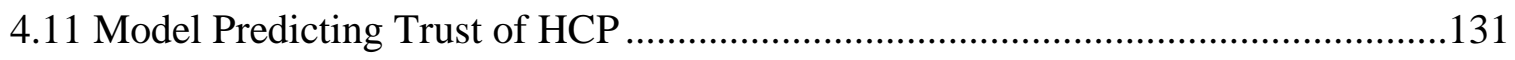

4.12 Model Predicting Lifestyle Behaviors ......................................................134

4.13 Model Predicting Number of HCP Visits .....................................................137

4.14 Model Predicting Number of ER Visits..........................................................139 


\section{LIST OF FIGURES}

\section{FIGURES}

1.1 Andersen's Behavioral Model of Health Services Use..........................................12

1.2 Andersen's Behavioral Model of Health Services Use adapted for study ..................21

3.1 Normal probability plots for total trust of HCP and total ALQ score ......................97

3.2 Normal probability plots for number of HCP visits.........................................98

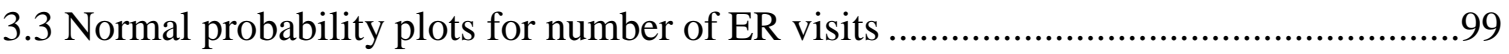

3.4 Box plots identifying extreme outliers on HCP visits and ER visits .......................101

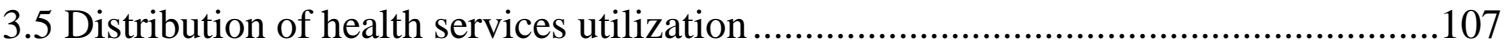




\section{CHAPTER I}

\section{RESEARCH PROBLEM}

It is known that adolescents living in rural areas are more likely than urban and

suburban adolescents to engage in risk-taking behaviors (Atav \& Spencer, 2002, p. 1092), to have less access to quality health services (Elliott \& Larson, 2004; Nasim, Fernander, Townsend, Corona, \& Belgrave, 2011; Niemira, 2010; Thomas, 2010), and demonstrate lower rates of health services utilization (Arcury, Preisser, Gesler, \& Powers, 2005; Garside, Ayres, Owen, Pearson, \& Roizen, 2002). This combination of factors may result in life-long health consequences.

A lack of trust of health care providers (HCP) has been reported in several qualitative studies among adolescents from diverse groups — both in the U.S. and internationally—when utilizing health services related to risk-taking behaviors (BrelandNoble, Burriss, \& Poole, 2010; Klostermann, Slap, Nebrig, Tivorsak, \& Britto, 2005; Leavey, Rothi, \& Paul, 2011; Renker, 2006; Tinnfält, Eriksson, \& Brunnberg, 2011). A single study in England described adolescents reporting high levels of trust of HCP when measuring adolescents' satisfaction with a nurse-led, drop-in, sexually transmitted disease (STD) clinic. The high levels of trust of HCPs reported among these adolescents were attributed to confidential, professional care provided by friendly staff (Ingram \& Salmon, 2007). Adolescents who received health services for a chronic illness reported higher levels of trust of HCP. These qualitative reports suggested higher levels of trust of HCP 
among adolescents with chronic illnesses were related to the adolescents' faith in their parents' trust of HCP (Broome \& Richards, 2003; Klostermann et al., 2005). The difference in levels of trust of HCP between adolescents who received preventative or acute health services and those that received chronic illness care (Blake, Robley, \& Taylor, 2012; Britto et al., 2004) seemed to be related to adolescents' interest in keeping knowledge of risk-taking behaviors from parents (Cogswell, 1985; Ingram \& Salmon, 2007; McKee, O'Sullivan, \& Weber, 2006). It seems likely that adolescents living in the rural United States would also report lower levels of trust of HCPs when receiving preventative and acute health services. Additionally, accessing health services in a rural area may pose considerable social barriers such as a perceived lack of confidentiality and anonymity in the health services setting (Garside et al., 2002). The blend of adolescent developmental stage, rural culture, limited choices of HCPs, and previous experience-or lack of experience - with health services, may help to explain lower levels of health services utilization among adolescents living in rural areas (Probst, Moore, \& Baxley, 2005).

\section{Background and Significance}

Adolescence begins at about age 10 with the onset of puberty (Neinstein, 2009), and newer research of brain development suggests adolescence continues throughout emerging adulthood to age 25 (Steinberg, 2008). The end of adolescence is defined by the finalization of prefrontal cortex brain development, resulting in improved emotional regulation and impulse control (Steinberg, 2008). One aspect of cognitive development during adolescence is the ability to perceive situations and people with relativism-which is the realization that truth is subjective, rather than absolute (Chandler, 1987). 
Development of this new perspective of relativism causes the adolescent to question the validity of statements once believed to be factual. This process develops a sophisticated understanding of knowledge, but frequently leads to an interim period of extreme skepticism (Steinberg, 2010). During this period of skepticism, adolescents may become increasingly distrusting of others, especially of adults in positions of authority, including HCPs.

Several issues make utilization of health services an important, but complicated concern for adolescents, especially in rural areas. Health behavior, minor consent and confidentiality issues, access to and utilization of health services in rural areas, rural socio-environmental conditions, and trust of HCP are all concerns that influence adolescents' utilization of health services.

\section{Health Behavior}

Health behavior is an individual's lifestyle practices that affect health, whether the effect is positive or negative (Gillis, 1997). Health behavior may have a health promoting effect, while other behaviors — often termed risk-taking behaviors — may have a negative effect on health. As part of the developmental process (Steinberg, 2010b), adolescents are known for adopting risk-taking behaviors - which are any activities that threaten the development, health, and well-being of the individual (Rew, 2005).

Adolescents have peak physical strength and immune function compared to other developmental periods; however, psychological, cognitive, and social maturity lags behind physiological maturity. As a result of this immaturity, adolescents frequently engage in risk-taking behaviors (Steinberg, 2008). Adolescents are more likely to engage in risk-taking behaviors as a result of neurologic developmental and associated cognitive 
changes, which lead to increased reward-seeking behavior during a time of diminished impulse-control (Steinberg, 2010b). Risk-taking plays a central role in normal adolescent development, creating the potential for self-discovery, as well as vulnerability to negative consequences. Risk-taking can serve as a means of self-discovery, by allowing adolescents to test abilities, explore potential consequences, gain new skills, and gather new experiences, which prepare the adolescent for future challenges. Risk-taking can also lead to harmful outcomes with long-term consequences (Centers for Disease Control and Prevention, 2012; Institute of Medicine \& National Research Council, 2011; Rew, 2005). Common risk-taking behaviors associated with the leading causes of morbidity and mortality among adolescents and adults in the U.S. include: (1) behaviors that result in unintentional injuries or violence; (2) tobacco, alcohol, and drug use; (3) unprotected sexual behaviors; (4) poor nutrition; and (5) physical inactivity (Centers for Disease Control and Prevention, 2012). Mortality rates triple between children in grade school and those aged 15- to 24-years because of adolescent risk-taking behaviors (MacKay \& Duran, 2007).

Health promoting behaviors are practices that have a positive effect on health. Pender, Murdaugh, and Parsons (2011) state that health-promoting behavior is associated with healthy lifestyle behaviors — which are patterns of daily activities that significantly affect health status in a positive way — and result in a high quality of life. While risktaking behaviors are the largest threat of adolescent morbidity and mortality, research shows that health-promoting behaviors significantly influence resilience to risk-taking behaviors and stress (Rew, 2001). Previous research has also demonstrated that adolescents are concerned about their health and how health behavior can adversely 
affect their physical attractiveness (Gillis, 1993), health (Halpern-Felsher \& Cauffman, 2001), and future success (Weiler, 1997).

\section{Minor Consent and Confidentiality}

Since adolescence includes both minors and adults (Neinstein, 2009; Steinberg, 2008), many adolescents are dependent upon parents/guardians for transportation, health insurance, and financial support for health services. In the U.S., federal law requires that all minors have the right to consent to testing and treatment for STDs without notifying or involving parents (Title X of the Public Health Service Act, 1970). For health services other than STD testing and treatment, each state has individually legislated minor consent and parental notification practices (Guttmacher Institute, 2013), meaning there is no national standard or consensus on minors' ability to consent for health services. As a result, many adolescents do not have the right to obtain confidential, private health services or to consent to treatment without the notification of parents/guardians (Cullen \& Salganicoff, 2011). The lack of confidentiality inherent in the relationship between the adolescent patient and their HCP results in diminished levels of trust.

\section{Access to and Utilization of Health Services}

Access to health services and utilization of health services are two inter-related, but distinct concepts. Access to health services is the degree of fit between a person and the health services system, including five dimensions of health services: availability, accessibility, accommodation, affordability, and acceptability (Penchansky \& Thomas, 1981). In reference to access to health services, availability refers to the supply of health services, accessibility involves transportation to the location of health services, accommodation involves ease of scheduling health services, affordability is the ability to 
pay for health services, and acceptability is the perception of attitudes between HCP and patient. Utilization of health services occurs with realized access to health services (Aday, Begley, Lairson, \& Balkrishnan, 2004).

Research has demonstrated that adolescents in general have low rates of both access to and utilization of health services (Ma, Wang, \& Stafford, 2005; Mulye et al., 2009; Rand et al., 2007). Contributors to low or inconsistent access to health services include lack of transportation, lack of health insurance, and out-of-pocket costs for services. Reasons for low utilization of preventative and acute health services include lack of parental support, along with issues related to confidentiality and minors' consent (Cullen \& Salganicoff, 2011; Lawrence, Gootman, \& Sim, 2009; Mulye et al., 2009). American adolescents frequently report foregone health services-which is not seeking health services when a subjective need for health services exists-for illness, injury, alcohol/drug treatment, mental health counseling, contraception, and treatment of STDs (Elliott \& Larson, 2004; Lehrer, Pantell, Tebb, \& Shafer, 2007). A lack of access to and utilization of health services, along with ambiguous legal status, compounds the problems of risk-taking behaviors among adolescents.

\section{Rural Socio-environmental Conditions}

People living in rural areas have additional barriers to utilization of health services such as lack of public transportation, long distances to travel, and scarcity of HCPs (Arcury et al., 2005; Nelson, 2008). General practice or family practice HCPs are frequently the only option available in rural communities (Geyman, Norris, \& Hart, 2001). Many rural areas report shortages of general practice and family practice HCPs, and limited access to specialty $\mathrm{HCPs}$ — such as pediatricians and adolescent medicine 
specialists - is an even greater problem (MacDowell, Glasser, Fitts, Nielsen, \& Hunsaker, 2010).

Adolescents living in rural areas face further barriers to utilizing health services. Because of the limited availability of HCPs in a rural community, frequently both the patient and the patient's family receive treatment from the same HCP and office staff. Parents expect all information disclosed by the adolescent to the HCP to be shared with the parent (McKee, O'Sullivan, et al., 2006). Evidence suggests that while most HCPs support providing confidential care to adolescents (Akinbami, Gandhi, \& Cheng, 2003; Lovett \& Wald, 1985; Resnick, Litman, \& Blum, 1992), the office staff report otherwise (Akinbami et al., 2003). The adolescent—and the HCP's office staff-may perceive a parent's expectation to receive disclosure of all information to imply that the HCP and office staff are obligated and willing to fulfill this expectation.

Accessing health services in a rural area also poses considerable social barriers such as a lack of anonymity and privacy. Anonymity is the ability to receive health services without being recognized by an acquaintance (Garside et al., 2002). Anonymity can be difficult to achieve in sparsely populated rural areas where it is common for an individual seeking health services to encounter acquaintances in the health services setting, whether the acquaintance is a member of the $\mathrm{HCP}$ office staff, another patient in the waiting room, or a passerby in the parking lot. Encountering an acquaintance while obtaining health services creates a situation in which the individual feels socially compelled to explain reasons for seeking health services, thereby eliminating privacy. Adolescents in a rural community report concern that an acquaintance may notify the adolescent's parents or gossip about the adolescent seeking health services (Garside et al., 
2002). Adolescents who perceive diminished anonymity in health services settings are more likely to forego needed health services (Elliott \& Larson, 2004; Lehrer et al., 2007). The lack of anonymity inherent in obtaining health services as an adolescent in a rural community (Garside et al., 2002) serves as an additional barrier to both utilization of health services and trust of HCPs.

\section{Trust of Health Care Provider}

Trust of HCP is a patient's accepted vulnerability to the HCP's possible— but not expected-ill will (Hall et al., 2002). The word trust implies vulnerability, because trust requires some level of risk (Baier, 1986; Potter, 2002) and the potential for either trust or distrust varies by the degree of risk involved (Hall, 2001). A lack of trust of the HCP was frequently reported by adolescents as a reason for not utilizing health services (BrelandNoble et al., 2010; Charman, Harms, \& Myles-Pallister, 2010; Elliott \& Larson, 2004; Scott \& Davis, 2006). In health care, trust has been demonstrated to influence many situations including adolescent patients' willingness to seek care (Breland-Noble et al., 2010; Charman et al., 2010), to disclose sensitive information (Blake et al., 2012; Farrant \& Watson, 2004; Leonard, Markham, Bui, Shegog, \& Paul, 2010), to submit to treatment (McKee, O'Sullivan, et al., 2006; Renker, 2006; Sayles, Macphail, Newman, \& Cunningham, 2010), to participate in research (Broome \& Richards, 2003), to adhere to

prescribed treatments (Brown, 2007), to continue a HCP relationship (Hudson, Nyamathi, \& Sweat, 2008), and to recommend a HCP to others (Ingram \& Salmon, 2007).

Trust of HCP varies across populations. Trust of HCP increases with age, with early adolescents reporting the lowest levels of trust and older adults reporting higher levels of trust (Hall, Dugan, Zheng, \& Mishra, 2001; Klostermann et al., 2005). Lacking 
trust of one's HCP inhibits utilization of health services among vulnerable populations (Breland-Noble et al., 2010; Kilbourne, Switzer, Hyman, Crowley-Matoka, \& Fine, 2006) and results in delayed care or foregone care (Mollborn, Stepanikova, \& Cook, 2005). A vulnerable population is a population in which health disparities are more likely to exist (Centers for Disease Control and Prevention, 2013). Adolescents (National Research Council \& Institute of Medicine, 2007) and people residing in rural areas (Leight, 2001) are both vulnerable populations. Weinert and Long (1990) theorize that people living in rural areas distrust outsiders - including HCPs—-which results in reliance on informal, non-expert health care information resources such as family and friends. When rural adults experience distrust of HCPs and instead rely on friends and family for health advice, adolescents learn to do the same, which may affect utilization of health services among adolescents.

Yet trust of HCPs among adolescents living in rural areas and its effect on utilization of health services has remained virtually unexplored. This study will add to the evidence regarding health behavior, health services access, and health services utilization among American adolescents living in rural areas, while providing an initial quantitative measurement of trust of HCPs using a psychometrically sound instrument.

\section{Statement of the Problem}

Barriers to trust associated with rurality and adolescents' developmentally appropriate suspicion of adults may result in a low level of trust of HCPs among adolescents living in a rural area. However, insufficient research measuring trust of HCP has been conducted among adolescents living in a rural area. More research is needed to measure trust of HCPs, demographic factors, social factors, individual health beliefs, 
health behavior, and utilization of health services among adolescents living in a rural area, so that interventions and policies can be designed to reduce these barriers.

\section{Purpose}

The purpose of this study was to examine individual characteristic variablessuch as demographic factors, social factors, and individual health beliefs-among adolescents' and determine the extent to which these variables influence trust of HCP, lifestyle behaviors, and utilization of health services among adolescents attending a public high school in rural Indiana. This study has added to the evidence regarding health services access and utilization among adolescents living in the rural United States, while providing an initial valid and reliable quantitative measurement of trust of HCPs among adolescents.

\section{Andersen's Behavioral Model of Health Services Use}

In this study, Andersen's Behavioral Model (ABM) of Health Services Use (Andersen, 2008) was adapted to provide a framework for conceptualizing individual characteristics, lifestyle behaviors, trust of health care providers, and utilization of health services among adolescents living in a rural area. The focus of the ABM is to evaluate utilization of health services, perceived and evaluated health outcomes, and satisfaction with health services (Andersen, Rice, \& Kominski, 2007). The model has evolved over time, with four revisions in response to expert feedback, health services research, medical sociology, and health policy (Andersen et al., 2007).

Andersen's initial model focused primarily on individual-level characteristics that impact families' utilization of health services (Andersen, 1968). Approximately a decade later, Andersen presented a modified version of his model, which added the external 
environment and health care system (Aday \& Andersen, 1974). In the third iteration of the model, personal health practices and health status were added (Andersen, Davidson, \& Gantz, 1994), while feedback loops were included in the fourth version of the model (Andersen, 1995). The current model includes a greater emphasis on contextual and individual determinants of utilization of health services (Andersen et al., 2007). The current model includes four broad domains: contextual characteristics, individual characteristics, health behavior, and outcomes (See Figure 1). Feedback loops connect these four domains, which demonstrates that outcomes affect predisposing, enabling, and need characteristics of the population, as well as directly affecting health behavior (Andersen, 2008).

\section{Contextual Characteristics Domain}

Contextual characteristics are the circumstances and environment of health services access. Contextual characteristics include health care organization factors, HCP factors, and community characteristics. Contextual characteristics are ways that individuals live, work and socialize that affect health outcomes (Andersen et al., 2007), and are usually measured at the county level such as the ratio of primary care providers to population, ratio of public health clinics to population, and average household income in a county. Andersen's model specifies three types of contextual characteristics: predisposing characteristics, enabling characteristics, and need characteristics.

Predisposing contextual characteristics. Predisposing contextual characteristics are existing conditions that predispose people to utilize health services, to not utilize health services, or to inhibit the use of health services (Andersen et al., 2007). Three 


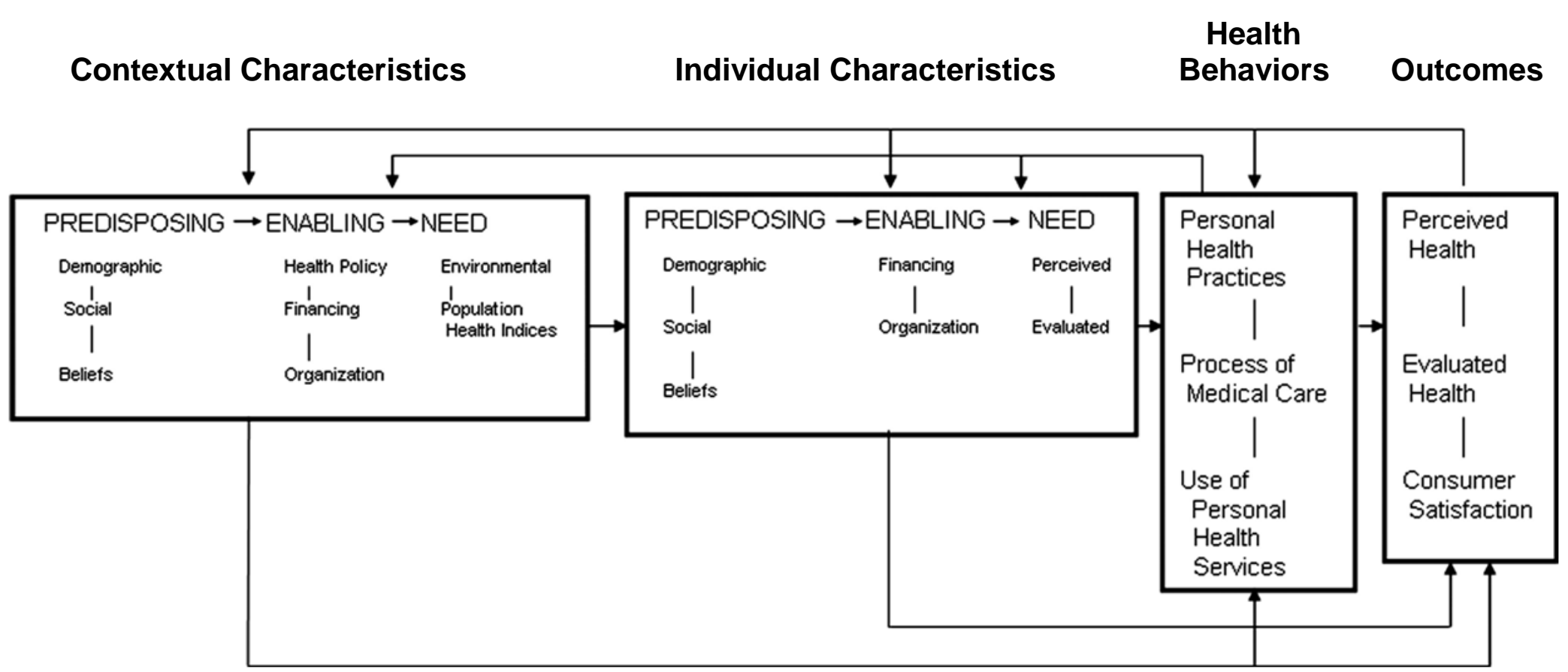

Figure 1.1. Andersen's Behavioral Model of Health Service Use (Andersen, 2008) 
types of predisposing contextual characteristics are demographic, social, and belief contextual characteristics. Demographic contextual characteristics include the composition of a community based on age, gender, and marital status. Social contextual characteristics describe how supportive or detrimental the communities in which people live and work may be to their health and access to health services. Social contextual characteristics include the educational level, ethnic and racial composition, proportion of recent immigrants, and employment level of a community. Contextual beliefs refer to underlying community or organizational values, cultural norms, and prevailing political perspectives regarding how health services should be organized, financed, and made accessible to the population (Andersen et al., 2007).

Enabling contextual characteristics. Enabling contextual conditions facilitate or impede utilization of health services (Andersen et al., 2007). Three types of enabling contextual conditions are health policy, financing, and organization of resources. Health policy refers to authoritative decisions made pertaining to health or influencing the pursuit of health that are made within any type of organization—such as a government, an accrediting body, or a managed care organization — and are made at any organizational level, from local to national. Financing characteristics at the contextual level suggest resources potentially available to pay for health services, such as per capita community income, wealth, rate of health insurance coverage, relative price of medical care, the method of compensating providers, and per capita expenditures for health services (Andersen et al., 2007). Organization at the contextual level describes what the system does with its resources, such as the manner in which health care personnel and health care facilities are coordinated and controlled in the process of providing health services 
(Andersen \& Newman, 2005). At the contextual level, organization includes the amount and distribution of health services personnel and facilities, ratio of HCPs to the population, HCP office hours, location of health services, variety of HCP types, outreach activities, and education programs (Andersen et al., 2007).

Need contextual characteristics. Contextual needs are conditions that lay people or HCPs recognize as requiring medical treatment. Two types of contextual need conditions are environmental conditions and population health indices. Environmental contextual conditions include health-related measures of the physical environment, such as access to healthy food and quality of housing, water, and air, while population health indices include mortality rates, morbidity rates, and disability days (Andersen et al., 2007).

\section{Individual Characteristics Domain}

In Andersen's model, individual characteristics are measurements of a single person and are also categorized to include predisposing, enabling, and need characteristics. These three sets of characteristics indicate an individual's predisposition to utilize health services, ability to secure health services, and level of illness (Andersen \& Newman, 2005).

Predisposing individual characteristics. Individual predisposing characteristics exist prior to the onset of need for health services and describe the propensity of individuals toward using health services (Aday \& Andersen, 1974). As with contextual characteristics, predisposing individual characteristics also include demographic, social, and belief factors. Individual demographic factors include age and gender, which suggest the likelihood that an individual will need health services as a biological necessity. Social 
characteristics are those factors that determine the status of a person in the community and that person's ability to cope with presenting problems. These include measures such as education, occupation, race, ethnicity, social network, and social interactions. Individual beliefs are attitudes, values, and knowledge an individual has about health and health services that can influence their perception of need for health services and utilization of health services (Andersen et al., 2007). Examples of individual beliefs measured in other studies are trust of HCP (Afilalo et al., 2004; Hammond, Matthews, \& Corbie-Smith, 2010), social connectedness (Rew, Resnick, \& Beuhring, 1999), and traditional masculinity beliefs (Marcell, Ford, Pleck, \& Sonenstein, 2007).

Enabling individual characteristics. Enabling individual characteristics describe the means and resources an individual has available to them for the utilization of health services (Aday \& Andersen, 1974). Financing of health services for the individual includes the income and wealth available to that person to pay for health services, along with the effective price of health services as determined by having insurance or costsharing requirements. Organization of health services for the individual describes the usual source of health care, the nature of that source of health care (private physician, community clinic, emergency room), means of transportation, travel time to receive health services, and waiting time to receive health services (Andersen et al., 2007).

Need individual characteristics. In Anderson's model, the term need refers to the reason to seek or receive health services. Need may be perceived by the individual and/or be evaluated by a HCP. Within the ABM, need is dichotomized as perceived need (subjective) or evaluated need (objective). 
Perceived need refers to an individual's view of his or her own general health and functional status. It also includes how the individual experiences and emotionally responds to illness, and how the individual makes decisions to seek health services. Perceived need can largely be explained by social characteristics and health beliefs, and is used within the model to explain the health care-seeking process and adherence to medical advice. Evaluated individual need represents professional judgment and objective measurement of a client's physical status and need for health services. It may include blood pressure, temperature, body mass index, laboratory test results, diagnoses, and prognoses. Evaluated need is used within the model to ascertain the type and amount of treatment that is needed (Andersen et al., 2007).

\section{Health Behavior Domain}

Andersen describes three types of health behavior: personal health practices, the medical process, and utilization of personal health services (Andersen, 2008). Personal health practices refer to an individual's lifestyle or behaviors that influence health, such as nutrition, physical activity (Andersen, 2008), avoidance of drugs, alcohol and tobacco, and adherence to medical advice (Andersen et al., 2007). The process of medical care includes the HCPs interactions with patients during the delivery of medical care, such as counseling, writing prescriptions, quality of communication, and the patient-provider relationship (Andersen et al., 2007). Actual use of health services is an essential component of health behavior in the model, including frequency, type, site, purpose, and coordination of health services received (Andersen, 1995, p. 6). Use of health services is also known as utilization of health services, which is defined as realized access to health services (Andersen, et al., 2007). 


\section{Outcomes Domain}

Outcomes are the result of contextual and individual characteristics, as well as health behavior, and are measured as perceived health, evaluated health, and consumer satisfaction (Andersen et al., 2007). Perceived health status indicates the extent to which a person can live a functional, comfortable, and pain-free existence. Measures include self-reports of general perceived health, independence for activities of daily living, and disability status. Evaluated health status is dependent upon the judgment of the HCP, based on established clinical standards. Measures include results of tests of physiological processes, function, diagnosis, and prognosis. Consumer satisfaction is an individual's approval of the health services received. Consumer satisfaction is measured by the patient's ratings of waiting time, travel time, communication with providers, and technical care received. In addition, consumer satisfaction can also be measured by whether an individual chooses to switch HCPs or health insurance plans (Andersen et al., 2007).

\section{Application of Andersen's Behavioral Model}

Since ABM (Andersen, 1968) has undergone four revisions - in 1974, 1994, 1995, and 2007— published studies have used different versions of the model. Interestingly, the 1995 version is the version most frequently cited, even after a future version had been published. This discrepancy was noted both by this author and in a systematic review of ABM studies (Babitsch, Gohl, \& von Lengerke, 2012). No published studies have cited the 2007 version of ABM. This discrepancy may be a matter of access to the literature. The 2007 version was published in a book — rather than a journal article — which may make the 2007 version less easily available. Alternatively, 
the full text of the 1995 version is publicly available on the internet and was the first article authored by Andersen to appear in a Google search of "Andersen's Behavioral Model." Thus, the citation frequency of the 1995 version may be a result of ease of access, rather than an indicator of conceptual value.

Health researchers, health policy analysts, and economists have used the ABM to explain and predict utilization of health services (Andersen et al., 2007). One notable economic and policy application of the ABM was the Health Insurance Experiment conducted by the Rand Corporation and funded by the U.S. Department of Health and Human Services. The purpose of the Health Insurance Experiment was to measure the effect of co-insurance (the insured consumer's share of the cost of health services) on demand for health services (Newhouse, 1974). For the purposes of this study, individuals were randomly assigned to health insurance plans with co-insurance amounts varying from no co-insurance to $95 \%$ co-insurance with a $\$ 1000$ out-of-pocket maximum, then tracked utilization of health services and expenditures (Manning et al., 1988). The Health Insurance Study used the high co-insurance to evaluate the short-term effects of out-ofpocket costs on utilization of health services and expenditures in Health Insurance Experiment Study. The results of the Health Insurance Experiment indicated that coinsurance helps prevent over-utilization of health services, but also prevents appropriate utilization of health services (Brook et al., 1983; Brook et al., 1984). In the same way, health insurance companies, HCP groups, and marketing companies could apply the ABM to explain and predict utilization of health services, health services expenditures, consumer satisfaction, and likelihood of switching HCPs or health insurance policies. Consumer satisfaction has frequently been operationalized based on an individual's 
decision to switch health insurance or HCP (Andersen et al., 2007). The overall purpose behind the use of $\mathrm{ABM}$ should determine the outcome of interest and inclusion of $\mathrm{ABM}$ domains when applying the model.

Few research studies have identified a conceptual model or theory when exploring adolescents' utilization of health services. Of the studies identifying a conceptual model when measuring adolescents' utilization of health services, ABM was the most frequently used model (Adams, Newacheck, Park, Brindis, \& Irwin, 2013; Marcell et al., 2007; Maulik, Mendelson, \& Tandon, 2011; Wu, Blazer, Li, \& Woody, 2011; Wu, Pilowsky, Schlenger, \& Hasin, 2007). Additional studies appear to have been organized according to ABM, but did not specify the conceptual model used (McKee, Fletcher, \& Schechter, 2006; Youngblade, Curry, Novak, Vogel, \& Shenkman, 2006). Studies using ABM among adolescents have focused primarily on the individual characteristics domain and the health behavior domain. One study included the contextual characteristics domain (Youngblade et al., 2006) along with indivudal characterisitcs and use of health services, but did not identify a conceptual framework or reference the ABM. No published studies have included all four ABM domains.

The present study used a modified version of the current iteration of the ABM (Andersen, et al., 2007), which focused on only the individual characteristics domain and health behavior domain of ABM. The variables selected for the conceptual model for this study have been identified in the literature as having been significantly associated with adolescents' utilization of health services (Coker et al., 2010; Probst et al., 2005; Vingilis, Wade, \& Seeley, 2007). As illustrated above (See Figure 1), Andersen's model contains four broad domains (Andersen, 2007), but only individual characteristics and health 
behavior were included in the adapted model for this study (See Figure 2). This study examined the influence of factors within the domain of individual characteristics on the domain of health behavior. With the ABM, the health behavior domain has indirect effects on the individual characteristics domain. As indicated by the bi-directional arrow, the direct effect of the health behavior domain on the individual characteristic of trust of HCP was also evaluated in the adapted model. This study collected data in a single community; therefore, no variance in contextual characteristics existed between research participants. Although the contextual characteristics domain was not included in the study model, contextual characteristics data were obtained from public use data sets to provide an overall picture of the community, which was used to compare the study sample to the community as a whole. Specific variables selected for the study for each of the domains represented in the adapted model are displayed in Table 1, along with conceptual and operational definitions of the variables. 
Individual Characteristics

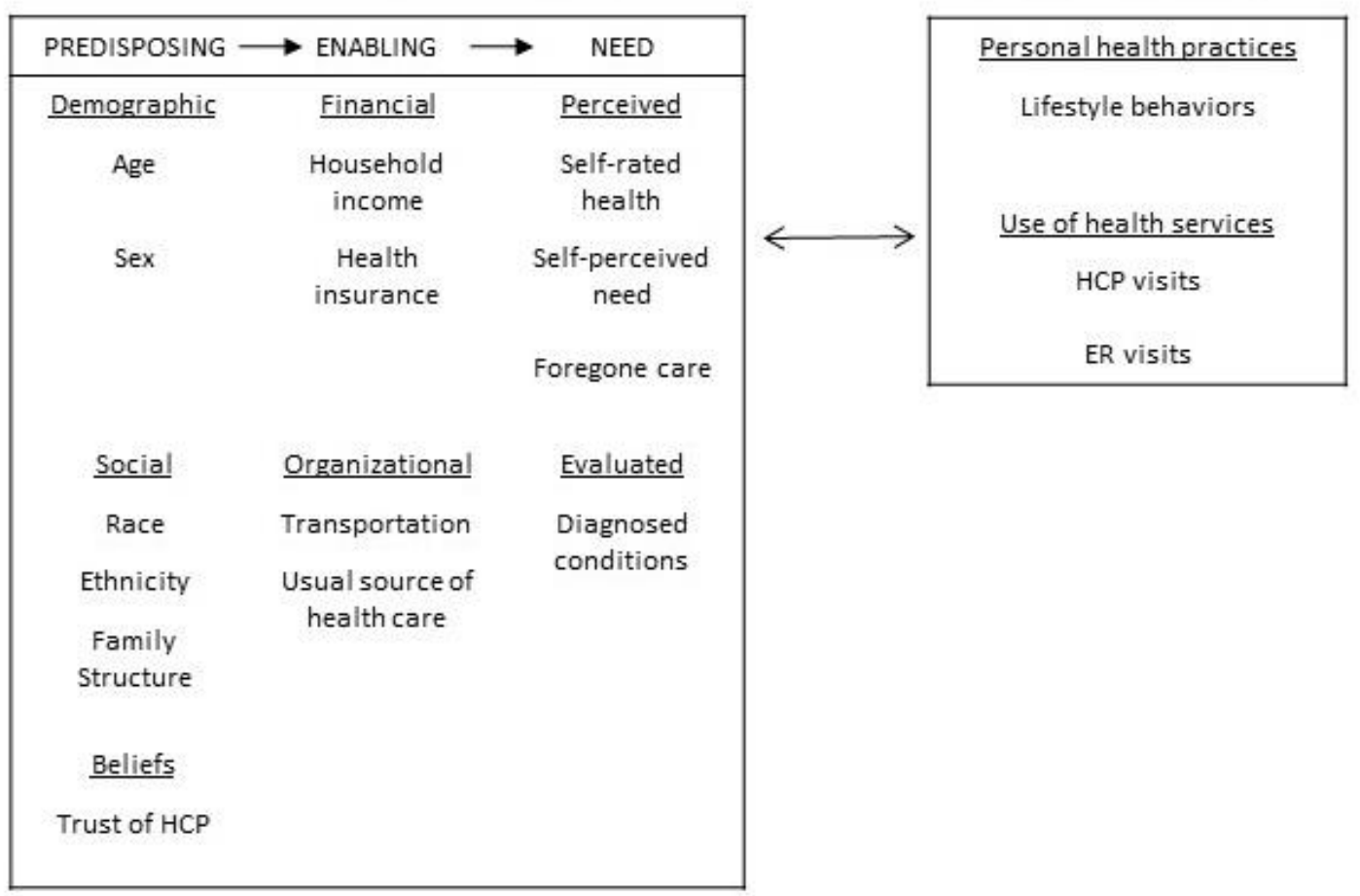

Figure 1.2. Andersen's Behavioral Model of Health Services Use adapted for study 
Table 1.

Definition of Study Variables

\begin{tabular}{llll}
\hline Variable & $\begin{array}{l}\text { Conceptual } \\
\text { definition }\end{array}$ & Operational definition & Psychometrics \\
\hline
\end{tabular}

Predictor Variables:

\begin{tabular}{|c|c|c|c|}
\hline $\begin{array}{l}\text { Trust of } \\
\text { health care } \\
\text { provider }\end{array}$ & $\begin{array}{l}\text { A patient's accepted } \\
\text { vulnerability to the } \\
\text { HCP's possible-but } \\
\text { not expected-ill } \\
\text { will (Hall et al., } \\
\text { 2002). }\end{array}$ & $\begin{array}{l}\text { Wake Forest Interpersonal } \\
\text { Trust in Physician Scale 10- } \\
\text { item 5-point Likert scale }\end{array}$ & $\begin{array}{l}\text { Cronbach's } \\
\alpha=.93 \\
\text { Pearson } r=.75\end{array}$ \\
\hline Self-rated health & $\begin{array}{l}\text { Personal assessment } \\
\text { of general health } \\
\text { (Manning, } \\
\text { Newhouse, \& Ware, } \\
\text { 1982, p. 152). }\end{array}$ & $\begin{array}{l}\text { In general, would you say } \\
\text { your health was } \\
\text { Excellent/very good/good/ } \\
\text { fair/poor }\end{array}$ & $\begin{array}{l}\text { Cronbach's } \\
\alpha=.92 \\
\text { Criterion } \\
\text { validity } \\
\text { Cohen's kappa } \\
=.71\end{array}$ \\
\hline $\begin{array}{l}\text { Self-perceived } \\
\text { need }\end{array}$ & $\begin{array}{l}\text { Subjective } \\
\text { requirement for } \\
\text { health services } \\
\text { (Andersen, 2007) }\end{array}$ & $\begin{array}{l}\text { In the last year, was there a } \\
\text { time when you thought you } \\
\text { should talk to a doctor or } \\
\text { nurse about your health? } \\
\text { Yes/ No }\end{array}$ & \\
\hline Foregone care & $\begin{array}{l}\text { Not seeking health } \\
\text { services when there } \\
\text { was a subjective } \\
\text { requirement for } \\
\text { health services } \\
\text { (Rew et al., 1999) }\end{array}$ & $\begin{array}{l}\text { Did you talk to a doctor or } \\
\text { nurse about your health at } \\
\text { that time? Yes/ No } \\
\text { If not, why? } \\
\text { Thought my problem would } \\
\text { go away/Didn't want } \\
\text { parents to know/Didn't } \\
\text { know where to go/Couldn't } \\
\text { pay/Afraid of what doctor } \\
\text { would say or do/Afraid } \\
\text { someone would see me/No } \\
\text { transportation/ Parent would } \\
\text { not go/ Doctor had not } \\
\text { helped before/Couldn't find } \\
\text { the time/Other reason }\end{array}$ & \\
\hline
\end{tabular}




\begin{tabular}{|c|c|c|c|}
\hline Variable & $\begin{array}{l}\text { Conceptual } \\
\text { definition }\end{array}$ & Operational definition & Psychometrics \\
\hline $\begin{array}{l}\text { HCP diagnosed } \\
\text { conditions }\end{array}$ & $\begin{array}{l}\text { Health conditions } \\
\text { diagnosed by a HCP }\end{array}$ & $\begin{array}{l}\text { Have you been diagnosed } \\
\text { with any of these } \\
\text { conditions? } \\
\text { Acne/ADHD/anemia/ } \\
\text { allergies/asthma/ } \\
\text { depression/diabetes/high } \\
\text { blood pressure/ } \\
\text { overweight/obese/none }\end{array}$ & \\
\hline \multicolumn{4}{|c|}{ Outcome Variables: } \\
\hline $\begin{array}{l}\text { Lifestyle } \\
\text { behaviors }\end{array}$ & $\begin{array}{l}\text { A multidimensional } \\
\text { pattern of } \\
\text { discretionary } \\
\text { activities and } \\
\text { perceptions that are a } \\
\text { part of the daily } \\
\text { approach to living } \\
\text { and that significantly } \\
\text { affect health status } \\
\text { (Gillis, 1997, p. 31) }\end{array}$ & $\begin{array}{l}\text { Adolescent Lifestyle } \\
\text { Questionnaire: } 43 \text {-item 5- } \\
\text { point Likert scale }\end{array}$ & $\begin{array}{l}\text { Cronbach's } \\
\alpha=.91 \\
\text { Pearson } r=.88\end{array}$ \\
\hline $\begin{array}{l}\text { Utilization of } \\
\text { health services }\end{array}$ & $\begin{array}{l}\text { Self-reported use of } \\
\text { personal health } \\
\text { services in the past } \\
12 \text { months (Ritter et } \\
\text { al., 2001, p. 16). }\end{array}$ & $\begin{array}{l}\text { Stanford Health Care } \\
\text { Utilization Survey: } 2 \text {-item } \\
\text { survey }\end{array}$ & $\begin{array}{l}\text { Pearson's } \\
r=.76-.94\end{array}$ \\
\hline $\begin{array}{l}\text { Trust of } \\
\text { health care } \\
\text { provider }\end{array}$ & $\begin{array}{l}\text { A patient's accepted } \\
\text { vulnerability to the } \\
\text { HCP's possible-but } \\
\text { not expected-ill } \\
\text { will (Hall et al., } \\
\text { 2002). }\end{array}$ & $\begin{array}{l}\text { Wake Forest Interpersonal } \\
\text { Trust in Physician Scale 10- } \\
\text { item 5-point Likert scale }\end{array}$ & $\begin{array}{l}\text { Cronbach's } \\
\alpha=.93 \\
\text { Pearson } r=.75\end{array}$ \\
\hline \multicolumn{4}{|l|}{ Covariates: } \\
\hline Age & Age in years & Years old & \\
\hline Sex & Biological sex & Male/Female & \\
\hline
\end{tabular}




\begin{tabular}{|c|c|c|c|}
\hline Variable & $\begin{array}{l}\text { Conceptual } \\
\text { definition }\end{array}$ & Operational definition & Psychometrics \\
\hline Ethnicity & $\begin{array}{l}\text { Hispanic ethnicity } \\
\text { (National Institutes } \\
\text { of Health, 2001) }\end{array}$ & Hispanic/Not Hispanic & \\
\hline Family structure & $\begin{array}{l}\text { The structure of } \\
\text { children and adults } \\
\text { living within one } \\
\text { household }\end{array}$ & $\begin{array}{l}\text { Do you live with your... } \\
\text { Biological mother/father } \\
\text { Step-mother/Step-father } \\
\text { Foster mother/father } \\
\text { Adoptive mother/father } \\
\text { Grandmother/ Grandfather } \\
\text { Someone else }\end{array}$ & \\
\hline $\begin{array}{l}\text { Household } \\
\text { income }\end{array}$ & $\begin{array}{l}\text { Adolescent reported } \\
\text { socio-economic } \\
\text { status (Ensminger et } \\
\text { al., 2000) }\end{array}$ & $\begin{array}{l}\text { Do you receive free or } \\
\text { reduced lunch? } \\
\text { Yes, free lunch/ } \\
\text { Yes, reduced lunch/ } \\
\text { No, I pay for my lunch }\end{array}$ & $\begin{array}{l}\text { Criterion } \\
\text { validity } \\
\text { Cohen's } \\
\text { kappa }=.79\end{array}$ \\
\hline Health insurance & $\begin{array}{l}\text { Program providing } \\
\text { compensation for } \\
\text { medical expenses }\end{array}$ & $\begin{array}{l}\text { What kind of health } \\
\text { insurance do you have? } \\
\text { Medicaid/ Military/ Private/ } \\
\text { None/Don't know }\end{array}$ & \\
\hline Transportation & $\begin{array}{l}\text { The process an } \\
\text { individual undergoes } \\
\text { to move to the } \\
\text { location of the HCP's } \\
\text { office }\end{array}$ & $\begin{array}{l}\text { How do you usually get to } \\
\text { the doctor's office or health } \\
\text { clinic? } \\
\text { Drive/Driven/Public } \\
\text { Transport/Walk/Other } \\
\text { How difficult was it for you } \\
\text { to get to the doctor's office } \\
\text { or health clinic? } \\
\text { Very difficult/Somewhat } \\
\text { difficult/ Not too difficult/ } \\
\text { Not at all difficult }\end{array}$ & \\
\hline
\end{tabular}




\begin{tabular}{llll}
\hline Variable & $\begin{array}{l}\text { Conceptual } \\
\text { definition }\end{array}$ & Operational definition & Psychometrics \\
\hline $\begin{array}{l}\text { Usual source of } \\
\text { care }\end{array}$ & $\begin{array}{l}\text { A particular HCP's } \\
\text { office or clinic } \\
\text { where an individual } \\
\text { usually goes to when } \\
\text { sick or needing } \\
\text { advice about health } \\
\text { services }\end{array}$ & $\begin{array}{l}\text { Was there a particular } \\
\text { doctor's office or clinic } \\
\text { where you usually go if you } \\
\text { were sick or need advice } \\
\text { about your health care? }\end{array}$ \\
& $\begin{array}{l}\text { Yes/No } \\
\end{array}$ & $\begin{array}{l}\text { Which place best describes } \\
\text { where you usually go when }\end{array}$ \\
& you were sick or need \\
& advice about your health? \\
& Clinic/doctor's office/ \\
& emergency room/ Don't \\
& know \\
& & \\
&
\end{tabular}




\section{Individual Characteristics Domain}

According to the ABM, the domain of individual characteristics includes

predisposing, enabling, and need variables. Predisposing characteristics exist prior to the onset of need for health services and describe the propensity of individuals to utilize health services (Aday \& Andersen, 1974, p. 213). In this study, the following sets of variables were included as individual predisposing characteristics: demographic variables (age, sex), social variables (race, ethnicity, family structure) and beliefs (trust of HCP) (See Figure 2).

Individual demographic variables included in the adapted model were age and sex. Previous research has demonstrated that older adolescents and female adolescents were more likely to utilize health services (Hoover, Tao, Berman, \& Kent, 2010; Mulye et al., 2009). Individual social variables included race, ethnicity, and family structure (See Table 1). Previous research has demonstrated that in the U.S., Caucasian adolescents were more likely to utilize health services than other racial and ethnic groups (Berdahl, Friedman, McCormick, \& Simpson, 2013). Family structure refers to whether the adolescent was living in a home with both parents, a single-parent home, was being raised by a grandparent or by some other guardian. Previous research has demonstrated that adolescents living with both parents have higher rates of health insurance, greater utilization of health services, and were more likely to report a usual source of care (USOC) (Probst et al., 2005).

Individual beliefs are attitudes that influence an adolescent's perception of need for health services and utilization of health services (Andersen et al., 2007). Trust of HCP (See Table 1) was selected for inclusion in the adapted model because adolescents have 
been known to report low levels of trust of HCP (Breland-Noble et al., 2010; Britto et al., 2004; Broome \& Richards, 2003; Brown, Arden, \& Hurst, 2007; Charman et al., 2010) and trust of HCP influences many situations in health care. While trust of HCP was an individual characteristic that influenced health behavior (See Figure 2) and was considered a predictor variable in this study, it is also true that other factors in the model may have logically influenced trust of HCP. Therefore, the role of trust of HCP was measured as both a predictor variable and an outcome variable in this study. Inclusion of trust of HCP as both a predictor variable and an outcome variable was further supported by the recursive nature of the ABM (See Figure 1), with the feedback loops demonstrating that health behavior affects predisposing, enabling, and need characteristics of the population (Andersen, et al., 2007).

Enabling resources describe the income and assets individuals have available to them to help with obtaining health services (Aday \& Andersen, 1974). In this study, enabling resources included financial variables (household income and health insurance), along with organization variables (transportation and usual source of care). It has been documented that the availability of health insurance and financial resources to pay for uninsured health care expenses impacts utilization of health services among adolescents (Berdahl et al., 2013; Probst et al., 2005).

Transportation has been shown to be a barrier to health services for people living in rural areas, including adolescents (Probst, Moore, \& Baxley, 2005). Rural areas frequently do not have public transportation such as trains, buses, or taxis available. Adolescents over age 16 may have a driver's license, but may not have consistent access 
to an automobile. Without consistent access to reliable transportation, access to health services and subsequent utilization to health services is impaired.

Having a usual source of care (USOC) means that an individual identifies a particular HCP or clinic as the typical supplier of health services when health services are needed. Having a USOC has been shown to be a significant predictor of health services utilization among adolescents (DeVoe, Tillotson, Wallace, Lesko, \& Angier, 2012). Uninsured individuals and minorities have been consistently least likely to have a USOC (Probst et al., 2005).

The third category of individual characteristics within the ABM includes the immediate need for health service utilization as perceived by the individual or evaluated by the HCP (Aday \& Andersen, 1974). Perceived health need is subjective and describes how the adolescent views his or her own health, while evaluated need is an objective measure of health. In this study, need included perceived need (self-rated health, selfperceived need, foregone care) and evaluated need (diagnosed conditions). Self-rated health and diagnosed conditions are strong predictors of utilization of health services among adolescents, while foregone care reports an unmet need for health services and accounts for subjective barriers to utilization of health services (Bradford \& O'Sullivan, 2007).

\section{Health Behavior Domain}

According to Andersen's behavioral model, the domain entitled health behavior includes personal health practices and use of health services (Andersen, 2008). Personal health practices include nutrition, physical activity, substance use, and self-care activities such as stress reduction and taking medications (Andersen, 1995), while use of health 
services includes type, site, purpose, and health services received (Andersen, 1995).

Personal health practices are also known as lifestyle behaviors_-which are a multidimensional pattern of discretionary activities and perceptions that are a part of the individual's daily approach to living that significantly affect health status (Gillis, 1997). Lifestyle behaviors may include both health promoting or risk-taking behaviors. Risktaking behaviors are associated with higher levels of emergency room visits, but fewer HCP visits (Elliott \& Larson, 2004; Lehrer et al., 2007). Adolescents engaged in health promoting behaviors are more resilient to risk behaviors and report lower rates of health services utilization (Rew, 2005). Use of health services includes type, site, purpose, and actual health services received (Andersen, 1995, p. 6), which is also known as health services utilization. Utilization of health services was an outcome of interest in this study.

\section{Current Study}

The purpose of this study was to examine individual characteristic variables and determine the extent to which these variables influence trust of HCP, lifestyle behaviors, and utilization of health services among adolescents attending public high school in rural Indiana. This purpose has been addressed by the following four research questions. 


\section{Research Questions}

The research questions for this study were:

R1: What relationships exist between variables (age, sex, family structure, trust of HCP, health insurance, household income, transportation, usual source of care, self-rated health, self-perceived need, foregone care, diagnosed conditions, lifestyle behaviors, HCP visits, and ER visits) in the study model?

R2: Which variables in the model were predictive of trust of HCP among adolescents attending a public high school in a rural area?

R3: Which variables in the model were predictive of lifestyle behaviors among adolescents attending public school in a rural area?

R4: Which variables in the model were predictive of utilization of health services among adolescents attending public school in a rural area?

\section{Conceptual Definition of Terms}

Access to health services. The degree of fit between a person and the health care system, including five dimensions of health services: availability, accessibility, accommodation, affordability, and acceptability (Penchansky \& Thomas, 1981).

Adolescent. A person between the ages of 10 and 24 (Steinberg, 2010a). In this study, adolescents age 14-19 were surveyed.

Foregone care. Not seeking health services when there was a subjective need for health services (Rew et al., 1999).

Health care provider. A professional with specialized education providing health services including, but not limited to nurses, nurse practitioners, primary care physicians, specialty physicians, and physician assistants. 
Lifestyle behaviors. A multidimensional pattern of discretionary activities and perceptions that are a part of the individual's daily approach to living and that significantly affect health status (Gillis, 1997, p. 31).

Public school. An institution providing general education to all children without cost, funded in whole or in part by government-collected tax revenue.

Risk-taking behaviors. Activities that threaten the development, health, and well-being of an individual. Common risk-taking behaviors associated with the leading causes of morbidity and mortality among adolescents in the U.S. include: (1) behaviors that result in unintentional injuries or violence, (2) tobacco, alcohol, and drug use, (3) unprotected sex, (4) poor nutrition, and (5) physical inactivity (CDC, n.d.).

Rural. A sparsely populated or remote geographic location; also an adjective describing the culture of people living in a sparsely populated or remote geographic location. For the purposes of this study, the definition of rural was provided by the Federal Office of Rural Health Policy, which states rural areas are defined as incorporated populations of less than 50,000 with core census blocks of fewer than 1,000 people per square mile and surrounding census blocks with an overall density of fewer than 500 people per square mile (Health Resources and Services Administration, n.d.a).

Trust of health care provider. A patient's accepted vulnerability to the HCP's possible—but not expected—ill will (Hall et al., 2002).

Utilization of health services. Realized access to health services (Andersen et al., 2007). In this study, utilization of health services was operationalized as number of HCP visits and emergency room visits within the past 12 months. 


\section{Conclusion}

Adolescents have elevated morbidity and mortality rates associated with risktaking behaviors, but utilize health services at low levels. Risk-taking behavior, access to health services, rural socio-environmental conditions, and trust were all concerns that influenced utilization of health services among adolescents living in a rural area. While studies have investigated these concepts separately, none has measured trust of HCPs, individual characteristic variables, health behavior, and health services utilization among American adolescents living in rural areas. This study seeks to add to the evidence regarding predictors of trust of $\mathrm{HCP}$, health behavior, and health services utilization among adolescents living in rural areas and to make recommendations for related health services practice, health policy, and future research. 


\section{CHAPTER II}

\section{REVIEW OF LITERATURE}

Adolescents' utilization of health services is a small, but growing area of research. Interest in disparities within adolescents' utilization of health services is recent. To understand the context of health services utilization among American adolescents living in a rural area, this chapter provides an overview of the literature. This chapter first explores the population of interest (adolescent, rural), then considers the outcomes of interest to this study (trust of HCP, lifestyle behaviors, utilization of health services), and finally discusses individual characteristic variables (See Figure 2 on p. 21) with known associations to adolescents' utilization of health services.

\section{Adolescence}

Adolescence is defined in many ways. Commonly, the teenage years are understood to encompass adolescence. Adolescence can be defined biologically, beginning with puberty and ending with physical maturation (Neinstein, 2009). The legal definition of adulthood in the US is age 18, except concerning the purchase of alcohol, in which case adulthood begins at age 21 . In addition, a recent theory from the preeminent authority on adolescent psychological development, Dr. Laurence Steinberg, is based on neurobiological and psychological evidence that suggests that brain and cognitive development continues throughout the mid-twenties (2008). Obviously, no 
standard definition of adolescence exists. The broadest definition of adolescence begins at age 10 with the onset of puberty (Neinstein, 2009) and continues throughout emerging adulthood to age 25, when the prefrontal cortex of the brain has developed (Steinberg, 2008). This study included adolescents enrolled in public high school, ages 14-19.

Several theories related to adolescence have been developed over the last century. Common viewpoints include that adolescents are largely modeled by their social or cultural environment (Bandura, 1977; Bronfenbrenner, 1999; Mead, 1928), or that the primary goals of adolescence are identity development (Erikson, 1963; Mead, 1928) or independence from parents (Erikson, 1963; Havighurst, 1953; Mead, 1928).

One of the most influential theories related to adolescence is Jean Piaget's theory of cognitive development. According to Piaget, adolescents' transition from concrete operational thought to formal operational thought between age 11 and age 15 (Piaget, 1958). This transition in cognitive development allows for abstract thinking and the use of propositional logic. This means the adolescent has reached an adult level of cognitive development, is able to imagine the past, present, and future conditions of a situation, and can speculate about the logical order of events. The adolescent using formal operational thought can imagine actions independent of what is seen or is performed. It was possible for the adolescent in the formal operational stage of development to use theories to hypothesize, make deductions, and solve problems (Piaget \& Inhelder, 1958).

Cognition changes in five major ways during adolescence: a) adolescents can consider possibilities, in addition to reality; b) abstract thinking becomes possible; c) meta-cognition occurs; d) thinking becomes multidimensional; and e) adolescents begin to comprehend relativity, rather than only absolutes (Steinberg, 2010). A major 
intellectual accomplishment of adolescence is the ability to consider possibilities and reason deductively (Klaczynski \& Narasimham, 1998; Morris \& Sloutsky, 2001). In addition to the adolescent's ability to consider abstract concepts is an increased interest in thinking about topics like interpersonal relationships, morality, and honesty (Kohlberg, 1970; Steinberg, 2010). Adolescents also begin thinking about thinking—known as metacognition. Meta-cognition results in increased introspection, self-consciousness, and intellectualization, which are important aspects of identity formation (Steinberg, 2010). This new introspection leads to a period of egocentrism, which results in two erroneous beliefs: the personal fable and the imaginary audience. The personal fable is adolescents' belief that their own experiences are unique, that others cannot understand those experiences, and conventional wisdom does not apply to their situation (Elkind, 1967). The imaginary audience is a self-consciousness that leads adolescents to imagine that their behavior and appearance is the focus of everyone's concern (Elkind, 1967). Adolescents also gain the ability to think in multiple dimensions, which allows for more sophisticated and complicated relationships. This new ability allows the adolescent to see multiple perspectives and to make various interpretations based on point of view (Steinberg, 2010). A final aspect of cognitive development during adolescence is the ability to perceive situations and people as relative perceptions, not absolute reality. This new perspective of relativism causes the adolescent to question the validity of statements once held as absolute truth. This process develops a capacity for a sophisticated understanding of knowledge, but may lead to an interim period of extreme skepticism (Steinberg, 2010). During this period of skepticism, adolescents may become increasingly distrusting of others. 
Adolescence is well-known as a period of increased risk- taking behavior. Adolescents are more likely than adults over age 25 to smoke cigarettes, binge drink, have casual sex, and engage in violent, criminal or otherwise reckless behaviors (Healthy People 2010, 2000; Mulye, et al., 2009; Steinberg, 2008, 2010). Steinberg (2008) explains the neurobiological and psychological reasons for increased risk-taking behavior in the Theory of Adolescent Risk-taking. Steinberg theorized that risk-taking behavior increases between childhood and adolescence because of the brain's socio-emotional system, which leads to increased reward-seeking — which is the pursuit of pleasurable activities — especially in the presence of peers. A significant increase in oxytocin receptors during this period increases the adolescent's attentiveness for and memory of social experiences, making reward-seeking in the presence of peers more important and memorable to the adolescent. It is theorized that increased reward-seeking occurs because of increased dopamine activity in the brain, which causes rewarding activities to be perceived as more gratifying. This increase in reward-seeking has its onset at puberty and peaks around age 15 (Steinberg, 2008). The personal fable belief also explains many of the risk-taking behaviors adolescents engage in (Lapsley, Flannery, Gottschlich, \& Raney, 1996). In summary, the adolescent brain perceives social interactions to be more important and perceives rewarding behaviors to be more gratifying, while the personal fable prevents adolescents from believing that their actions have logical consequences. In combination with the deficiencies in decision-making and impulse control inherent with an under-developed prefrontal cortex of the brain, it is clear why adolescents may engage in risk-taking behaviors, especially in the presence of peers. 
Risk-taking behaviors decline between adolescence and adulthood because of changes in the brain's cognitive control system, which improves the adolescent's selfregulation ability (Steinberg, 2008). Functional MRI studies demonstrate that the prefrontal cortex of the brain does not finalize development until approximately age 25 , therefore limiting impulse control and full decision-making capabilities until the midtwenties. During the second half of adolescence, the brain also undergoes significant remodeling, by both pruning redundant synapses and myelination of the prefrontal cortex of the brain (Steinberg, 2008). When prefrontal brain development combines with improved emotional regulation and a reduction in dopamine-related brain activity, it is apparent why risk-taking behaviors diminish significantly in late adolescence.

As described above, Piaget theorizes that adolescents have reached an adult level of cognitive development, are able to imagine the past, present, and future conditions of a situation, and can speculate about the logical order of events (Piaget, 1969). Multiple studies of adolescent health care decision-making have supported this theory (Cauffman, et al., 2010; Cauffman \& Steinberg, 1995; Steinberg \& Cauffman, 1996, Lewis, 1980). The results of these studies demonstrate no difference between the health care decisionmaking abilities of adults and adolescents age 14 or greater. These results appear to contradict Steinberg's theory and the overwhelming evidence of widespread adolescent risk-taking behaviors. However, these decision-making studies were conducted in controlled environments without the influence of peers. Steinberg states that peer relationships have a significant impact on adolescent risk-taking behaviors (2008). During adolescence, oxytocin receptors in the brain proliferate (Steinberg, 2008), which creates an increased sense of bonding with peers. Increased bonding with peers is an 
essential developmental step identified by theorists, allowing adolescents to learn social norms and develop autonomy from parents (Bronfenbrenner, 1999; Erikson, 1963; Havighurst, 1953; Mead, 1928; Steinberg, 2008). Steinberg theorizes that the presence of peers stimulates the neural circuitry of the brain's socio-emotional system, resulting in increased perception of reward while with peers (2008). Therefore, while adolescents may be capable of logical decision-making by age 14 when alone in a controlled environment, the presence of peers increases risk-taking behaviors by increasing the reward perceived by the brain.

Adolescents are simultaneously capable of making logical decisions in controlled environments, while choosing risk-taking behaviors when with peers. Since a HCP usually meets with an adolescent in a controlled environment, a $\mathrm{HCP}$ is in a unique position to assist the adolescent in making logical decisions regarding health promotion prior to engaging in risk-taking behavior. A HCP can help the adolescent patient find health promotion options that fit into the adolescent's life that function within the adolescent's need for social interaction, such as obtaining long-acting contraception, screening for STDs, or counseling an adolescent to find ways to integrate physical activity into time spent with friends. As discussed above, changes in adolescent cognition include a new, relativistic perspective - which is the realization that truth is subjective, rather than absolute (Chandler, 1987) — and results in an interim period of extreme skepticism (Steinberg, 2010). During this period of skepticism, adolescents may become increasingly distrusting of others-including HCP's. An adolescent's distrust of their $\mathrm{HCP}$ is a barrier to adequate health services because it prevents disclosure of risk-taking behaviors (Smetana, 2010). Non-disclosure of risk-taking behaviors obstructs the 
implementation of health promotion interventions. It is imperative that the adolescent develop an appropriate trust of the HCP, in order to overcome developmental skepticism, and allow for disclosure of risk-taking behaviors, so that health-promoting interventions can be implemented.

In summary, adolescent health issues have become an increasing public health concern in recent years. Several major health organizations have made reports on the health issues specific to adolescents, including Healthy People, the Kaiser Family Foundation, the Indiana Coalition to Improve Adolescent Health, and the Institute of Medicine (Cullen \& Salganicoff, 2011; Healthy People 2010, 2000; Indiana Coalition to Improve Adolescent Health, 2009; Lawrence et al., 2009). Common risk-taking behaviors associated with the leading causes of morbidity and mortality among adolescents and adults in the U.S. include: (1) behaviors that result in unintentional injuries or violence, (2) tobacco, alcohol, and drug use, (3) unprotected sexual behaviors, (4) poor nutrition, and (5) physical inactivity (Centers for Disease Control and Prevention, 2012). The incidence of risk-taking behavior is linked to biophysical cognitive development, as well as to social and learning development. While risk-taking behaviors are of consequence among adolescents across the nation, adolescents living in rural areas are even more susceptible.

\section{Rural}

More than $90 \%$ of the United States landmass is comprised of rural areas, with approximately $20 \%$ of the American population residing in those areas (Rural Institute at The University of Montana, 2005). People living in rural areas have distinct values, norms, and beliefs that influence health (Lee \& Winters, 2004). Rural dwellers are a 
vulnerable population targeted with recommendations from health care agencies (Agency for Healthcare Research and Quality, 2012; Bennett, Olatosi, \& Probst, 2008; Institute of Medicine, 2005). This section describes theory related to rural health, followed by a description of disparities in rural health.

The Rural Nursing Theory was first put forth by Weinert and Long (1989), then expanded by Lee and Winters (2004), followed by Bushy (Bushy, 2012). The initial work from Weinert and Long was based on Fawcett's health/person/environment/nursing metaparadigm of nursing (Fawcett, 1984) and derived from ethnographic interviews with people residing in rural Montana during the late 1970's and early 1980's. This work demonstrated that people living in rural areas have distinct values, norms, and beliefs that influence their definition of health and utilization of health services. Rural dwellers defined health as the ability to work or be productive in one's role (1987). Work was of primary importance to people living in rural areas, with health being a secondary concern measured in relation to the ability to function within their roles. People living in rural areas were reluctant to accept outsiders into the rural social structure, preferring trusted insiders instead — which also applies to HCPs. The self-reliance and independence of rural dwellers produced a reluctance to accept help—especially from outsiders — resulting in health services delayed to the point of severe illness or incapacitation. People living in rural areas maintained relationships with nurses and other HCPs across personal, social, and professional spheres, resulting in privacy limitations and a lack of anonymity. The prioritization of work along with self-reliance and distrust of outsiders created situations in which rural dwellers preferred to rely on family and friends for informal treatment of health concerns, rather than utilizing the formal health care system (Long \& Weinert, 
1989). Informal health care systems were the foundation of the rural health care system and needed to be enhanced and sustained by HCPs and formal health services. As a result of the rural culture of health described above, nurses working in a rural area had little anonymity within their private lives, had to fill a diffuse generalist role, and experienced isolation from their professional peers (Weinert \& Long, 1990).

The work of Lee and Winters (2004) supported portions of the Rural Nursing Theory (Weinert \& Long, 1989), while also contributing some new concepts. Lee and Winters (2004) used naturalistic inquiry when conducting interviews with 38 rural dwellers employed in service work from 2000 to 2001. Analysis of the interviews supported the following concepts from the Rural Nursing Theory: insider, lack of anonymity, familiarity, and self-reliance. In addition, four main themes were derived from analysis of the interviews: definition of health, distance and access to resources, the symptom-action-time-line process, and choice. The definition of health described by these individuals included the ability to function within one's role, but ultimately meant having good quality of life. Distance created difficulty in accessing health care resources, especially in obtaining specialist physician care, prescription medications, and emergency care. Symptom-action-time-line describes the process of recognizing and assessing symptoms, the decision to act on that assessment, and the timeline used when confronted with illness or injury. The decision to act on the assessment of an illness or injury included four steps: (1) a wait-and-see approach; (2) self-care such as home remedies, over-the-counter medications, and rest; (3) consultations with family members, and finally (4) a visit to a HCP. The timeline in seeking a $\mathrm{HCP}$ was influenced by the failure of self-care measures, the assessment that the illness or injury was beyond self-care, the 
urging of family members, the distance to the $\mathrm{HCP}$, and the availability of health services covered by health insurance. The concept of choice included choice to live in a rural area and choice of HCP. Choice of rural residence was related to close and extended family living in the rural area or perceived improved quality of life in a rural area. Rural residents used five criteria to choose a HCP: distance (choosing a nearby HCP first), road conditions (avoidance of icy roads, poorly maintained roads, and difficult mountain passes), perceived quality of care, familiarity with HCP, and availability of family and friends near the HCP's office (Lee \& Winters, 2004).

Bushy and Leipert (2005) expanded on the nursing aspect of the Rural Nursing Theory. Factors influencing nursing students' choice of a rural practice setting were evaluated in a mixed methods study with content analysis of qualitative responses $(\mathrm{n}=$ 44) (Bushy \& Leipert, 2005) revealing further support for Rural Nursing Theory. Analysis of the qualitative data supported concepts from Weinert and Long (1989) such as insider/outsider, lack of anonymity, and nurses filling a generalist role, in addition to supporting concepts from Lee and Winters (2004) including quality of life, distance and access to health services, road conditions, choice of rural setting, and familiarity. In addition to supporting previous work, two main themes derived were (1) nurses choose a rural practice setting for personal, professional, and financial reasons and (2) anticipated challenges to rural practice include contextual features of the environment, professional realities, and patient related considerations. Personal reasons for choosing a rural practice include family, connection to community, love of nature, quality of life, and familiarity with the community. Professional reasons for choosing a rural practice were related to perceiving a high level of health disparities/need in the community, desire to work with a 
particular vulnerable population, interest in family practice, and interest in a range of experiences. Financial reasons for choosing a rural practice were for loan repayment programs, competitive pay, and health insurance. Contextual features of the environment creating challenges to rural practice include distance, isolation, travel conditions, informal social networks, the politics of familiarity, and limited job opportunities. Professional challenges to rural practice were lack of anonymity; threats to maintaining patient confidentiality; privacy and politics in a small practice; outsider bias by long-time residents; few or no specialists for patient referrals; less time, personnel, and equipment; fewer professional development opportunities; and educating the public about nurse practitioners. Patient-related challenges to a rural practice were a large patient load, higher acuity patients, high rates of uninsured patients, professional or ethical conflicts about treatment regimen, and knowing the family history or background (Bushy \& Leipert). While some nurses may consider the generalist role to be overwhelming and a lack of anonymity to be an invasion of privacy, these results seemed to indicate that nurses planning to practice in a rural area expressed familiarity with and acceptance of these conditions. Nurses were held in high esteem among those residing in a rural area (Bushy \& Leipert, 2005), which may ease some of the negative consequences of rural nursing.

People living in rural areas are a vulnerable population, meaning health disparities are more likely to exist among them (Bennett et al., 2008; Centers for Disease Control and Prevention, 2013; Institute of Medicine, 2005). People living in rural areas are more likely than their urban counterparts to be obese, smoke, or be diagnosed with cancer, diabetes, hypertension, or respiratory disease (Danaei et al., 2010). Rural dwellers are 
also less likely to have a high school diploma, more likely to be low-income, and less likely to have health insurance (Bennett et al., 2008; Ziller, Coburn, Loux, Hoffman, \& McBride, 2003). These disparities result in higher mortality rates and shorter life expectancies for people living in rural areas (Danaei et al., 2010).

Individuals living in rural areas have disparities in education, income, and access to health insurance. Adults living in rural areas are nearly $40 \%$ less likely to have a high school diploma than urban adults. People living in rural areas are more likely than urban residents to be employed in low wage jobs without health insurance benefits (Ziller et al., 2003). Rural residents (15.3\%) are less likely than their urban counterparts (17.8\%) to have health insurance, with this difference widening with increasing level of rurality (Bennett et al., 2008). Lower level of education is associated with lower income level, and lower income level is associated with less access to health insurance. Being uninsured or underinsured results in less utilization of health services, poorer self-rated health, and higher rates of foregone care (Bennett et al., 2008; Ziller et al., 2003).

Chronic disease disproportionately affects rural people. Rates of diabetes, coronary artery disease, cancer, obesity, and chronic respiratory disease are greater in rural areas (Murray et al., 2006). High rates of poor nutrition, physical inactivity, and tobacco use contribute to the chronic disease disparity in rural areas (Danaei et al., 2010). Not surprisingly, people living in rural areas consistently report lower self-rated health than their urban counterparts (Bethea, Lopez, Cozier, White, \& McClean, 2012). Highrisk lifestyle behaviors, chronic disease, and diminished self-rated health are common themes in rural health (Danaei et al., 2010). 
Utilization of health services does not appear to be a priority among many people living in rural areas. A nationally representative survey demonstrated health services avoidance is a significant problem among rural people, especially among adolescents and young men (Spleen, Lengerich, Camacho, \& Vanderpool, 2014). Focus groups with women living in rural areas revealed that the combination of low-income, lack of social support, and low priority applied to disease prevention results in delayed HCP visits, increased emergency room utilization, and progression of chronic disease (Murimi \& Harpel, 2010). Health services delayed or avoided are common among people living in rural areas (Lee \& Winters, 2004; Long \& Weinert, 1989).

People living in rural areas have significant barriers to utilization of health services (Aday, Quill, \& Reyes-Gibby, 2010) such as lack of transportation, long distances to travel, unpredictable road conditions, and scarcity of HCPs (Arcury et al., 2005; Bushy, 2012; Nelson, 2008). Rural areas are defined by a small population in a broad geographical area (Klugman, 2008a), which means people living in rural areas have longer distances to travel to utilize health care. Rural areas also typically lack public transportation and longer distances to travel mean higher fuel costs for a low-income population (Arcury et al., 2005; Danis, 2013). Transportation difficulty can have a significant effect on utilization of health services. A large study of cancer patients in Washington state revealed later stage at diagnosis and delayed treatment for those living in rural areas and reporting transportation difficulty (Scoggins et al., 2012). In addition, many rural areas are designated as Medically Underserved Areas or Health Professional Shortage Areas - which means a shortage of HCPs exists (Health Resources and Services Administration, n.d.b). In a study conducted in rural New York state, the supply of HCPs 
had a direct effect on the probability of identifying a usual source of care (USOC) and an indirect effect on utilization of health services (Continelli, McGinnis, \& Holmes, 2010). A study (Laditka, Laditka, \& Probst, 2009) measuring the effect of location on hospitalizations for ambulatory care sensitive conditions - which are conditions where appropriate outpatient health services could prevent or reduce the need for admission to the hospital (National Quality Measures Clearinghouse, 2014) and an indicator of access to effective primary HCPs - demonstrated that people living in rural areas do not have access to adequate primary HCPs. Thus, both transportation barriers and a shortage of HCPs in rural areas result in reduced utilization of health services.

Trust of HCP affects utilization of health services among people of all ages living in rural areas. Overall, trust of HCP is lowest among minorities, males, low-income individuals, the uninsured, and people with low levels of education (Armstrong, Ravenell, McMurphy, \& Putt, 2007). These conditions on trust of HCP also apply to people living in rural areas (Nelms et al., 2013). A telephone survey of both rural $(\mathrm{n}=$ 586) and urban $(\mathrm{n}=433)$ people in North Carolina revealed that rural residents reported more fear of hospitals and distrust of doctors. These beliefs demonstrated ambivalence about health services use, with fear of hospitals resulting in reports of increased adherence with doctor's orders, while distrust of doctors predicted low adherence to doctor's orders (Harju, Wuensch, Kuhl, \& Cross, 2006). Low levels of trust of HCP can result in reluctance and delay in utilizing health services.

Adolescents living in rural areas report engaging in more risk-taking behaviors than their urban counterparts do. Adolescents living in rural areas are more likely to smoke, be physically inactive, and report poor nutrition (Curtis, Waters, \& Brindis, 2011; 
Youngblade et al., 2006), which mimics high-risk lifestyle behaviors of adults in rural areas (Danaei et al., 2010). A study examining Florida CHIP data $(n=28,408)$ in a nested model of adolescent risk-taking behavior, revealed community characteristics directly predicted adolescent risk-taking behavior and indirectly predicted health services utilization and expenditures (Youngblade et al., 2006). It is likely that many of the same factors that influence health disparities among rural adults also affect adolescents living in a rural area.

Adolescents living in rural areas face more barriers to using health services than adults. In addition to the barriers described above, adolescents also perceive a lack of privacy in utilizing health services in a rural area (Elliott \& Larson, 2004; Garside et al., 2002). Many rural areas lack pediatric or adolescent specialists (MacDowell et al., 2010) and as a result, frequently adolescents and their family members all receive treatment from the same provider and office staff. This becomes complicated when parents expect all information disclosed by the adolescent to the $\mathrm{HCP}$ to be shared with the parent (McKee, O'Sullivan, et al., 2006). Evidence suggests that while most HCPs support providing confidential care to adolescents (Akinbami et al., 2003; Lovett \& Wald, 1985; Resnick et al., 1992), office staff report otherwise (Akinbami et al., 2003). The adolescent—and the HCP's office staff-may perceive a parent's expectation to receive disclosure of all information to imply that the HCP and office staff are obligated to fulfill this expectation (Garside et al., 2002). When an adolescent and their parents are all receiving health services from the same provider, the parent has increased contact with the HCP and office staff, providing additional opportunities to discuss the adolescent's health services received. This situation is additionally problematic when the office staff 
members are known acquaintances of the adolescent and parent, which is a common occurrence in a rural area.

\section{Outcome Variables}

\section{Lifestyle behaviors.}

Adolescence is a critical developmental stage for the formation of positive lifestyle behaviors (Curtis, 2011). Lifestyle behaviors are a multidimensional pattern of discretionary activities and perceptions that significantly affect health status and make up one's daily approach to living (Gillis, 1997). The concept of lifestyle behaviors is based on Pender's Health Promotion Model (Pender et al., 2011) and is focused on activities that are health-promoting in nature or are protective against risk-taking behaviors (Gillis). Consideration of lifestyle behaviors among adolescents is important because of the high

prevalence of risk-taking behaviors in this population. While risk-taking behaviors are the largest threat to adolescent morbidity and mortality, research shows that healthpromoting behaviors significantly influence resilience to risk-taking behaviors (Rew, 2001). Research has also shown that adolescents are concerned about their health and how lifestyle behaviors can affect their physical attractiveness (Gillis, 1993), health (Halpern-Felsher \& Cauffman, 2001), and future success (Weiler, 1997). Lifestyle behaviors include seven factors: identity awareness, nutrition, physical participation, safety, social support, health awareness, and stress management (Gillis, 1997). Each of these factors of lifestyle behaviors are described below.

Identity awareness is an ongoing process of self-reflection and personal growth, which results in an adolescent's development of values, beliefs, and life goals (Gillis, 1997) and identity formation is a key developmental task of adolescence (Erikson, 1963). 
In relation to lifestyle behaviors, the process of identity awareness involves reflecting on values, beliefs, goals, and commitments, then considering alternative discretionary lifestyle behaviors that affect health. In particular, identity awareness involves knowing one's strengths and weaknesses, setting goals for oneself, examining beliefs, being happy, liking oneself, striving for excellence, and believing one's life has purpose (Gillis). Positive identity development is a known protective factor against risk behaviors among adolescents (Kerpelman \& Mosher, 2004; Viner et al., 2012).

Nutrition is the development of healthy eating habits and includes choosing healthy foods and eating patterns (Gillis, 1997). Nutrition is an important lifestyle behavior among adolescents, since the CDC identified poor nutrition as one of the key risk-taking behaviors resulting in morbidity among American adolescents (CDC, 2012). Recent studies measuring intake of fruits, vegetables, and sugar sweetened beverages reveal adolescents are not meeting nutritional guidelines (Davis, Bennett, Befort, \& Nollen, 2011; Eaton et al., 2012). In 2011, only 20.9\% of adolescents nationwide reported not drinking any cans of soda pop in the last week, with $11.3 \%$ of adolescents drinking three or more cans of soda pop daily. In addition, $4.8 \%$ of adolescents nationwide had not eaten any fruit within the last 7 days, while $5.7 \%$ of adolescents had not eaten any vegetables within the last week (Eaton et al., 2012). Nutrition indicators suggest adolescents living in rural and urban areas have similar nutrition status (Davis et al., 2011).

Physical participation is active involvement in sports, exercise, or other types of physical activity. Physical inactivity is a significant problem among American adolescents. More than $70 \%$ of American adolescents are not meeting recommended 
physical activity guidelines, with nearly $14 \%$ reporting no physical activity at all. Lack of physical activity is an even greater problem among adolescents living in rural areas. Studies reveal rural residency is a risk factor for overweight and obesity and that risk appears related to physical inactivity. An analysis of National Survey of Children's Health data revealed overweight and obese adolescents were more likely to live in rural areas and report more than three hours of television and/or computer time daily (Lutfiyya, Lipsky, Wisdom-Behounek, \& Inpanbutr-Martinkus, 2007). A secondary analysis of 2005 California Health Interview Survey-Adolescent data demonstrates rural adolescents report 60 minutes of physical activity on average only 4.21 days per week (Curtis et al., 2011), rather than seven days a week as recommended by the CDC (2012). Physical participation is an important factor of lifestyle behaviors among adolescents. Safety is making informed choices that are health protective in nature (Gillis, 1997). As a factor of lifestyle behaviors, safety includes such behaviors as wearing a seatbelt, using protection against pregnancy and STDs during sex, and avoiding tobacco, alcohol, and drugs. Safety is an important factor of lifestyle behaviors since in the United States unintentional injuries are consistently the leading cause of death for adolescents ages $10-14$ (29.3\% of all deaths) and 15-19 (41.7\% of all deaths) (Heron, 2012). Unintentional injury includes a wide range of health problems encountered by adolescents because of risk-taking behaviors, involving accidents, sports, and not using appropriate personal protective equipment such as seatbelts and helmets (Eaton et al., 2012). This may include motor vehicle accidents, falls, being struck by another object or person, fractures, sprains, strains, open wounds, and contusions. Between 2002-2004, $42 \%$ of all visits to the emergency room by adolescents were for the initial treatment of 
an injury (MacKay \& Duran, 2007). Safety is the single most important lifestyle behavior factor in diminishing adolescent mortality.

Safety relates to reproductive health among adolescents through the use of protection to prevent pregnancy and STDs. In the United States, teen pregnancy, birth, abortion, and STD rates are higher than those in most other developed countries. After a 14-year decline, birth rates for teens age 15 to 19 increased three percent in 2006 to 41.9 per 1,000 (Lawrence et al., 2009; Mulye et al., 2009). Teen mothers are more likely to drop out of school and confront unemployment, poverty, welfare dependency, and other negative results than women who postpone childbearing (Lawrence et al., 2009; Mulye et al., 2009). Sexually transmitted diseases continue as a major health concern for adolescents. Chlamydia and gonorrhea rates have been increasing over the last decade for both females and males age 15-19. Approximately $35 \%$ of $14-19$ year olds test positive for the strains of HPV related to cervical and other cancers. In 2007, adolescents represented 4\% of all new cases of HIV infections in the U.S. (Lawrence et al., 2009; Mulye et al., 2009). Safety lifestyle behaviors related to sexual activity are a health concern with long-lasting consequences.

Safety lifestyle behaviors also include avoidance of substance abuse. Commonly abused substances among adolescents include tobacco, alcohol, marijuana, prescription medications and other illegal drugs. A large number of adolescents who begin using tobacco early in life continue using tobacco throughout adulthood (Lawrence et al., 2009; Mulye et al., 2009). Almost one fourth of adolescents smoke by the time they graduate from high school, and nearly 90 percent of adults who smoke began at or before age 18 (Mulye et al., 2009). Alcohol is the most commonly abused substance among adolescents 
and marijuana is the most prevalent illicit drug among adolescents (Mulye et al., 2009). Abuse of over the counter drugs and prescription medications are also on the rise among adolescents. A major risk of substance abuse among adolescents is long-term dependence and addiction (National Center for Chronic Disease Prevention and Health Promotion \& Division of Adolescent and School Health, 2009). Substance abuse is a serious problem among adolescents and is often associated with mental illness and other risk taking behaviors (Cullen \& Salganicoff, 2011; Healthy People 2010, 2000; Lawrence et al., 2009). Avoiding tobacco, alcohol, marijuana, prescription medications and other illegal drugs is an important safety lifestyle behavior among adolescents.

Health awareness is a factor of lifestyle behavior that promotes and maintains health through education and consultation (Gillis, 1997). Health awareness through education includes self-directed activities like reading articles about health topics and discussing health issues with others, while health awareness through consultation includes discussing health improvement with a teacher, coach or HCP and reporting unusual body changes to a friend, parent, or HCP. In a study of adolescents in rural Texas, health awareness was significantly associated with a variety of health-promoting behaviors like healthy nutrition, physical activity, safety, stress management, and social connectedness (Rew, Arheart, Thompson, \& Johnson, 2013).

Social support is a lifestyle behavior that concerns friendships and functional sources of assistance (Gillis, 1997). Among adolescents, peers typically provide social support, but family, teachers, and coaches may also provide social support (Gillis). Research among adolescents indicates that social support promotes physical activity (Duncan, Duncan, \& Strycker, 2005) and acts as a buffer against unprotected sex, STDs 
(Mazzaferro et al., 2006), and depression (Holt \& Espelage, 2005). With the developmental priority adolescents place on peer relations, social support seems a particularly critical factor of lifestyle behaviors.

Finally, stress management involves having strategies to cope effectively with tension and pressure (Gillis, 1997). Adolescence is commonly recognized as a period of emotional turmoil. Recent research indicates that physiological indicators of stress are heightened during adolescence, which is theorized to facilitate adaptation to new challenges during the transition to adulthood (Stroud et al., 2009). While this heightened stress response is normal for adolescence, it may result in difficulty coping among adolescents with certain existing health problems such as asthma (Long et al., 2011) or those at risk for mental health problems (Stroud et al., 2009). Stress management techniques have been identified as having a significant influence on adolescents' emotional coping over time (Kraag, Van Breukelen, Kok, \& Hosman, 2009).

With adolescents' tendency toward risk-taking behaviors, it is important to assess health protective lifestyle behaviors. Lifestyle behaviors include identity awareness, nutrition, physical participation, safety, health awareness, social support, and stress management. These seven factors make up a significant portion of adolescent risk-taking and resilience to risk-taking behaviors. Evidence demonstrates that adolescents living in a rural area are less likely than their urban counterparts to have quality nutrition, to employ adequate safety measures, or engage in sufficient physical participation (Atav \& Spencer, 2002; Brady \& Weitzman, 2007; Curtis et al., 2011). A study measuring peer influence on rural adolescent's $(\mathrm{n}=1081)$ lifestyle behaviors demonstrated that social support was a significant predictor of nutrition, physical participation, health awareness, and stress 
management. While social support did not predict safety, a significant correlation was demonstrated (Rew et al., 2013). More research is needed among adolescents living in a rural area for an initial description of identity awareness and for further exploration of the other six lifestyle behaviors.

\section{Trust of health care provider.}

Trust is an important concept in the relationship between the patient and the HCP and has been defined and studied by several scholars. Hupcey, Penrod, Morse \& Mitcham (2001) — authors well-known for developing concept analysis methods - have provided a conceptual analysis of trust (Hupcey, Morse, Lenz, \& Tason, 1996; Hupcey \& Penrod, 2005; Morse, 1995; Morse, Hupcey, \& Cerdas, 1996; Morse, Hupcey, Mitcham, \& Lenz, 1996; Penrod \& Hupcey, 2005). The resulting definition of trust is:

Trust emerges from the identification of a need that cannot be met without the assistance of another and some assessment of the risk involved in relying on the other to meet this need. Trust is a willing dependency on another's actions, but is limited to the area of need and is subject to overt and covert testing. The outcome trust is an evaluation of the congruence between expectations of the trusted person and actions (2001, p. 290).

According to Hupcey, et.al. (2001a), three major attributes of trust are: (a) a need exists that cannot be met without the help of another, (b) prior knowledge and or experience with the other person, and (c) some assessment of risk within the relationship. Within the adolescent patient-provider relationship, an adolescent patient has a need that cannot be met without the help of the HCP. Frequently, the adolescent patient does not have prior experience sharing sensitive information with the HCP and the adolescent perceives a risk that the provider may notify the adolescent's parents of information that the adolescent communicates to the provider. This is especially problematic within general medicine or family practices, where the HCP treats all members of a family and 
privacy between family members and the provider is fluid (Elliott \& Larson, 2004;

Garside, et al., 2002). When an adolescent patient does not have previous experience with a $\mathrm{HCP}$ to demonstrate evidence that the $\mathrm{HCP}$ will not share confidential information, it is clear why trust may not be an inherent attribute of the adolescent patient-provider relationship.

Baier authored a seminal philosophical analysis of trust. Her analysis defines trust (1986, p. 259) in this way:

Trust is letting other persons take care of something the truster cares about, where such caring for involves some exercise of discretionary powers. In addition, with knowledge of each party's reasons for confident reliance on the other to continue the relationship could in principle also be entrusted.

Baier (1985, p. 232) asks, "Whom should I trust, in what way, and why?" It is likely that adolescents also ask this question as they pass through the developmental period of skepticism (Steinberg, 2010) that accompanies learning relativity. Baier's definition of trust also mentions discretionary power, which is noteworthy since there is a differential of power inherent in the adolescent patient and the HCP in the health care relationship. Legally, an adolescent cannot autonomously consent to all treatments; therefore, the adolescent's relationship with the HCP is actually a contract between the adolescent's parents and the HCP. Therefore, no trust is inherent within the health care relationship for the adolescent. According to Baier, when a power differential exists, "[those without power] cannot ignore the virtues of watchful distrust (1986, p. 253)."

Low levels of trust of HCP have been identified in various groups. Recent evidence demonstrates that health care distrust exists among both minorities and nonminorities (Armstrong, 2008, Whetten, 2006; Yang, 2011). Telephone surveys with 255 
individuals in Atlanta revealed distrust of HCP competency were equal among both African-Americans and Caucasians (Armstrong, 2008). Interviews with 611 HIV-positive individuals' revealed distrust of $\mathrm{HCP}$ resulted in lower rates of health services utilization, regardless of ethnicity (Whetten, 2006). Analysis of 5268 surveys showed distrust of health care resulted in foregone cancer screenings (Yang, 2011). Recent evidence suggests that other vulnerable populations also exhibit low levels of trust, such as people living in rural areas (McAlearney, 2012). Focus groups with Appalachian women revealed distrust of HCP resulted in avoidance of pap tests (McAlearney, 2012).

Low levels of trust of HCP influence a variety of health-related behaviors. Among adolescents, trust influences patients' willingness to seek care (Breland-Noble et al., 2010; Charman et al., 2010), disclose sensitive information (Blake et al., 2012; Farrant \& Watson, 2004; Leonard et al., 2010), submit to treatment (McKee, O'Sullivan, et al., 2006; Renker, 2006; Sayles et al., 2010), participate in research (Broome \& Richards, 2003), adhere to prescribed treatments (Brown, 2007), continue a HCP relationship (Hudson et al., 2008), and recommend a HCP to others (Ingram \& Salmon, 2007).

Several studies describe how adolescents' conceptualize trust of HCP. These studies suggest adolescents value honesty, respect, fidelity, HCP competence, and confidentiality when developing a trusting relationship with a HCP. Britto (2004) conducted a multi-phase study to develop a health care preferences scale for adolescents with chronic illness. Within the health care preferences scale, the respect/trust subscale included items measuring honesty, respect, and HCP competence (Britto, 2004). Farrant and Watson (2004) surveyed adolescents with chronic illness regarding desirable qualities of a HCP. One of the most important identified qualities was trusting the HCP to 
keep information confidential (Farrant \& Watson, 2004). The qualities of a HCP most preferred by adolescents with chronic illness were measured in a mixed methods study which identified one theme as "being trustworthy and honest," which was attained through continuity of HCP, not withholding information, being a confidante, and maintaining confidentiality (van Staa, Jedeloo, \& van der Stege, 2011). Klostermann, Slap, Nebrig, Tivorsak, \& Britto (2005) conducted a qualitative study using focus groups to determine how adolescents with and without chronic illness perceived trust of HCP. Thematic analysis revealed four elements of HCP trust were fidelity, confidentiality, HCP competency, and a global perspective (Klostermann, Slap, Nebrig, Tivorsak \& Britto, 2005). Grounded theory analysis of focus groups and interviews conducted with African-American adolescents diagnosed with depression $(\mathrm{N}=28)$ revealed a theme titled, "trust and frustration." Participants disclosed distrusting HCP whom they perceived to have failed to effectively treat their depressive symptoms, did not maintain confidentiality, did not make an effort to listen, or did not demonstrate care (Breland, 2010). Phenomenological analysis of focus groups discussing trust of both traditional and internet-based mental health care revealed adolescents' concerns were maintaining privacy and confidentiality (Charman, 2010). In a study aimed at determining British adolescents' $(n=48)$ help-seeking preferences for mental health care, focus group analysis revealed that adolescents' doubted their family HCPs' competence in helping with emotional problems (Leavey, 2011). A mixed methods study among American adolescents $(\mathrm{N}=1948)$ living in rural areas and small towns determined lack of trust in HCP's confidentiality to be a significant barrier to health services. Focus groups aimed at ascertaining American adolescents' $(\mathrm{N}=747)$ perspectives on health services revealed 
both males and females obtaining both reproductive and general health services do not trust that HCPs will maintain confidentiality (Cogswell, 1985). The results of these studies show that adolescents value honesty, respect, fidelity, HCP competence, and confidentiality when developing a trusting relationship with a HCP.

Loss of an adolescent's trust of HCP can result from a single interaction. Adolescents perceive betrayal of trust as breaking confidentiality or failure to help. African-American adolescents $(n=28)$ revealed distrust of HCPs who break confidentiality or fail to help with symptoms of depression (Breland, 2010). Focus groups with Australian adolescents $(n=20)$ seeking mental health services revealed experiencing breaches in trust when HCPs discussed the adolescent's health care with parents without discussing it with the adolescent first (Charman, 2010). Semi-structured interviews with teenagers experiencing perinatal violence revealed that one negative experience with a single authority figure may result in distrust of authority figures in general (Renker, 2006).

Parents play dual roles in adolescents' trust of HCPs. While studies of adolescents with chronic disease report having faith in parent's trust of HCP (Farrant, 2004; Klostermann, 2005), adolescents seeking health services for contraception report distrusting HCPs due to previous experience of parental accompaniment to HCP appointments (Cogswell, 1985; McKee, 2006). Adolescents' seem to desire parents' involvement with health care with a serious, ongoing health condition such as diabetes, kidney disease, or spina bifida, but shun parents' involvement when seeking health services for reproductive health care. 
Trust of HCP has not been measured with valid and reliable instruments among adolescents. Of 19 studies measuring trust of $\mathrm{HCP}$ among adolescents, five studies measured trust of HCP quantitatively. Results varied widely with 57.3\% (Chandra, 2006), 64.4\% (Cheng, 1993), 75\% (Farrant, 2004), 89.1\% (McKee, 2007), and 100\% (Ingram, 2007) of surveyed adolescents reporting trust of HCP. In each of these five studies, trust of HCP was measured using only one or two investigator developed survey items, none of which described trust of HCP psychometrics.

A dearth of empirical evidence concerning trust of $\mathrm{HCP}$ among adolescents exists, which results in significant gaps in the literature. The empirical reports discussed here also lack adequate participant diversity. A single study measured trust of HCPs among rural adolescents and no studies included measurement of trust of HCP among homosexual, Hispanic, or Native American/Alaska Native adolescents. Further research should measure trust of HCP among diverse samples of adolescents using a valid and reliable instrument.

\section{Utilization of health services.}

Among all age groups in the US, adolescents have the lowest rates of outpatient health services visits and are under-represented in proportion to the population. The most common reasons adolescents present for a health services visit are for upper respiratory conditions, acne, routine medical exams, physicals for extra-curricular activities, and prenatal care (Ma et al., 2005). A secondary data analysis of the 1999 Medical Expenditures Panel Survey $(n=6879)$ revealed descriptive statistics for adolescents' utilization of health services (Simpson et al., 2004). Simpson et al. (2004) demonstrated that in 1999, adolescents' ages 10-14 years (65.7\%) and ages $15-17$ years $(63.3 \%)$ had at 
least one HCP visit within the last year, with children ages $0-4(82.4 \%)$ and ages 5-9 $(66.6 \%)$ reporting greater rates of HCP visits. With the additional health needs that come with the physical changes, cognitive maturation, and associated risk behaviors of adolescence, it seems that HCP visits would increase with age, rather than the decrease demonstrated here. In 1999, adolescents ages 10-14 visited a HCP 4.2 times per year and adolescents ages 15-17 made nearly the same number of HCP visits ( $M=4.3)$. In addition, adolescents' ages 10-14 (8.8\%) and ages 15-17 (12.6\%) used the emergency room at least once within the last 12 months (Simpson et al., 2004). According to a study analyzing National Health Interview Survey data (Mulye et al., 2009), by 2006 adolescents ages 10-17 were much more likely (84.2\%) to have had at least one HCP visit in the past year than in 1999 (63.3\%-65.7\%) (Simpson et al., 2004). Adolescents ages 1017 were more likely to have used the emergency room at least once (17.5\%) in 2006 (Mulye et al., 2009), as compared to adolescents in 1999 (8.8\%-12.6\%). The implementation of CHIP (1997) likely contributed to this increase in utilization of health services.

Most concerning was the number of adolescents reporting foregone care. Foregone care is not having sought health services when a subjective need for health services existed (Rew et al., 1999). Adolescents most frequently forego care for injuries (Elliott \& Larson, 2004), contraception (McKee, Fletcher, et al., 2006), and mental health concerns (Lehrer et al., 2007).

Several studies have measured foregone health services among adolescents. In a study (Rew, Resnick, \& Beuhring, 1999) designed to describe foregone care among Hispanic adolescents $(\mathrm{n}=717)$ using Andersen's Behavioral Model of Health Services 
Use (ABM), $28.3 \%$ of participants reported foregone care. The reasons identified for foregone care were: (1) thought my problem would go away (76.4\%), (2) afraid of what the doctor would say or do (52.7\%), (3) did not want my parents to know (48.8\%), (4) could not get there (42.4\%), (5) did not think doctor could help me (35.9\%), (6) could not pay or cost too much (33.9\%), (7) did not know who to go see (33.5\%), (8) hard to make an appointment (31.5\%), (9) no insurance or did not know how to use it (31.0\%), (10) hours were not good for me (27.6\%) and (11) other reasons not specified (55.7\%). More than half of participants reported "other" reason for foregone care, suggesting the answers provided in the survey were not sufficient in describing barriers to health services. Females were significantly $(p<.05)$ more likely to report the following reasons for foregone care: (1) thought my problem would go away, (2) afraid of what the doctor would say or do, and (3) did not want my parents to know. A single predictor of foregone care was identified among females; social connectedness had an inverse relationship with foregone care and explained $70.32 \%$ of the variance $(p=.000)$. Social connectedness is "the perception that one can reliably count on others to provide emotional and instrumental support" (Rew et al., 2013, p. 280) and is similar to the concept of social support. Social connectedness and alcohol use both had a negative relationship with foregone care among males and these predictors resulted in $75.95 \%$ variance explained among participants $(\mathrm{p}=.003)$.

In a study designed to investigate foregone care and barriers to health services among adolescents ages 15-17 years living in rural Minnesota $(\mathrm{n}=1948)$ in 2001, Elliott and Larson (2004) surveyed adolescents in schools and those who had dropped out of school. The survey was investigator-developed and items were mostly drawn from the 
Youth Risk Behavior Survey, the National Longitudinal Study on Adolescent Health, and the Minnesota Student Survey items. While 90\% of participants reported a perceived need for health care during the past year, $44 \%$ of those reported foregone care. Logistic regression revealed a six-factor model predicting $22 \%$ of the variance in foregone care, which included: (1) engaging in activities that could cause harm to you or others, (2) being sexually active, (3) using marijuana, (4) expecting parenthood by age 20, (5) good self-rated health, and (6) being male. Barriers to utilization of health services among those reporting foregone care were examined using factor analysis and revealed five factors: (1) anxiety/fear, (2) access, (3) self-reliance, (4) non-supportive parent, and (5) helpless/hopeless. Bradford and O'Sullivan $(2006,2007)$ conducted a descriptive study to determine the relationship between health status and utilization of health services among $9^{\text {th }}$ graders at a school based health clinic by $(\mathrm{n}=171)$ in rural Mississippi. Health status was determined with the Child Health and Illness Profile_-Adolescent Edition, which evaluates physical, psychological, and social health within four domains (satisfaction, discomfort, resilience, and risk) to determine health status (excellent, good, fair, poor, very poor) (Bradford \& O'Sullivan, 2006). In addition, the participants completed an investigator-developed demographic questionnaire and a health services utilization questionnaire. The investigators asked about the adolescents' usual source of care (USOC) for routine care such as check-ups and for sick care in separate questions. Most participants reported HCP office/clinic as USOC for both check-ups (54.4\%) and sick care (36.2\%). Foregone care over the past three months was reported by $37 \%$ of participants (Bradford \& O'Sullivan, 2006). Of those reporting foregone care, the following reasons were given with percentage of participants reporting the reason: (1) 
thought the problem would go away $(63.9 \%)$, (2) did not want to miss school $(37.1 \%)$, (3) afraid of what the doctor might say (19.7\%), (4) afraid parents might find out $(13.1 \%),(5)$ could not get an appointment $(9.8 \%),(6)$ could not get out of class $(9.8 \%)$, (7) had no transportation $(6.6 \%),(8)$ could not pay/no insurance $(6.6 \%)$, (9) parent or guardian would not go (4.9\%), and (10) did not know where to go or whom to see $(3.3 \%)$ (Bradford \& O’Sullivan, 2007).

McKee (2006) conducted a cross-sectional study to identify predictors of and barriers to timely initiation of gynecologic care for sexually active low-income adolescent females in three Bronx, NY high schools. The National Longitudinal Adolescent Health Survey, the Whitaker self-esteem scale, the family subscale from Multidimensional scale of Perceived Social Support, and an investigator-developed survey including items to measure confidential care and trust of HCP were distributed to females ages 13-19 $(n=819)$. Sixty-eight percent of participants reported visiting a HCP in the last year and $34.3 \%$ reported foregone care. Believing the problem would resolve on its own was the most commonly reported reason for foregone care. A desire to keep HCP visit from parents' knowledge was the second most common answer among sexually active females, while fear of what the doctor would say was second most common among non-sexually active females. A four-factor model predicting foregone care included the following variables: (1) sexual activity $(b=.44, \mathrm{p}=.005),(2)$ family social support $(b=.37, \mathrm{p}=.001),(3)$ self-esteem $(b=.07, \mathrm{p}=.006)$, and (4) family financial difficulty $(b=-.84, \mathrm{p}=.015)$ (McKee \& Fletcher, 2006). McKee and Fletcher's model suggests risk behaviors, social support, identity awareness, and financial barriers predicted foregone care. In addition, the study also measured trust of HCP for inclusion 
in the prediction models, but trust of HCP was measured with two investigator-developed questions without prior psychometric testing. Trust of HCP was not a significant predictor in any models.

The Elliott \& Larson (2004) study reported a higher proportion of foregone care (44\%) than other studies (Rew, 1999 demonstrated 28.9\% reporting foregone care; Bradford, 2006 reported 37\% foregone care; and McKee \& Fletcher, 2006 reported $34.3 \%)$. The increase in reported foregone care may be related to rural socioenvironmental factors, inclusion in the sample of adolescents who had dropped out of school, or a variation of the phrasing of the foregone care questions. Typically, foregone care has been measured with, "Has there been any time over the past year when you thought you should get medical care, but did not?" Instead, the investigators asked two questions: (1) Was there any time over the past year when you thought you should see a nurse or doctor, followed by (2) Did you receive care for that need?. The authors suggest that the two-part question measuring foregone care may have encouraged participants to consider the question more carefully, resulting in higher reports of foregone care.

These studies demonstrate that adolescents' frequently forego care. Frequently reported reasons for forgone care were (1) thought my problem would go away, (2) didn't want my parents to know, and (3) afraid of what the doctor might say or do (Bradford \& O'Sullivan, 2006; Elliott \& Larson, 2004; McKee \& Fletcher, 2006). Adolescents' foregone health services have significant human and economic costs. Note that adolescents frequently forego health services for contraception, then commonly receive prenatal health services (McKee, Fletcher et al., 2006). In 2009, 409,840 infants were born to females ages $15-19$, costing U.S. taxpayers nine billion dollars in health care 
costs, foster care costs, legal costs, and lost tax revenue (CDC, 2011). Similar consequential situations are repeated throughout the lifecycle with a variety of health concerns such as smoking leading to pulmonary disease, untreated mental health concerns creating a future need for extensive psychiatric care, and obesity resulting in care needs for a variety of cardiac diseases. Nearly half of all adults have at least one chronic disease (CDC, 2012), costing the U.S. economy more than one trillion dollars annually (Milken Institute, 2007). Lifestyle behaviors are patterns developed during adolescence that frequently persist throughout adulthood resulting in either a healthpromoting lifestyle or chronic disease. These cause-and-effect situations demonstrate the importance of developing a trusting relationship with a HCP during adolescence.

\section{Individual Characteristic Variables}

Utilization of health services is associated with many individual characteristic variables. Among adolescents, individual characteristic variables include age, sex, race, ethnicity, family structure, household income, health insurance, transportation, usual source of care, self-rated health, self-perceived need, and diagnosed conditions. Evidence of the relationship each of these variables has with adolescents' utilization of health services is described below.

\section{Age and sex.}

Age and sex are variables that suggest the likelihood that an individual will need health services as a biological necessity. When considering age, older people generally utilize more health services than younger people, both in the U.S. and internationally (Babitsch et al., 2012). Older adolescents also utilize more health services than younger adolescents (Hoover et al., 2010; Simpson et al., 2005; Simpson et al., 2004), mostly 
related to contraceptive, STD, and obstetric care among older adolescent females (Hoover et al., 2010). Overall — in both the U.S. and internationally — men tend to utilize less health services than women, among adults (Babitsch et al., 2012) as well as adolescents (Hoover et al., 2010; Ma et al., 2005; Mulye et al., 2009). Older adolescent males (age 18-25) are least likely of any group to utilize health services (Spleen et al., 2014).

\section{Race and ethnicity.}

Race and ethnicity are known to have a significant effect on utilization of health services. Studies indicate that racial and ethnic minorities are less likely to utilize health services among both adults (Andersen et al., 2002; Blackwell, Martinez, Gentleman, Sanmartin, \& Berthelot, 2009) and adolescents (Ma et al., 2005; Simpson et al., 2004). This correlation remains significant when holding family income and insurance status constant, indicating that social and cultural barriers to utilization of health services among minorities exist (Simpson et al., 2005; Simpson et al., 2004).

\section{Family structure.}

Family structure influences utilization of health services among adolescents. Adolescents living with only one parent were $5.5 \%$ less likely to have a $\mathrm{HCP}$ visit in the prior year than those living with two parents (Probst et al., 2005). Among children and adolescents, living in a single-father family was associated with less access to health services than living with a single mother only (Gorman \& Braverman, 2008; Leininger \& Ziol-Guest, 2008). Adolescents living with someone other than parents had the lowest utilization rates, being $18.1 \%$ less likely to have a $\mathrm{HCP}$ visit in past year than those living with both parents (Probst et al., 2005). Thus, utilization of health services among 
adolescents appears to decrease across family structure, with the two-parent family having the highest rates, followed by the single-mother family, then the single-father family, and finally living with someone other than parents.

\section{Health insurance.}

Having health insurance is the factor most likely to provide access to health services among most Americans (Institute of Medicine, 2004). The implementation of the State Childrens Health Insurance Program (SCHIP) in 1997 (The Balanced Budget Act. Title XXI: The State Childrens Health Insurance Program, 1997) sought to fill the gap of low-income adolescents' health insurance coverage. An examination of 2000-2002 Medical Expenditure Panel Survey data and the 2001 Nationwide Inpatient Sample revealed that adolescents were less likely to have insurance than infants and children (Simpson et al., 2005). An evaluation of HCP office visits demonstrated that among adolescents, the privately insured receive the most HCP visits, followed by the publicly insured, with uninsured adolescents being least likely to receive a HCP visit (Simpson, 2004). While SCHIP has made a significant advancement in the number of adolescents with health insurance and HCP visit rates, more improvement is needed.

\section{Household income.}

Lack of financial resources and underserved populations are both common themes in utilization of health services research. An examination of national databases from 1987-2000 shows that while the focus on improving adolescent health insurance rates

with the Child Health Insurance Program (CHIP) has made an improvement in adolescent health services utilization, low-income and publicly insured adolescents were still less likely to receive needed health services visits (Simpson et al., 2004). An analysis of 
1999-2000 National Health Interview Survey data focusing on adolescents living in rural areas revealed that those living in low-income households were less likely to have health insurance, less likely to have a usual source of care, and less likely to have had a HCP visit within the past year (Probst et al., 2005).

\section{Transportation.}

Transportation barriers are frequently reported in utilization of health services literature. As described above, rural areas are defined by a small population in a broad geographic area (Klugman, 2008a), which results in more transportation barriers since distances are greater and rural areas typically lack public transportation. Adolescents living in rural areas report transportation difficulty as a barrier to utilization of health services. In a study of foregone mental health care among adolescents in rural Minnesota $(n=497)$, transportation barriers were identified as a barrier to utilization of health services. Of those participants reporting foregone mental health services, $7.8 \%$ stated transportation barriers contributed to inability to utilize health services, with females reporting transportation difficulty at nearly twice the rate of males (Samargia, Saewyc, \& Elliott, 2006). A study measuring foregone health services in rural Minnesota revealed a five-factor model predicting foregone health services : (1) anxiety/fear, (2) access issues, (3) self-reliance, (4) non-supportive parent, and (5) helpless/hopeless. The second factor - access issues — included transportation barriers (Elliott \& Larson, 2004).

\section{Usual source of care.}

Usual source of care (USOC) means that an individual identifies a particular HCP or clinic as the typical supplier of health services when health services are needed. Reports of USOC vary widely among various samples of adolescents. A nationally 
representative telephone survey of parents of adolescents $(n=45,897)$ revealed $92.8 \%$ 10-17 year-olds had a USOC (Adams et al., 2013). These results seem promising until the contrast between USOC reported by parents is compared to adolescent-reported USOC. When polling adolescents , USOC rates drop to $63 \%$ among Hispanics in Connecticut (Rew et al., 1999), 64\% of rural minority high school students in Mississippi (Bradford \& O'Sullivan, 2006), 75.8\% of African-American adolescent males in Maryland (Maulik et al., 2011), 80\% among minority adolescent females in New York, and $81 \%$ of adolescent CHIP recipients in Florida and New York. These results seem to indicate that low income and minority adolescents are less likely to report a USOC than reported by parents of American adolescents in general.

\section{Self-rated health.}

Self-rated health is a global measure of wellness, which is a valid and stable measurement of health among both adults (Idler \& Angel, 1990) and adolescents (Fosse \& Haas, 2009). Self-rated health is an important indicator of overall wellness because the individual is able to indicate subjective health conditions that may not reveal themselves on narrow measurements of health. Among adolescents, fair or poor self-rated health is associated with chronic health conditions such as asthma, diabetes, overweight, and obesity (Fosse \& Haas, 2009) as well as increased rates of health services utilization (Bradford, 2007).

\section{Self-perceived need.}

Self-perceived need measures an individual's subjective requirement for health services (Andersen, 2007). Only one study has reported self-perceived need among

adolescents (Elliott \& Larson, 2004; Samargia, Larson, \& Elliott, 2006). In that study, 
91\% of adolescents reported a self-perceived need in the past year (Elliott \& Larson, 2004). The percentages of participants reporting perceived need for conditions were: illness (91\%), reproductive concerns (53\%), mental health concerns (46\%), STDs (42\%), injuries (39\%), substance abuse (11\%), and various chronic conditions ranging from $1 \%$ to $42 \%$ (Elliott \& Larson, 2004; Samargia, Larson, \& Elliott, 2006). Girls and adolescents living in two parent families were more likely to report a mental health need (Samargia, Larson, \& Elliott, 2006).

\section{Foregone care.}

Foregone care is not seeking health services when there is a subjective need for health services (Rew et al., 1999). Foregone care also describes barriers to utilization of health services. Common reasons for foregone care that adolescents report are: (1) thought my problem would go away, (2) afraid of what the doctor might say or do, and (3) didn't want my parents to know (Bradford \& O'Sullivan, 2006; Elliott \& Larson, 2004; McKee \& Fletcher, 2006; Rew et al., 1999).

\section{Diagnosed conditions.}

Among studies of utilization of health services, evaluated need can be determined in a variety of ways. In many studies, evaluated need is drawn from medical records as physical measurements, lab results, or HCP diagnosed conditions. Studies that collect data from individual participants — rather than medical record reviews - have asked participants to report conditions diagnosed by a HCP. Among adolescents, common HCP diagnosed conditions include acne, allergies, attention deficit hyperactivity disorder (ADHD), anemia, asthma, cancer, diabetes, high blood pressure, overweight, and obesity, all of which are associated with fair or poor self-rated health (Fosse \& Haas, 2009) and 
increased utilization of health services (Youngblade, 2006). Rates of diagnosed conditions varied among adolescents between Florida (12.2\%) and New York (17.7\%) (Klein et al., 2006), while 19\% of adolescents reported a diagnosed condition nationally (Adams et al., 2013). Forty-three percent of adolescents living in rural Missouri reported diagnosed conditions (Elliott, 2004). The percent of adolescents living in rural Indiana reporting diagnosed conditions was not available.

\section{Conclusion}

Adolescents living in rural areas are a vulnerable population and demonstrate health disparities. Adolescents have elevated morbidity and mortality rates associated with risk-taking behaviors, but utilize health services at the lowest levels of any group. Lifestyle behaviors, trust of $\mathrm{HCP}$, family structure, low household income, and transportation barriers are all concerns that influence adolescents' utilization of health services in rural areas. While studies have investigated these concepts separately, none has measured trust of HCPs, lifestyle behaviors, and other predictors of health services utilization among American adolescents living in rural areas. This study seeks to add to the evidence regarding trust of $\mathrm{HCP}$, lifestyle behaviors, and predictors of health services utilization among adolescents living in rural areas. 


\section{CHAPTER III}

\section{METHODS}

In this study, the relationship between trust of HCP, lifestyle behaviors, and utilization of health services among adolescents living in a rural area was examined. This chapter includes a discussion of the methods used in this study. First, a discussion of the study design including power analysis, recruitment, setting, and inclusion/exclusion criteria is presented. A discussion of human subjects' considerations follows, along with a description of the sample, and then a discussion of measurement instruments to assess the study variables. Data collection and data management procedures are also described. Finally, the statistical analyses plan is described.

\section{Study Design}

A cross-sectional design was used to explore individual characteristics, trust of HCP, lifestyle behaviors, and utilization of health services at a single point in time among adolescents living in a rural area. Previously validated, standardized questionnaires were administered via pen and paper to measure the primary study outcomes: trust of HCP, lifestyle behaviors, and utilization of health services.

\section{Power Analysis}

To determine an appropriate sample size for this study, an apriori power analysis was conducted using $G^{*}$ Power software (G*Power, 2013). This study included eleven predictor variables (age, sex, family structure, trust of HCP, household income, health 
insurance, transportation, usual source of care, self-rated health, foregone care, and HCP diagnosed condition) for multiple regression analysis of all of the outcome variables (trust of HCP, lifestyle behaviors, utilization of health services). Since trust of HCP was used as both a predictor variable and an outcome variable, the multiple regression analyses for lifestyle behaviors and utilization of health services included trust of health care provider as an additional predictor variable. Race and ethnicity were not included in the analysis because of the low minority population of the sample. American Community Survey 2008-2012 five-year estimates data from the U.S. Census Bureau reports 97.0\% of residents in Salem, Indiana identify as Caucasian and 98.3\% identify as non-Hispanic (United States Census Bureau, 2013). Race and ethnicity were included in the study model and in data collection for the purpose of describing the sample. Making use of 0.80 power, moderate effect size of $\mathrm{R}^{2}=.15$, alpha of 0.05 , and twelve predictor variables, a minimum sample size of 123 participants was suggested (Cohen, 1988). To correct for missing data, the investigator aimed for a $10 \%$ greater sample size than the minimum identified for 136 total participants. Participant rate was determined by tracking the number of individuals whose parents' dissented participation, the number of individuals that verbally dissented participation, and the number of individuals' anonymously that dissented participation by returning a blank survey packet.

\section{Recruitment}

Three hundred and sixteen potential participants $-9^{\text {th }}$ and $12^{\text {th }}$ graders at Salem High School—matched the inclusion criteria for this study according to data obtained from the high school guidance counselor (personal communication, J. Martin, May 2014). The investigator worked with school administrators to determine classes available 
for survey, aiming to recruit 68 participants from both the $9^{\text {th }}$ and $12^{\text {th }}$ grade. School administrators requested all students in each grade were offered participation in the study, so that the teaching plans could be maintained across sections of the courses. Recruitment flyers were posted in the classrooms in which the study was conducted. The study was presented to participants and informational letters to potential participants and passive consent letters for parents of minors were distributed to potential participants.

\section{Setting}

The setting of this study was a rural community. Rural is a multifaceted concept and frequently defined and measured as an area or population that is not urban. In this study, the Federal Office of Rural Health Policy provided the definition used to define rural. The Office of Rural Health Policy defined rural areas as incorporated populations of less than 50,000 with core census blocks of fewer than 1,000 people per square mile and surrounding census blocks with an overall density of fewer than 500 people per square mile (Health Resources and Services Administration, n.d.a). This method was consistent with other studies of adolescents living in a rural area, including a recent study of risk-taking behaviors among adolescents living in rural California $(n=663)$ (Curtis et al., 2011).

The setting of the study is described according to the Andersen's domain of contextual characteristics. Contextual characteristics are the ways that individuals live, work, and socialize that affect health outcomes and are defined as the circumstances and environment of health services access (Andersen et al., 2007). Contextual characteristics were gathered at the county level, unless otherwise specified. The population of the Indiana county was mostly (98.3\%) non-Hispanic whites (United States Census Bureau, 
2013). Twenty-five percent of the population of the county's residents were under age 18 , with single parents heading nearly a third (32\%) of families with children under age 18 (American Community Survey 5-year estimates, 2012).

The county in which the high school was located was a mostly low-income community. The median household income $(\$ 41,125)$ was considerably lower than the state $(\$ 48,374)$ and national $(\$ 53,046)$ median household incomes. The low-income status of residents may be related to lower educational attainment. Concerning adults over age 25 , obtaining a high school diploma ( $80.3 \%)$ seems somewhat valued, but higher education was less important (11.6\% with a bachelor's degree). By comparison, the national rate of adults over age 25 having a high school diploma was $87.0 \%$, with more than twice the rate (23.0\%) of earning a bachelor's degree. Across the U.S., 19.2\% of children ages five to 18 lived beneath the poverty level, with a greater proportion (21.2\%) in the studied county (U.S. Census Bureau, 2012). During the 2013 fiscal year, $43 \%$ of children within the county participated in the National School Lunch program (County Health Rankings \& Roadmaps, 2014), while 70.0\% of children participated nationally (USDA Food and Nutrition Service, 2014). In 2009, 51\% of eligible households within the county received Supplemental Nutrition Assistance Program benefits while nearly two-thirds of eligible household receive benefits nationally (DeParle \& Gebeloff, 2009). Since nearly half (49\%) of eligible households do not participate in the Supplemental Nutrition Assistance Program, it is likely that eligible children also do not participate in the National School Lunch Program. This county's comparably low level of education and higher disability rates likely contribute to lower household income and greater poverty. However, fewer eligible households receive low- 
income nutrition program benefits, which may indicate hesitancy to use public assistance. The Rural Nursing Theory has described hesitancy to use public assistance as indicative of the self-reliance and independence of rural dwellers that results in a reluctance to accept help (Lee \& Winters, 2004; Long \& Weinert, 1989).

Environmental concerns within the county include air pollution and water pollution. Approximately $16 \%$ of residents were exposed to drinking water that violated safety standards as opposed to $2 \%$ exposed across Indiana. For example, the municipal water supply for the high school has failed drinking water quality tests for chlorination byproducts (haloacetic acids and trihalomethanes) from 2003-2013 (Environmental Protection Agency, 2014; S__ Municipal Utilities, 2013). Evidence demonstrates that the water chlorination byproducts haloacetic acids and trihalomethanes are associated with asthma and atopic dermatitis (Richardson et al., 2010). Particulate matter in county air (13.7 mcg per cubic meter) was worse than the state $(13.5 \mathrm{mcg})$ and national levels (11.5 mcg) (County Health Rankings \& Roadmaps, 2014). Exposure to contaminated air and water are public health concerns in the county in which this study was conducted.

Population health indices indicate lower levels of health among county residents. The rates of health insurance coverage among residents of the county were similar to national estimates, with $66.2 \%$ having private health insurance, $31.2 \%$ having public health insurance, and $14.1 \%$ having no health insurance. Thirty-one percent of adults were obese in both the county under study and in the state of Indiana, while $37.0 \%$ of adults in the county were smokers - which was much higher than the state average of 23\%. (County Health Rankings \& Roadmaps, 2014). Twenty-one percent of adults within the county report having foregone care due to cost. More adults in the county under study 
(21.2\%) report poor self-rated health than across the U.S. (17.1\%) and the average life expectancy was lower (75.0 years) in this county, compared to 76.5 years nationally (Community Health Status Indicators, 2009). The residents of the county under study had similar rates of insurance and obesity compared to state or national samples, but were more likely to be smokers, to have foregone care due to cost, to report poor self-rated health status, and to die prematurely.

\section{Inclusion and Exclusion Criteria}

The target population for this study were adolescents living in a rural area. This study surveyed a sample of English-speaking students, age 14-19, enrolled in a single public high school in rural Indiana. In order to obtain a sample reflective of the population and avoid selection bias, the sample was drawn from students enrolled in required courses with class time available for survey. Inclusion criteria for this study were: (1) age 14-19; (2) able to read, speak, and understand the English language; (3) able to complete a self-administered questionnaire; (4) enrolled in grade 9 or grade 12 at a public high school in a rural area; (5) willing to participate; and (6) parents of minors did not refuse consent. Exclusion criteria for this study were: (1) inability to read, speak, and understand English; (2) adolescent unwilling to participate; and (3) parent of minor refused consent (See Appendix A for Parental Passive Consent Letter).

\section{Human Subjects Protection}

Informed consent acted as a foundation for the protection of research participants. This study used an adolescent-centered informed assent/consent approach, which indicated that the adolescent participant was the primary target of the research discussion and decision, with the parent serving a passive role (Dent, 1993). This approach was 
consistent with evidence-based guidelines informing the inclusion of adolescents in their own health care (Society of Adolescent Health and Medicine, 2010) and is known to improve the authenticity of data obtained from marginalized adolescents (Dent, 1993). Previous studies have shown that children as young as seven years old are qualified to provide assent in the research process (Broome, 1999).

The human subjects' protection plan for this study was designed with minimal risk in mind. Subsequent to IRB approval (See Appendix B), approximately one week in advance of the planned data collection, the investigator provided the faculty/staff of the classes in which data collection would take place with passive consent letters addressed to parents (See Appendix A) to be distributed to students in the sample. The parental passive consent letters included information regarding the nature of the study and an opportunity to contact the investigator for dissent of participation. In the absence of expressed dissent, parental consent was assumed. Any participants that refused consent/assent were given an alternative activity—a seek-and-find word puzzle — to complete during the data collection time period. Individuals choosing to anonymously dissent were instructed to retain the survey packet until the end of the data collection period, then turn in the blank survey packet.

On the day that the study was conducted, the investigator explained the study, anonymity of the study, and study procedures to the participants. Participants included both minors (ages 14-17) and adults (ages 18-19). A cover sheet explaining the study and procedures were distributed to participants. Minors received a survey packet including an informational cover sheet (See Appendix C), while the adult participants received a survey packet including a passive consent letter (See Appendix D). Numbered packets 
containing the cover sheet/letter, demographics and individual characteristics survey, Wake Forest Interpersonal Trust in Physician Scale, Adolescent Lifestyle Questionnaire, and Health Care Utilization Questionnaire were distributed to all participants assenting to the study. The packets were numbered in order to maintain the four questionnaires from each participant together. The investigator allowed the participants an opportunity to ask questions about the study. The surveys remained anonymous and all forms were provided in paper and pen format. Students were allowed the remaining class time-approximately 30 minutes - to complete the surveys. When the students had completed the survey, the questionnaires were collected from each participant. The completed questionnaires were kept secure in a locked file at the University of Louisville, School of Nursing Research Office. Data were saved on the University of Louisville, School of Nursing's encrypted SharePoint site.

Data were collected in a classroom setting at a public high school. Instructors were present to maintain order in the classroom, but instructors were advised to refrain from pacing around the room or positioning themselves in any way that would allow viewing participants' surveys. Participants were encouraged to use a cover sheet during survey completion for privacy of survey responses.

\section{Sample Description}

This sample of adolescents included 224 individuals attending $9^{\text {th }}$ grade or $12^{\text {th }}$ grade at Salem High School in Salem, Indiana during May 2014. As determined by the school administrators, potential study participants were accessed through $9^{\text {th }}$ grade physical education classes and $12^{\text {th }}$ grade English classes. Both $9^{\text {th }}$ grade physical education and $12^{\text {th }}$ grade English are required courses in the state of Indiana, meaning all 
students in each grade were invited for participation in the study. The a priori power analysis, which was based on a medium effect size, determined the necessary sample size for this study to be 123 participants. As a result of complying with school administrators request to offer the study to all students in each course, the recruited sample for the study was 224 participants, which was $82 \%$ greater than determined necessary by the apriori power analysis. Oversampling helped to account for missing data.

Three-hundred and sixteen total students were enrolled in the $9^{\text {th }}$ grade $(\mathrm{N}=162)$ and $12^{\text {th }}$ grade $(\mathrm{N}=154)$ at the high school when the survey was conducted. A total of $227(71.8 \%)$ students were present in $9^{\text {th }}$ grade PE classes $(n=128,79.0 \%)$ and $12^{\text {th }}$ grade English classes $(n=99,64.3 \%)$ on the days of the survey and received survey packets. Thirty-four $9^{\text {th }}$ graders were absent from school on the day of the survey. The $12^{\text {th }}$ grade English instructor noted that five of the $12^{\text {th }}$ grade students were taking standardized tests and would not be available for survey, along with 20 absent students, and approximately thirty $12^{\text {th }}$ grade students that were at risk for not graduating and had stopped attending class. Over a two-day period, 224 (70.9\%) adolescents returned completed surveys. Two adolescents anonymously dissented participation by returning a blank survey packet, while one adolescent verbally dissented participation. All dissenting adolescents were in the $12^{\text {th }}$ grade. No parents of minors refused consent. As 227 survey packets were distributed and 224 completed survey packets returned, a $98.7 \%$ response rate was calculated for this study. 


\section{Measurement of Variables}

To test the research questions, four questionnaires were administered: (1) the Wake Forest Interpersonal Trust in Physician Scale (Appendix E), (2) the Adolescent Lifestyle Questionnaire (Appendix F), (3) the Stanford Health Care Utilization Questionnaire (Appendix G), and (4) an investigator-developed demographic and individual characteristics questionnaire (Appendix H). A description of each of the four questionnaires is presented below.

\section{Demographic and Individual Characteristics Questionnaire}

Adolescent research participants completed a self-report demographic and individual characteristics questionnaire created by the principal investigator (See Appendix H). Age was a continuous variable measured in years with one item containing six options ranging from 14 years to 19 years. Sex was a dichotomous nominal variable measured with a single self-report item of male or female. Race was a nominal variable measured with one item indicating self-identified classification among the five major groups included on government surveys: American Indian/Alaska Native, Asian, African-American, Pacific Islander, or White. Participants were able to choose more than one race. Ethnicity was a dichotomous nominal variable measured with a single item of self-identification as Hispanic or Not Hispanic. Family structure was a nominal variable measured with two self-report items indicating the primary adults living in the home with the adolescent. Options for adult female the participant lived with included biological mother, step-mother, foster mother, adoptive mother, grandmother, or someone else. The options for adult male the participant lived with included biological father, step-father, foster father, adoptive father, grandfather, or someone else. Household income was an 
ordinal variable measured by a single item representing participation in the National School Lunch Program—indicated by free or reduced lunch status—a valid adolescent reported socio-economic status indicator (Ensminger et al., 2000). Health insurance was a nominal variable measured with a single question including the following responses: Medicaid or Hoosier Healthwise, military insurance, private insurance, other insurance, no insurance, or I don't know. Transportation was measured with two items. The first item was a nominal variable that asked about usual transportation to the doctor's office, which included drive, driven by someone else, public transportation, walk, and some other way. The second item was an ordinal variable that measured difficulty of getting to doctor's office, with four responses ranging from very difficult to not at all difficult. Usual source of care was measured with two items. The first item was a dichotomous nominal variable that asked if there was a particular doctor's office where the participant usually went to if they were sick or need advice about their health. The second item was a nominal variable that asked for a description of the usual source of care, whether it was a clinic, doctor's office, or emergency room. Self-rated health was an ordinal variable that measured subjective wellness with five options ranging from excellent to poor. Foregone care was a subjective measure of health need which was measured with three questions. The first question measured self-perceived need as a dichotomous nominal variable by asking if the participant thought they needed to see a doctor or nurse in the last 12 months. The second question was also a dichotomous nominal variable and asked if the participant received care for the self-perceived need. The third question was a nominal variable that offered options to describe why the individual did not obtain the care that was perceived as needed. Each of the three foregone care items were measured as 
separate items. Diagnosed conditions was an objective indicator of health measured as a nominal variable that asked if the participant has been diagnosed with any of the following conditions: acne, attention deficit hyperactivity disorder, anemia, allergies, asthma, depression, diabetes, high blood pressure, overweight, obesity, or none of the above. Two measures of health behaviors included participant-reported tobacco use, height, and weight. Tobacco use was a continuous variable measured by number of times cigarettes, cigars, or smokeless tobacco was used in the past 30 days, which was transformed into a dichotomous nominal variable indicating any use of tobacco in the past 30 days. Self-reported height and weight was adjusted for known report bias and was used to determine body mass index (BMI) as an objective measure of weight status. Multiple years of national YRBS data has allowed for extensive reliability testing of adolescent's self-reported height and weight. In general, adolescents over-report height by 2.7 inches and under-report weight by 3.5 pounds (Brener, McManus, Galuska, Lowry, \& Wechsler, 2003). It was necessary to adjust self-reported measures of height and weight using formulas provided by the CDC. The BMI for age growth charts were used as a reference for weight categorization (Centers for Disease Control and Prevention, 2011). With the growth chart system of BMI classification, percentile ranges determined the weight category of adolescents. A BMI greater than the 95th percentile was considered obese and a BMI greater than the 85 th percentile was considered overweight.

\section{Wake Forest Interpersonal Trust in Physician Scale}

The outcome variable trust of $\mathrm{HCP}$ was measured as a continuous variable using the Wake Forest Interpersonal Trust in Physician Scale. The Wake Forest Interpersonal 
Trust in Physician Scale was a 10-item scale developed to measure patient's trust of the primary health care provider (See Appendix E), with financial support from the Robert Wood Johnson Foundation. This scale was chosen for its conceptual basis of trust of physician—including fidelity, competence, honesty, confidentiality, and global trust— which was more similar than other trust scales to the aforementioned conceptual basis of trust of HCP described by adolescents in research studies (fidelity, HCP competency, honesty, confidentiality, and global trust). Although the name of this scale suggests it measures only trust in physicians, the scale was developed with all HCPs in mind and has been tested for use with a variety of HCPs.

The original scale included 78 items, based on the five domains of trust. These items were revised and deleted based on responses from an expert review panel, two focus groups and eight rounds of pilot testing. This resulted in a 26-item scale that was pilot tested with a national sample. Several additional measures were also administered to the national sample for purposes of validity testing. These additional measures included: a physician trust scale (Kao, Green, Davis, Koplan, \& Cleary, 1998), insurer trust scale (Zheng, Hall, Dugan, Kidd, \& Levine, 2002), and a patient satisfaction scale (Hall, Feldstein, Fretwell, Rowe, \& Epstein, 1990).

The 26-item scale was pilot tested using a national telephone sample $(\mathrm{n}=959)$. Inclusion criteria included age 20 or above, having health insurance over the last 12 months and having visited with the same health care provider two times within two years. The national sample was mostly white (83.6\%), between 30 and 60 years old (60\%), and reported using a physician for primary care (98.3\%). Items with a high level of nonresponse were deleted, along with items that resulted in responses in only one or two 
categories because those items lacked discriminatory power. An exploratory principal component factor analysis with varimax and promax rotations was conducted and initial factors were extracted by selecting only items with above average Eigenvalues. The factors were verified by considering a scree plot and the magnitudes of the residual correlation matrix. Results of the principal component factor analysis, scree plot and residual correlation matrix identified a single factor. To shorten the scale, the authors deleted items with the lowest factor loadings and lowest item-to-total correlations (below .60). Next, items ranked by factor loadings were deleted until the main factor could explain close to $100 \%$ of the variance. Tucker reliability measures, Akaike information, parsimony, and internal consistency were taken into account in this process (Hall, et al., 2002). This resulted in a 10-item scale, which measured only four domains of trust (fidelity, HCP competency, honesty, and global trust). The items measuring confidentiality were not significant in the factor analysis and were subsequently deleted.

Of the regional sample, a random subsample of 306 participants were resurveyed to test for test-retest reliability, resulting in a test-retest correlation coefficient of .75. The retest was conducted two months after the original assessment. According to Nunnally (1994), two weeks is an appropriate time frame for retesting. Other than a longer than usual wait between tests, the test-retest correlation coefficient indicates high reliability.

The authors of the Wake Forest Interpersonal Trust in Physician Scale carefully considered validity of the instrument. When creating items for the scale, the word trust and its synonyms were avoided, in order to enhance construct validity. Experts were used to evaluate items for face validity. Construct validity of the final instrument was established by obtaining the Pearson's $r$ correlation between physician trust and insurer 
trust $(\mathrm{r}=.15, \mathrm{p}<.0001)$, general satisfaction $(\mathrm{r}=.51, \mathrm{p}<.0001)$ and a previously tested measure of trust $(r=.75, p<.0001)$. Pearson's correlation $r$ was also obtained for length of time with physician $(\mathrm{r}=.09, \mathrm{p}<.0001)$ and Spearman's $s$ correlation was used for total lifetime visits $(s=.15, \mathrm{p}<.0001)$, intention to change physician $(s=-.71, \mathrm{p}<$ $.0001)$, willingness to recommend physician $(s=.74, \mathrm{p}<.0001)$ and satisfaction with physician $(s=.51, \mathrm{p}<.0001)$. The results from the Wake Forest Interpersonal Trust in Physician scale (Cronbach's alpha $=.93$ ) were also compared to the Kao physician trust scale $($ Cronbach's alpha $=.93)$, insurer trust scale $($ Cronbach's alpha $=.91)$, and the general satisfaction scale (Cronbach's alpha $=.89)$.

The Wake Forest Interpersonal Trust in Physician scale has high reliability and good construct validity. It has also been used with a wide variety of HCPs, including physicians, nurses, chiropractors, physician's assistants and nurse practitioners. The aspect of this scale that allows the participant to apply the scale to their own $\mathrm{HCP}-$ regardless of discipline — was a quality that stood out from the other trust scales. Limitations of this scale are that it has not been tested with an adolescent population.

The Wake Forest Trust in Physician scale has ten items, scored on a five-point Likert scale. Three items were negatively worded $(2,3,8)$ and were reverse coded. In a national sample of 959 adults with established primary care relationships (including HCPs other than physicians) the mean total score was 40.8 , with a standard deviation of 6.2 .

\section{Adolescent Lifestyle Questionnaire}

The outcome variable lifestyle behaviors was measured as a continuous variable using the Adolescent Lifestyle Questionnaire (ALQ). This scale was chosen for its 
inclusion of health behavior from a health promotion standpoint. The ALQ (See Appendix F) was a 43-item scale made up of seven subscales developed to measure determinants of a healthy lifestyle among adolescents (Gillis, 1997). The conceptual framework for the ALQ was based on Pender's (1996) definition of a healthy lifestyle, which was "a multidimensional pattern of discretionary activities and perceptions that are a part of an adolescent's daily approach to living and that significantly affect health status in a positive manner" (Gillis, 1997, p. 31).

In developing the ALQ, the aim was to create a healthy lifestyle measurement tool specific to adolescents. Criteria specific to adolescents were that the resulting scale be short, with a consistent response mode, that contained items that reflected adolescent activities, focused on healthy lifestyle practices, and based on health-enhancement rather than risk-reduction. A qualitative research study was conducted using interviews with 30 middle class, rural Canadian adolescents to develop the meaning of healthy lifestyle activities. Scale items were developed from statements made by research participants congruent with the definition of healthy lifestyle. The original version of the ALQ included 66 items across seven categories: physical participation, nutrition, safety, social support, health awareness, stress management, and identity awareness. These behaviors were measured in a 5-point Likert format of frequency of behavior, ranging from (1) never to (5) almost always (Gillis, 1997).

The original ALQ was piloted for reliability, item clarity, and response variance. The pilot study was conducted over three weeks with a sample of 73 adolescents in a school-based study. Psychometrics included reliability coefficient of .76, Cronbach's alpha of .93 , and subscale reliability coefficients of .60-.87. Frequency distribution 
indicated the full range of responses were used for most scale items. Items were edited or deleted based on participant confusion related to terminology. Four nurses with advanced study of adolescent health promotion reviewed the pilot instrument for content validity using readability, cultural relevance, age appropriateness of behaviors, and conceptual congruence of items as criteria. Four different nurses with advanced training in adolescent health promotion were asked to match the items to the seven subscale categories. Items meeting 75\% agreement were retained, while the others were deleted or modified based on expert feedback from the eight nurses, resulting in a 56-item scale (Gillis, 1997).

A second study ensued for further psychometric testing, including item analysis, factor analysis, and reliability measures. A stratified sample $(n=292)$ of adolescents in ages 12-19 from a large rural school district in Canada completed the survey. Corrected item-total correlations were calculated for the total scale and for each of the seven subscales. Five items that depressed the coefficient alpha of either the total scale or the subscale were deleted, resulting in 51 items. Forty-seven of the remaining 51 items had item-total correlations of .25 or higher, with four items having correlations between .21.24. The items-total correlation matrix was reviewed to identify redundant items, but no correlations were greater than .70 , so all 51 items were retained.

Construct validity was assessed using factor analysis. Principal axis factoring extraction with oblique rotation was used to determine the number of independent hypothetical factors in the data. Kaiser's criterion was applied and ten factors with an eigenvalue greater than 1.00 were retained, which resulted in explaining $64.5 \%$ of the variance in the measure. Since using Kaiser's criterion with more than 50 items may 
result in too many factors, the coefficient alphas were reviewed. It was determined that three of the factors had two items that lacked sufficient reliability to serve as a subscale, therefore the hypothesized seven factor structure was retained. Eight items with factor loadings less than .45 or that did not load cleanly on a single factor were eliminated, resulting in 43-items. These 43 items were again entered into factor analysis. All items loaded onto expected factors with factor loadings of .45 or more. The seven factor solution explained $56 \%$ of the variance and was retained. The seven factors and associated eigenvalues were: (1) identity awareness (8.24), (2) nutrition (4.38), (3) physical participation (2.71), (4) safety (2.02), (5) health awareness (1.66), (6) social support (1.56), and (7) stress management (1.30). The correlation between factors range from .02-.57, signifying each factor was distinct and lacked redundancy (Gillis, 1997).

Reliability of the 43-item ALQ was assessed using internal consistency and testretest reliability. The total scale demonstrated high internal consistency $(\alpha=.91)$, with subscale alphas ranging from .60 to .88 . The alpha for the stress management subscale ( $\alpha$ $=.60)$ was less than the desired $\alpha \leq .70$, but the mean inter-item correlation of the fouritem subscale was .27, which was acceptable for a 43-item scale. A Spearman-Brown correction to eight items for the stress management subscale resulted in a coefficient alpha of .77. The 43-item ALQ was administered again $(n=65)$ in two weeks. Test-retest reliability was high with Pearson's $r=.88$ for the total scale score and ranging from .80 to .88 for subscales (Gillis, 1997). The test-retest timeframe of two weeks apart was less than the recommended three to four weeks (Nunnally \& Bernstein, 1994).

Limitations to the ALQ include cross-loadings of items on social support and stress management subscales, risk of bias related to short test-retest timeframe, and a 
need for testing with diverse American populations. In addition, one item on the health awareness factor appears dated and states: I read pamphlets, teen magazines about health topics of interest. It is likely that adolescents are now more likely to read about health topics of interest online, rather than in pamphlets or magazines. The ALQ was developed nearly 20 years ago, prior to the widespread use of the internet. The ALQ may benefit from updating this item to include relevant information sources for adolescents. The ALQ has 43 items, scored on a five point Likert scale measuring frequency of behavior, ranging from (1) never to (5) almost always (Gillis, 1997). In this study, the overall scale score was used in data analysis. The ALQ author did not report the mean total score and standard deviations. Another study with American older adolescents reported the ALQ total mean score was $186.06(\mathrm{SD}=27.56)($ Rew, Wong, Torres, \& Howell, 2011).

\section{Stanford Health Care Utilization Questionnaire}

The Stanford Health Care Utilization Questionnaire (HCUQ) (See Appendix G) is a four-item questionnaire developed by the Stanford Patient Education Center for use in the Chronic Disease Self-Management Program to measure outpatient HCP visits, emergency room use, hospital inpatient stays, and number of days inpatient. This questionnaire was chosen for its standard questions concerning outpatient HCP visits and emergency room visits. Inpatient hospital stays/days was not measured in this study, therefore only the two questions concerning outpatient HCP visits and emergency room utilization from this questionnaire was used. Utilization of health services was measured as a continuous variable indicating the number of times the participant visited a $\mathrm{HCP}$ or the emergency room in a 12-month period - known as count data - which was a discrete 
number measuring the number of occasions an event occurs in a given interval of time (Coxe, West, \& Aiken, 2009).

Reliability of the HCUQ was assessed using test-retest reliability. The HCUQ was administered by mailed self-report questionnaire to participants $(\mathrm{n}=51)$ in the Chronic Disease Self-Management Program, with a second HCUQ mailed ten days after the first one was received in return. The HCUQ was administered by having the participant record a whole number indicating visits to $\mathrm{HCP}$ and emergency room in the past 6 months. Pearson's $\mathrm{r}$ for HCP visits was .76, which indicated a moderate level of reliability. Chart reviews indicated that participants under-reported HCP visits by $17 \%$. Pearson's $\mathrm{r}$ for emergency room visits was .94, which indicates a high level of reliability (Ritter et al., 2001).

This study adapted the HCUQ to measure HCP visits and emergency room visits over the past 12 months. Health care provider visits and emergency room visits were measured individually. A review of other studies measuring utilization of health services among adolescents indicated that 12 months was the most frequent timeframe used (Berdahl et al., 2013; Klein et al., 2006; Maulik et al., 2011; McKee \& Fletcher, 2006; Mulye et al., 2009; Probst et al., 2005; Rew et al., 1999; Simpson et al., 2005; Simpson et al., 2004; Wu et al., 2007). Other timeframes used to evaluate utilization of health services were a three-month timeframe (Bradford \& O'Sullivan, 2006, 2007) and a twoyear timeframe (Elliott \& Larson, 2004). Having changed the timeframe to 12 months allowed the investigator to compare utilization of health services rates to other studies and samples across the nation. 


\section{Data Collection}

When the study was conducted, the investigator explained the study, anonymity of the study and assent procedures to the participants. As described in the human subjects' protection section above, a cover sheet that explained the study and assent procedures was distributed, with minors receiving a cover sheet explaining assent (See Appendix C) and adults receiving a cover sheet explaining passive consent (See Appendix D). The cover sheets and surveys were distributed in numbered packets to all students assenting to the study. All forms were provided in paper and pen format. When the students had completed the survey, the survey packets were collected from each participating student.

\section{Data Management Procedures}

Each participant's survey packet was assigned a unique four-digit alpha-numeric code to maintain participant anonymity. The investigator entered the data into two separate datasets, which were merged and compared for inconsistencies and out-of-range scores. Inconsistencies and out-of-range scores were compared to the original survey completed by the study participant for correction. Copies of the verified data were kept on the University of Louisville School of Nursing's encrypted SharePoint site, separate from the survey packets. The completed survey packets were kept secure in a locked file at the University of Louisville School of Nursing Research Office. All research data were collected, maintained, and entered for statistical analysis by the investigator.

\section{Data Measurement}

The Statistical Package for the Social Sciences (SPSS) version 22.0 software package was used for data analyses. An alpha of .05 was used for all statistical analyses 
to reduce probability of a Type 1 error (Polit \& Beck, 2008). Missing data was handled with pairwise exclusion. Descriptive statistics—including means, frequencies, and distributions - were computed for all variables. Psychometric evaluations for both scales were conducted using Cronbach's alpha.

Some participants marked multiple answers for race, family structure, and health insurance. This situation was handled by creating multiple variables for these questions (Race1, Race2, etc.). For calculating the descriptive statistics, the totals for each of the groups was calculated across variables (ex: a participant was counted as living with both the biological mother and the grandmother). With the correlations and regression models, groups must be mutually exclusive and dichotomous or continuous level of measurement; therefore, multiple group membership was handled differently. Race was measured as white/not white for the correlations. Race was excluded from the regressions due to the low number of minorities in this sample, which was described earlier. Family structuremother was measured as lives with biological mother/does not live with biological mother for both the correlations and the regressions, since family structure is primarily measured this way in child health services utilization literature (Leininger \&Ziol-Guest, 2008). Family structure — father was measured similarly to family structure - mother. With health insurance in the linear regression models, the categories were dummy coded into dichotomous nominal variables indicating type of health insurance. The individuals marking two insurances all marked having Medicaid in addition to either military insurance or private insurance. Since child health services utilization literature frequently indicates the effect of the Child Health Insurance Program (Medicaid) on insured rates 
and utilization rates (Deck \& Vander, 2006; Klein et al., 2006), these individuals were grouped as Medicaid for the regressions.

\section{Data Preparation}

The dataset was tested for meeting the assumptions of independence of observations, normality, linearity, and homoscedasticity. Independence of observations was tested by reviewing a scatter plot of residuals, normality was tested by inspecting the histogram of scores for each variable, while linearity and homoscedasticity were evaluated by reviewing the scatter plot for each variable. The SPSS functions tolerance and variance inflation techniques were used to assess for multicollinearity. Skewed data was transformed using log transformation as described in the guidelines suggested by Tabachnick and Fidell (2007).

\section{Normality}

Parametric tests — such as linear regression and correlations - assume normal distributions for continuous variables. Normal distribution is a theoretical distribution of values that makes a bell shaped symmetrical curve. Violations of the normal distribution include skewness and kurtosis (Tabachnick \& Fidell, 2007).

Distributions of the continuous dependent variables (trust of HCP, lifestyle behaviors, HCP visits, and ER visits) were assessed for normality using histograms, normal probability plots, the skewness statistics, and kurtosis statistic. First, histograms and normality plots for each continuous variable were examined. Next, the skewness statistic and the kurtosis statistic were examined. Skewness is a measure of the asymmetry in variable distribution, while kurtosis measures the spread of values in a normal distribution (Tabachaneck, 2007). With the skewness and kurtosis statistics, a 
value $+/-1$ was considered a normal distribution and a value $+/-2$ was considered acceptable. If non-normality was identified using the skewness and kurtosis statistics, then the data were further evaluated using the Kolmogorov-Smirnov statistical test and the Shapiro-Wilk statistical test. The Kolmogorov-Smirnov test is a non-parametric test goodness of fit test, comparing the sample to a continuous normal probability distribution. The Shapiro-Wilk test compares the sample distribution to the normal distribution. With the Kolmogorov-Smirnov statistical test and the Shapiro-Wilk statistical test, a significant $p$-value indicated a non-normal distribution. As indicated by skewness and kurtosis statistics in Table 3.1 and Figures 3.1, both the total Trust score and the total ALQ score were normally distributed. Alternatively, Figures 3.1-3.3 demonstrated that HCP visits and ER visits were both non-normally distributed. 
Table 3.1

Normality Statistics for Continuous Outcome Variables

\begin{tabular}{lccccccc}
\hline Variable & $\mathrm{N}$ & $\mathrm{M}(\mathrm{SD})$ & Range & Skewness & Kurtosis & $\begin{array}{c}\text { Kolmogorov- } \\
\text { Smirnov test }\end{array}$ & $\begin{array}{c}\text { Shapiro- } \\
\text { Wilk test }\end{array}$ \\
\hline Total Trust score & 211 & $38.68(7.49)$ & $17-50$ & -.376 & -.527 & - & - \\
Total ALQ score & 197 & $156.54(24.32)$ & $95-215$ & -.182 & -.046 & - & - \\
$\begin{array}{l}\text { HCP visits } \\
\text { (raw data) }\end{array}$ & 212 & $3.63(5.58)$ & $0-50$ & 5.813 & 44.259 & $.26, p<.001$ & $.50, p<.001$ \\
$\begin{array}{l}\text { HCP visits } \\
\text { (outliers deleted) }\end{array}$ & 206 & $2.93(2.68)$ & $0-12$ & 1.40 & 1.81 & $.21, p<.001$ & $.85, p<.001$ \\
$\begin{array}{l}\text { HCP visits } \\
\text { (log transformed) }\end{array}$ & 206 & $.50(0.29)$ & $0-1.11$ & -.091 & -.560 & $.13, p<.001$ & $.95, p<.001$ \\
$\begin{array}{l}\text { ER visits } \\
\text { (raw data) }\end{array}$ & 217 & $.80(1.35)$ & $0-8$ & 2.420 & 7.387 & $.33, p<.001$ & $.65, p<.001$ \\
$\begin{array}{l}\text { ER visits } \\
\text { (outliers deleted) }\end{array}$ & 214 & $.67(1.03)$ & $0-.4$ & 1.55 & 1.63 & $.36, p<.001$ & $.21, p<.001$ \\
$\begin{array}{l}\text { ER visits } \\
\text { (log transformed) }\end{array}$ & 214 & $.16(0.22)$ & $0-.70$ & .958 & -.509 & $.39, p<.001$ & $.72, p<.001$ \\
\hline
\end{tabular}




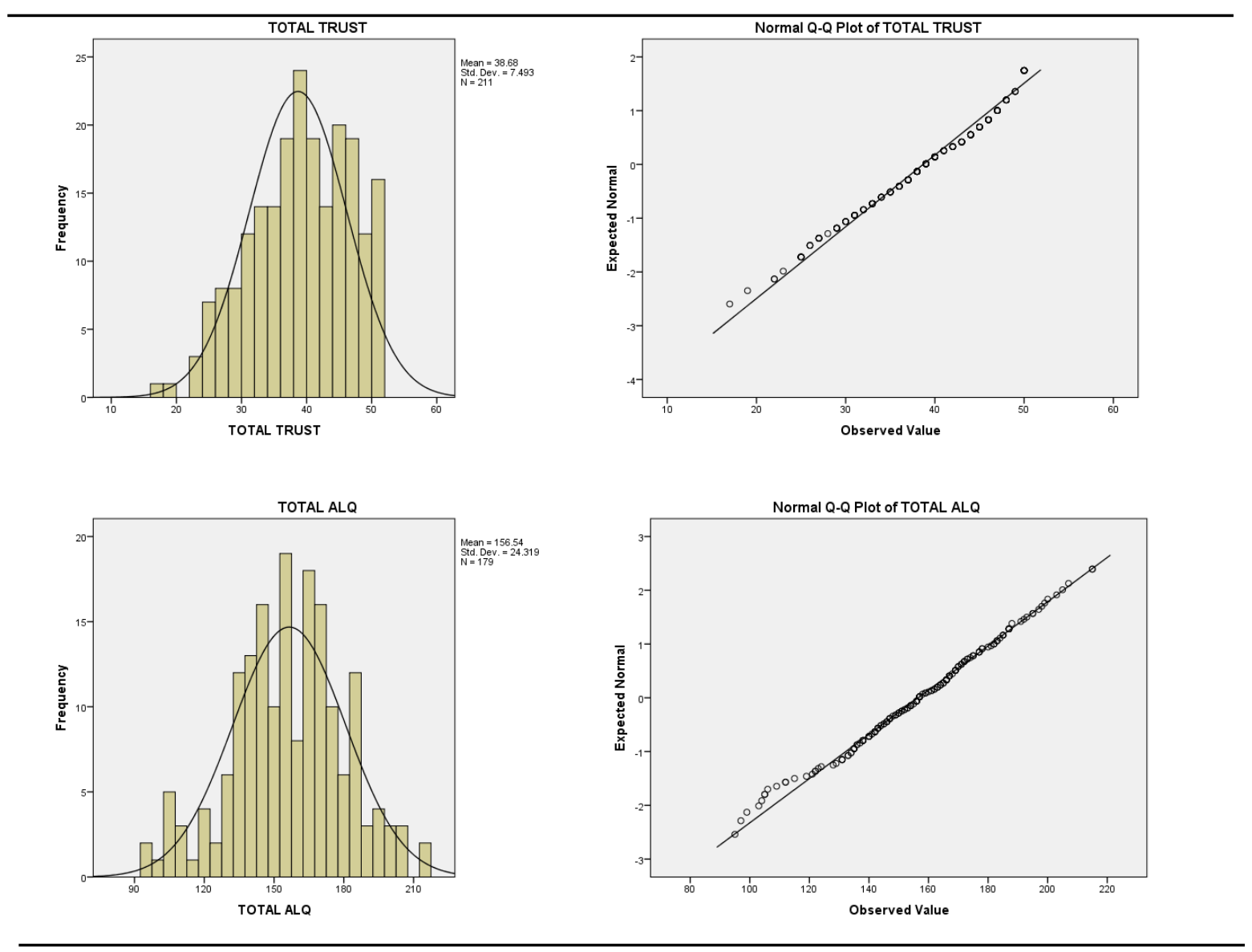

Figure 3.1. Normal probability plots for total trust of HCP score $(\mathrm{n}=211)$ and total ALQ score $(\mathrm{n}=179)$ 


\section{HCP visits (raw data)}

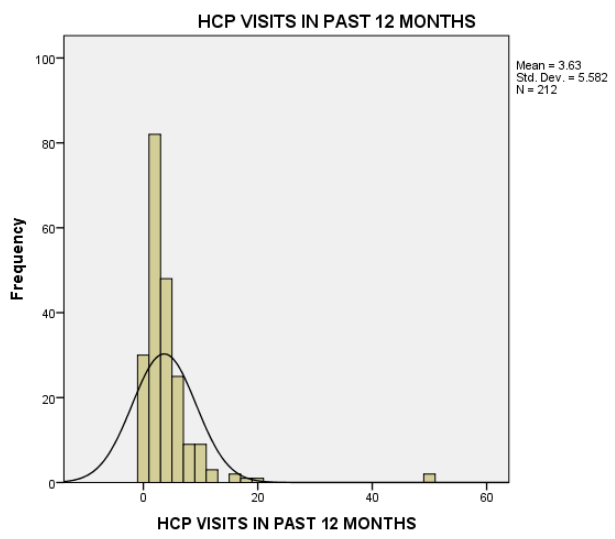

\section{HCP visits (outliers deleted)}

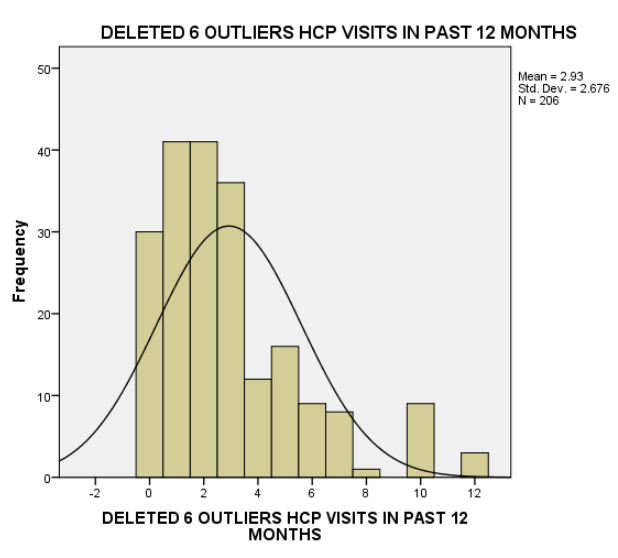

\section{HCP visits (log transformed)}

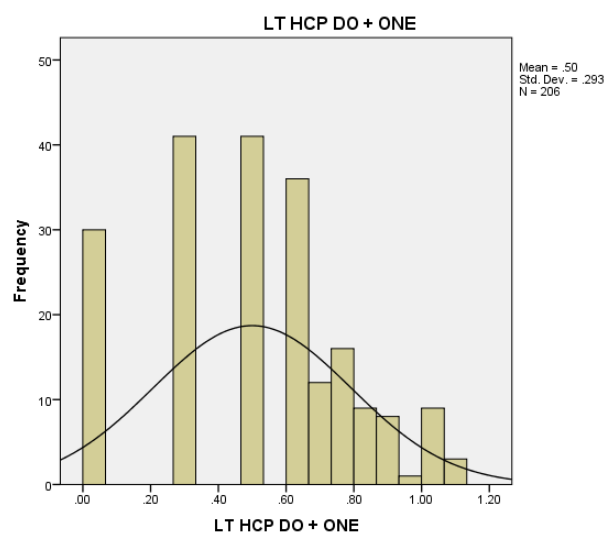

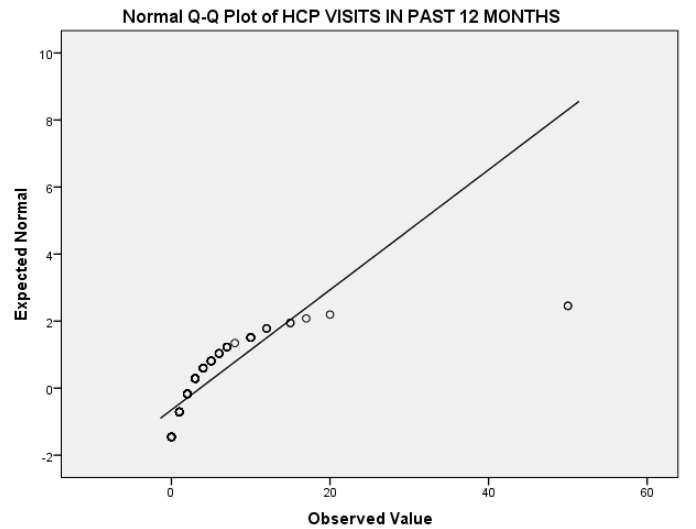
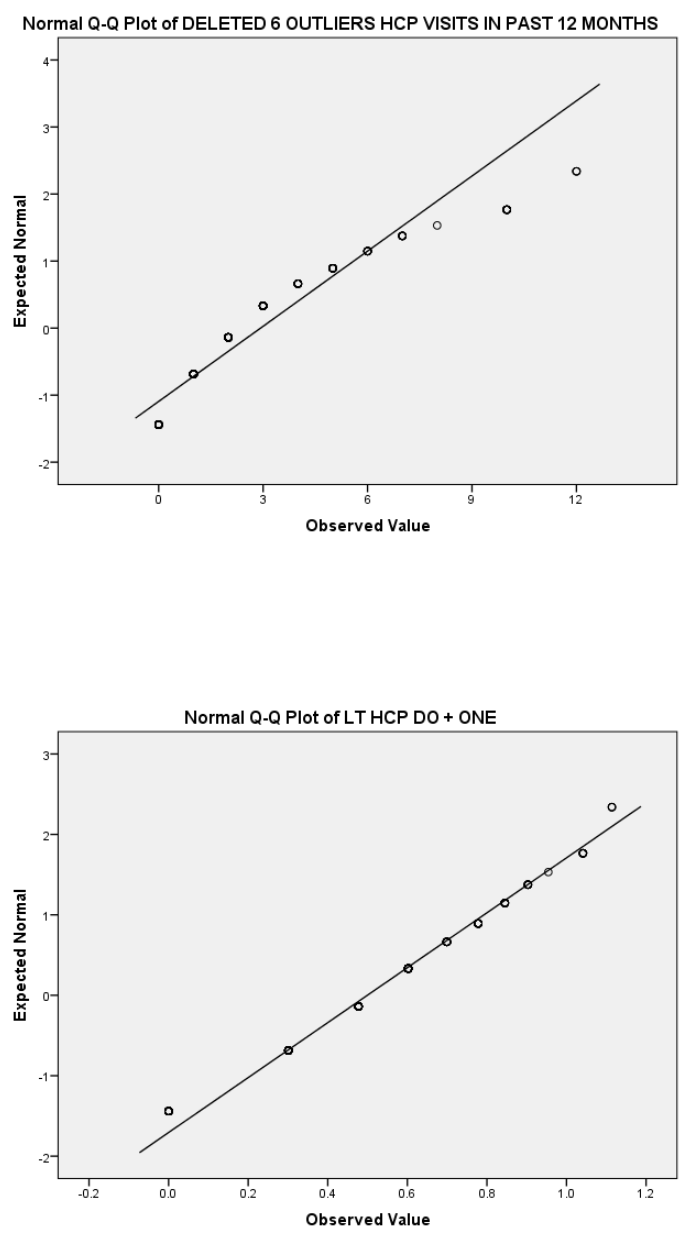

Figure 3.2. Normal probability plots for HCP visits $(\mathrm{n}=212)$ 
ER visits (raw data)

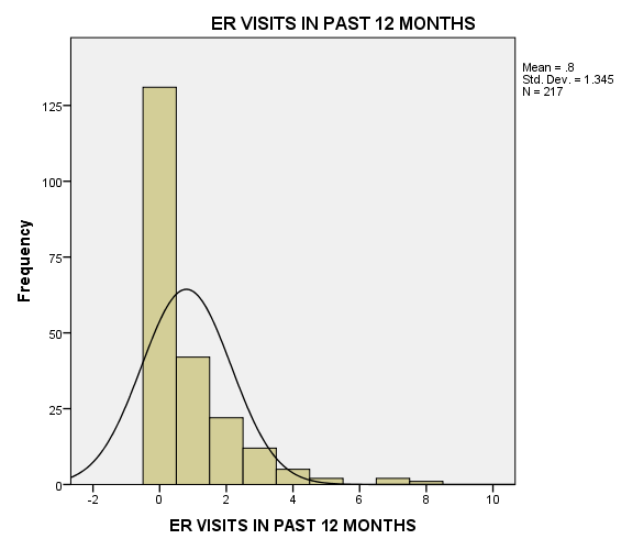

ER visits (outliers deleted)

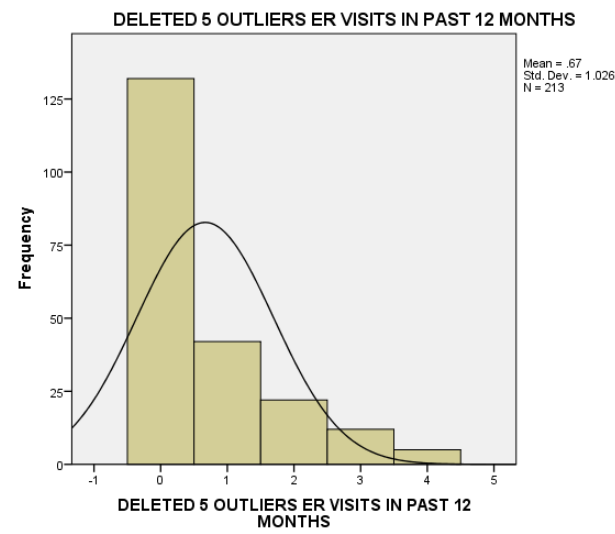

ER visits (log transformed)

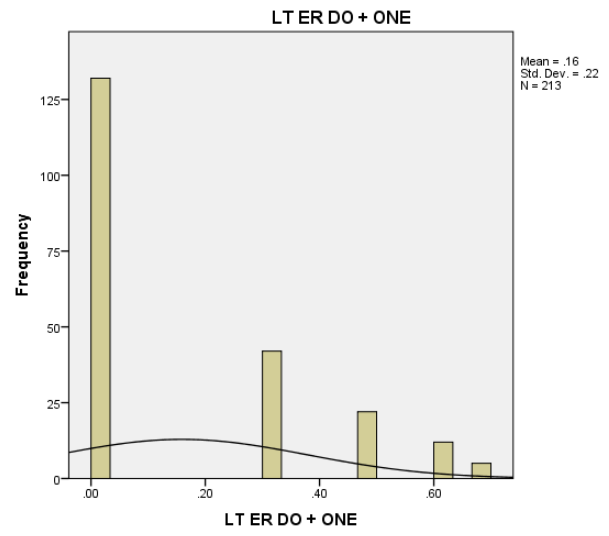

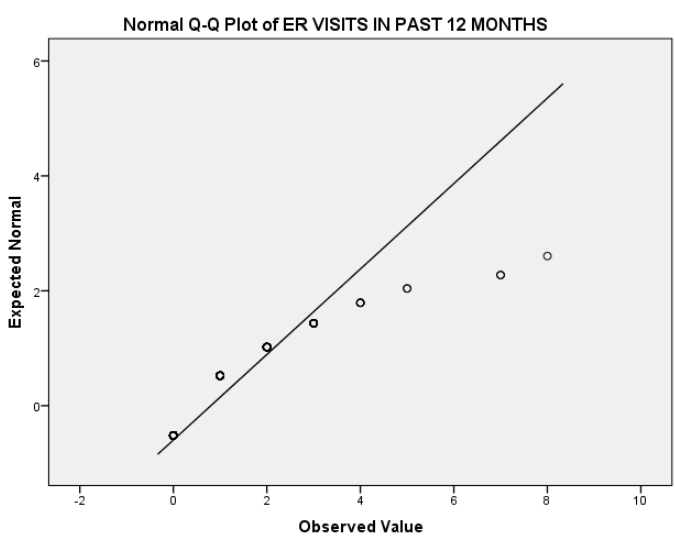
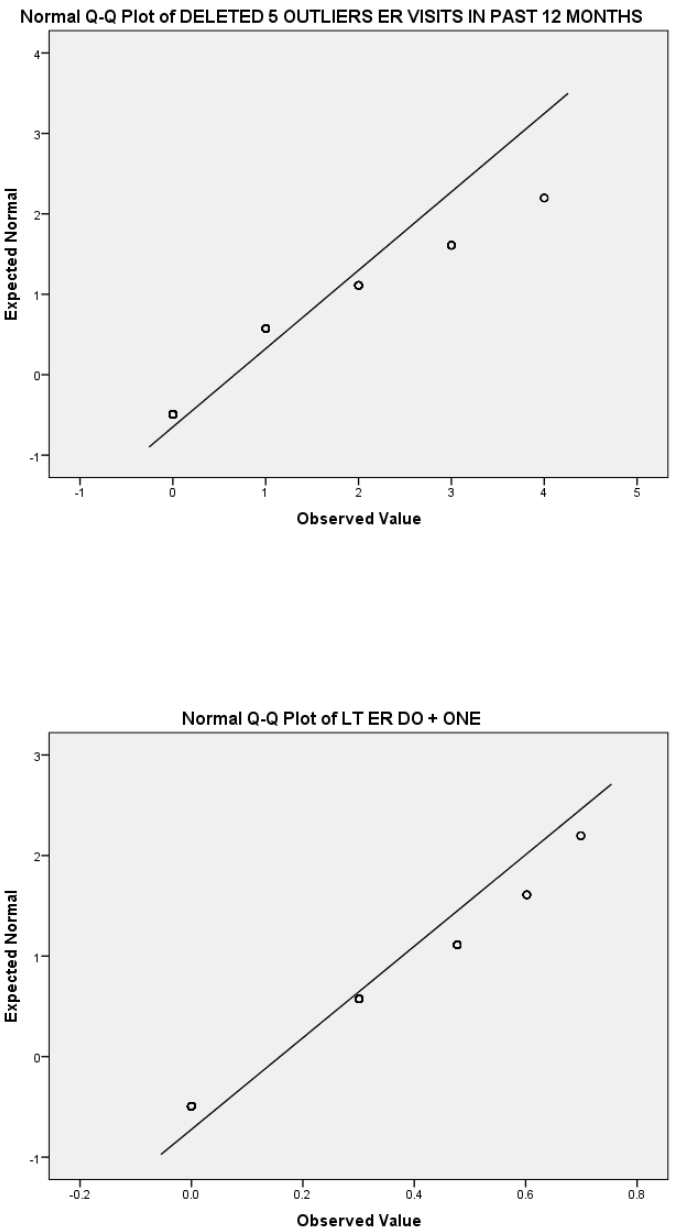

Figure 3.3. Normal probability plots for ER visits $(\mathrm{n}=217)$ 
Measures were taken to correct the non-normal distribution of HCP visits and ER visits. The impact of outlier scores on HCP visits and ER visits were evaluated with box plots. Box plots (See Figure 3.4) demonstrated six extreme outlier scores on HCP visits and five extreme outlier scores on ER visits. The original paper survey for each of these 11 outlier scores were reviewed to ensure that the data were recorded accurately. Two of the research participants with outlier HCP visit scores indicated the reason for the unusual number of HCP visits with a handwritten note: a complicated pregnancy and a knee injury. These extreme outlier scores and participant experiences do not represent the typical score and experience of an adolescent living in a rural area. These extreme outlier scores also make up less than $3 \%$ of the total study participation, therefore a new variable was created that removed these extreme outlier HCP visits and ER visits. The new variables without the extreme outlier scores were re-evaluated for meeting the assumption of a normal distribution. HCP visits and ER visits without the extreme outlier scores remained non-normal (See Table 3.1, Figure 3.2, and Figure 3.3). 

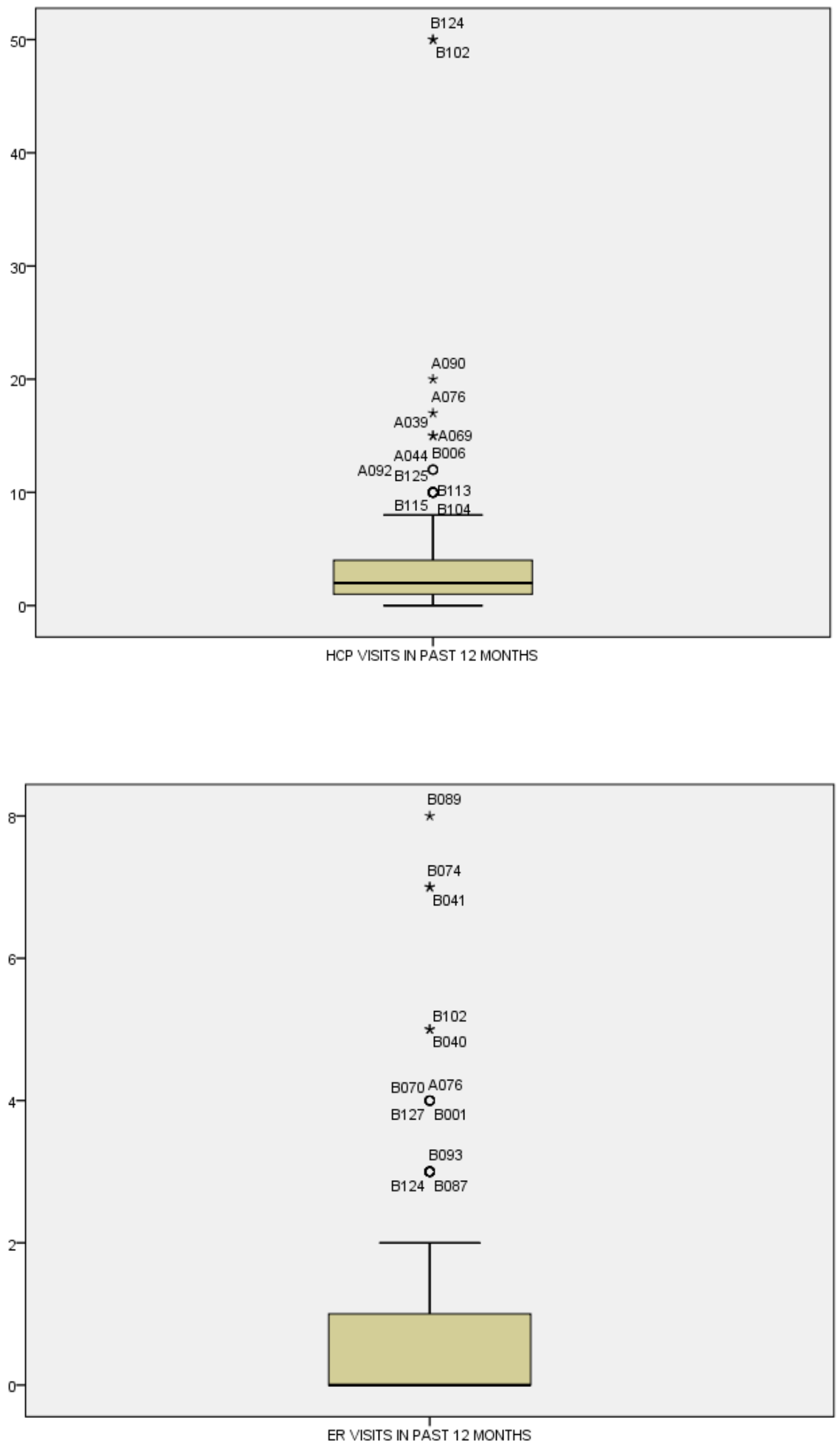

Figure 3.4. Box plots identifying extreme outliers on HCP visits and ER visits 
In a continued attempt for normal distribution of HCP visits and ER visits, each of the new variables without the extreme outlier scores were log transformed. The log transformed HCP visit and ER visit variables were evaluated for meeting the assumption of normal distribution, but remained non-normally distributed (See Table 3.1, Figure 3.2, and Figure 3.3). At this point, it was decided that both HCP visits and ER visits would be transformed into dichotomous variables indicating use (1) or non-use (0) of the HCP and ER for Research Questions 2 and 3, which are linear regressions that require normally distributed data.

\section{Research Question 1}

Correlations were used to answer research question 1: What relationships exist between variables (age, sex, race, ethnicity, family structure, trust of $\mathrm{HCP}$, household income, transportation difficulty, usual source of care, self-rated health, self-perceived need, foregone care, diagnosed conditions, lifestyle behaviors, HCP visits and ER visits) in the study model? Pearson's $r$ was used to evaluate the relationship between normally distributed continuous variables, while point biserial correlations were used to evaluate the relationship between normally distributed continuous variables and dichotomous variables. Spearman's rho was used to evaluate the relationship between non-normally distributed continuous variables and ordinal variables. Since correlations require dichotomous variables, the categorical and ordinal variables were dummy coded as follows: race (white, yes/no), ethnicity (Hispanic, yes/no), family structure-mother (lives with biological mother, yes/no), family structure - father (lives with biological father or stepfather, yes/no), household income (receives free or reduced lunch, yes/no), transportation difficulty (somewhat or very difficult, yes/no), usual source of care (has 
HCP as usual source of care, yes/no), and self-rated heath (reports excellent or very good health, yes/no). Dichotomous variables were coded as no $=0$ and yes $=1$. A correlation matrix was developed in order to understand the relationships between variables. In addition, one-way analysis of variance with Tukey's post hoc analysis and KruskalWallis tests were used to explore relationships between the dependent variables and nominal variables with three or more categories. Since the grandparent, foster parent, adoptive parent, and someone else groups within family structure - mother and family structure-father had few individuals per group, these groups were collapsed into a single group for both family structure - mother and family structure - father.

\section{Research Question 2}

Hierarchical linear regression was used to evaluate predictors of trust of $\mathrm{HCP}$ with blocks of variables entered into the regression model based on Andersen's Behavioral Model of Health Services Use (ABM). Regression diagnostic procedures were followed to examine the data for meeting the assumptions of linearity, normality of the residuals, homoscedasticity, and fixed independent variables measured without error. The SPSS functions tolerance and variance inflation techniques were used to assess for multicollinearity. The first block of variables included individual predisposing characteristics, followed by individual enabling characteristics, and finally including individual need characteristics. Since linear regression requires the independent variables to be normally distributed continuous variables or dichotomous variables, the categorical and ordinal variables were dummy coded as follows: family structure - mother (lives with biological mother, yes/no), family structure - father (lives with biological father or stepfather, yes/no), household income (receives free or reduced lunch, yes/no), health 
insurance (no health insurance, yes/no; Medicaid, yes/no; military insurance, yes/no; private/other health insurance, yes/no), transportation difficulty (somewhat or very difficult, yes/no), usual source of care (has HCP as usual source of care, yes/no), selfrated heath (reports excellent or very good health, yes/no), HCP diagnosed depression (yes/no), had a HCP visit in the past 12 months (yes/no), and had an emergency room visit within the past 12 months (yes/no). Dichotomous variables were coded as no $=0$ and yes $=1$. Continuous variables included in the analysis were age and lifestyle behaviors (ALQ scale score).

\section{Research Question 3}

Hierarchical linear regression was also used to predict lifestyle behaviors with blocks of variables entered into the regression model based on ABM. Regression diagnostic procedures were followed to examine the data for meeting the assumptions of linearity, normality of the residuals, homoscedasticity, and fixed independent variables measured without error. The SPSS functions tolerance and variance inflation techniques were used to assess for multicollinearity. The first block of variables included individual predisposing characteristics, followed by individual enabling characteristics, and finally including individual need characteristics. Since linear regression requires the independent variables to be normally distributed continuous variables or dichotomous variables, the categorical and ordinal variables were dummy coded as follows: family structuremother (lives with biological mother, yes/no), family structure—-father (lives with biological father, yes/no), household income (receives free or reduced lunch, yes/no), health insurance (has health insurance, yes/no; Medicaid, yes/no; military insurance, yes/no; private/other health insurance, yes/no), transportation difficulty (reports 
somewhat or very difficult transportation, yes/no), usual source of care (has HCP as usual source of care, yes/no), self-rated heath (reports excellent or very good health, yes/no), any HCP diagnosed condition (yes/no), had a HCP visit in the past 12 months (yes/no), and had an emergency room visit within the past 12 months (yes/no). Dichotomous variables were coded as no $=0$ and yes $=1$.

\section{Research Question 4}

Utilization of health services (number of HCP visits and number of ER visits) were measured with count data-which are discrete numbers measuring the number of occasions an event occurs in a given interval of time (Coxe et al., 2009). A Poisson regression was proposed, but due to violation of assumptions, a negative binomial regression was conducted to predict both HCP visits and ER visits. Negative binomial regression is a generalized linear model, which is used to provide accurate results with count data (Coxe, West, \& Aiken, 2009). Negative binomial regression was used to predict number of HCP visits and number of ER visits, due to over-dispersed count data. The assumptions of negative binomial regression are: 1) independence of observations, 2) logarithm of the count data dependent variable changes linearly, 3) changes in the count data dependent variable are multiplicative, 4) the distribution was a combination of the Poisson distribution and gamma distribution called a negative binomial distribution; and 5) over-dispersed data. To evaluate if the data met the assumption of a negative binomial distribution, residual plots were reviewed, the distribution plot was reviewed, and the variance must have been larger than the mean.

Negative binomial regression is a non-parametric test, therefore a variety of variables types can be used: continuous variables, count data, dichotomous variables, 
and categorical variables. Initially, the categorical variables were added to the model in the originally measured categories, but due to failure of the matrix to converge, some of the categories were collapsed. The independent variables entered into the model for both number of HCP visits and number of ER visits were age, sex, family structure - mother (lives with biological mother, yes/no), family structure - father (lives with biological father, yes/no), trust of HCP, household income (receives free or reduced lunch, yes/no), health insurance (no insurance, Medicaid or military insurance, private or other insurance), transportation (drives self to appointments, yes/no), usual source of care (yes/no), self-rated heath (excellent, very good, good, fair, poor), perceived health need (yes/no), HCP diagnosed condition (yes/no), and lifestyle behaviors. Dichotomous variables were coded as no $=0$ and yes $=1$. Self-rated health was coded on a continuum with poor $=0$ and excellent $=4$. When predicting number of $\mathrm{HCP}$ visits, number of ER visits was added as a predictor; and when predicting number of ER visits, number of HCP visits was added as a predictor. 


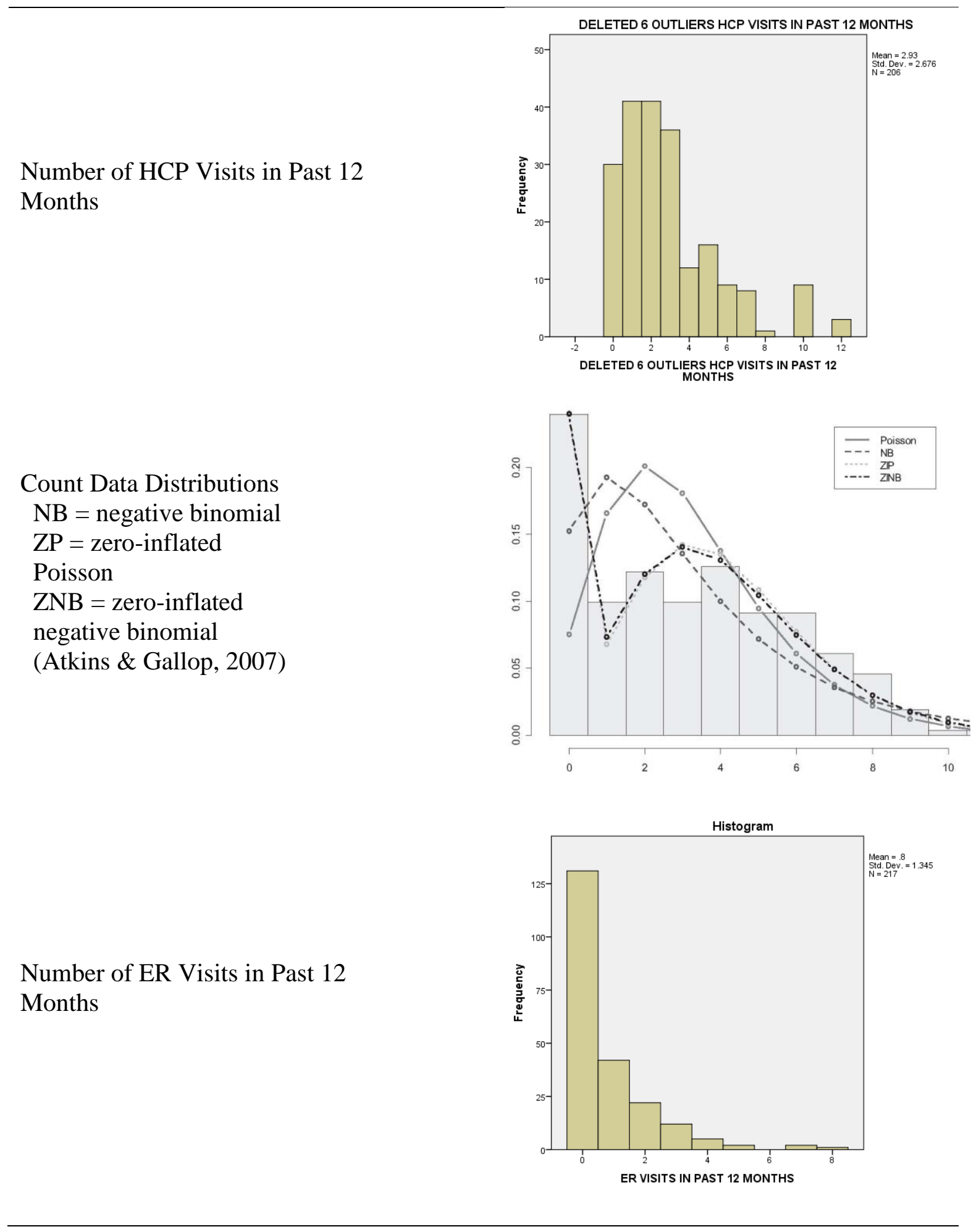

Figure 3.5. Distribution of health services utilization 


\section{Ethical Considerations}

This study received ethical approval from the University of Louisville Human Subjects Protection Program. This study posed no greater than minimal risk; therefore, a waiver of written informed consent was granted. This study included subjects regardless of gender or minority status, and sought to include both pediatric and adult subjects.

\section{Conclusion}

Using a cross-sectional design, this study explored trust of HCP, lifestyle behaviors, and utilization of health services among adolescents living in a rural area. Two-hundred and twenty four $9^{\text {th }}$ and $12^{\text {th }}$ graders were surveyed in this study using the Wake Forest Trust in Physician Scale, the Adolescent Lifestyle Questionnaire, and the Stanford Health Care Utilization Questionnaire. Understanding the factors that influence and predict trust of HCP, lifestyle behaviors, and utilization of health services helped to address a multifactorial problem and will be foundational to future intervention work to decrease health disparities among adolescents living in a rural area. 


\section{CHAPTER IV}

\section{RESULTS}

The findings the study are presented in this chapter. The purpose of this study was to examine individual characteristic variables and determine the extent to which these variables influence trust of health care provider, lifestyle behaviors, and utilization of health services among adolescents attending public high school in rural Indiana. In this chapter, descriptive statistics for the individual characteristic variables and dependent variables are presented, along with reliability of the study instruments, and finally a summary of findings specific to each research question are presented.

\section{Predisposing Individual Characteristics}

Results of predisposing individual characteristics reported by participants are presented in Table 4.1, including age, sex, race, ethnicity, and family structure. Since trust of HCP was used as both a predictor variable and an outcome variable, descriptive statistics for trust of HCP were presented along with the outcome variables. The mean age of the sample was 16.4 years $(\mathrm{N}=224, \mathrm{SD}=1.472$; range 14 to 19$)$ and $54 \%$ of the sample were female. The majority of participants were Caucasian (95.0\%), while 3.6\% were American Indian/Alaska Native, 3.2\% were Asian, and 2.3\% were African American. Seven individuals identified as multiracial and two individuals $(0.9 \%)$ chose not to report race. Most reported non-Hispanic ethnicity (92.0\%). The majority of participants reported living with their biological mother $(77.7 \%)$ and/or biological father 
$(55.8 \%)$ within a two-parent home $(63.8 \%)$. In addition, $21.9 \%$ reported living in a oneparent home and $13.9 \%$ living with someone other than their parents. 
Table 4.1

Predisposing Individual Characteristics of the Sample $(N=224)$

\begin{tabular}{|c|c|c|c|}
\hline \multicolumn{2}{|l|}{ Variable } & $\mathrm{n}(\%)$ & $\mathrm{M}(\mathrm{SD})^{*}$ \\
\hline \multirow[t]{8}{*}{ Age } & & & $16.4(1.47)$ \\
\hline & 14 & $6(2.7 \%)$ & \\
\hline & 15 & $88(39.3 \%)$ & \\
\hline & 16 & $30(13.4 \%)$ & \\
\hline & 17 & $6(2.7 \%)$ & \\
\hline & 18 & $85(37.9 \%)$ & \\
\hline & 19 & $7(3.1 \%)$ & \\
\hline & Missing & $2(0.9 \%)$ & \\
\hline \multirow[t]{3}{*}{ Sex } & Female & $121(54.0 \%)$ & \\
\hline & Male & $100(44.6 \%)$ & \\
\hline & Missing & $3(1.3 \%)$ & \\
\hline \multirow[t]{6}{*}{ Race } & African American & $5(2.3 \%)$ & \\
\hline & American Indian/Alaska Native & $8(3.6 \%)$ & \\
\hline & Asian & $7(3.2 \%)$ & \\
\hline & White & $210(95.0 \%)$ & \\
\hline & Multiracial & $7(3.2 \%)$ & \\
\hline & Missing & $3(1.3 \%)$ & \\
\hline \multirow[t]{3}{*}{ Ethnicity } & Hispanic & $13(5.8 \%)$ & \\
\hline & Non-Hispanic & $206(92.0 \%)$ & \\
\hline & Missing & $5(2.2 \%)$ & \\
\hline \multirow{14}{*}{$\begin{array}{l}\text { Family } \\
\text { structure }\end{array}$} & Lives with biological mother & $174(77.7 \%)$ & \\
\hline & Lives with biological father & $125(55.8 \%)$ & \\
\hline & Lives with stepmother & $6(2.7 \%)$ & \\
\hline & Lives with stepfather & $34(15.2 \%)$ & \\
\hline & Lives with grandmother & $8(3.6 \%)$ & \\
\hline & Lives with grandfather & $8(3.6 \%)$ & \\
\hline & Lives with adoptive/foster mother & $6(2.7 \%)$ & \\
\hline & Lives with adoptive/foster father & $4(1.7 \%)$ & \\
\hline & Lives with another adult female & $27(12.1 \%)$ & \\
\hline & Lives with another adult male & $30(13.4 \%)$ & \\
\hline & No adult female in household & $2(0.9 \%)$ & \\
\hline & No adult male in household & $24(15.2 \%)$ & \\
\hline & Missing data for mother & $1(0.4 \%)$ & \\
\hline & Missing data for father & $1(0.4 \%)$ & \\
\hline
\end{tabular}

Note: Some participants marked multiple answers for race and family structure. Totals and percentages reflect participant responses and therefore, may not equal $100 \%$. $* \mathrm{M}=\mathrm{Mean}, \mathrm{SD}=$ Standard Deviation 


\section{Enabling Individual Characteristics}

Self-reported data concerning enabling individual characteristics were collected including income, health insurance, transportation, and usual source of care (See Table 4.2). Eighty-two individuals (36.6\%) self-reported participation in the National School Lunch Program and indicated free-lunch $(26.3 \%)$ or reduced-lunch $(10.3 \%)$ status, which was used as a household income proxy measure. Two individuals $(0.9 \%)$ chose not to answer the free or reduced lunch question. Most commonly, participants reported private health insurance $(34.4 \%)$ or Medicaid $(22.3 \%)$. Many participants $(35.7 \%)-$ mostly $9^{\text {th }}$ graders - did not know their health insurance status. Driven by someone else $(62.9 \%)$ was the most common route of transport to the HCP's office and half $(51.3 \%)$ of participants reported transportation was not at all difficult. While $12.9 \%$ of the $9^{\text {th }}$ graders reported being driven by someone else (since most $9^{\text {th }}$ graders were not old enough to drive), many of the $12^{\text {th }}$ graders $(38.3 \%)$ also reported being driven by someone else. Most students reported a usual source of health care $(81.7 \%)$, with $60.3 \%$ reporting a HCP's office as the usual source of care. 
Table 4.2

Enabling Individual Characteristics of the Sample $(N=224)$

\begin{tabular}{|c|c|c|}
\hline Variable & & $\mathrm{n}(\%)$ \\
\hline Household & Free lunch & $59(26.3 \%)$ \\
\hline \multirow[t]{3}{*}{ Income } & Reduced lunch & $23(10.3 \%)$ \\
\hline & Self-pay lunch & $140(62.5 \%)$ \\
\hline & Missing & $2(0.9 \%)$ \\
\hline Health & Private & $77(34.4 \%)$ \\
\hline \multirow[t]{6}{*}{ Insurance } & Medicaid & $50(22.3 \%)$ \\
\hline & Military & $9(4.0 \%)$ \\
\hline & Other & $16(7.1 \%)$ \\
\hline & None & $8(3.6 \%)$ \\
\hline & I don't know & $80(35.7 \%)$ \\
\hline & Missing & $4(1.8 \%)$ \\
\hline \multirow[t]{6}{*}{ Transportation type } & Drive & $74(33.0 \%)$ \\
\hline & Driven & $141(62.9 \%)$ \\
\hline & Walk & $3(1.3 \%)$ \\
\hline & Some other way & $2(0.9 \%)$ \\
\hline & Public transportation & $0(0.0 \%)$ \\
\hline & Missing & $4(1.8 \%)$ \\
\hline \multirow[t]{5}{*}{ Transportation difficulty } & Not at all difficult & $115(51.3 \%)$ \\
\hline & Not very difficult & $81(36.2 \%)$ \\
\hline & Somewhat difficult & $23(10.3 \%)$ \\
\hline & Very difficult & $4(1.8 \%)$ \\
\hline & Missing & $1(0.4 \%)$ \\
\hline \multirow[t]{3}{*}{ Usual source of care } & Yes & $183(81.7 \%)$ \\
\hline & No & $37(16.5 \%)$ \\
\hline & Missing & $4(1.8 \%)$ \\
\hline \multirow[t]{7}{*}{ Usual source of care type } & HCP office & $135(60.3 \%)$ \\
\hline & Clinic & $45(20.1 \%)$ \\
\hline & Urgent care & $16(7.1 \%)$ \\
\hline & $\mathrm{ER}$ & $13(5.8 \%)$ \\
\hline & Don't know & $6(2.7 \%)$ \\
\hline & None & $5(2.2 \%)$ \\
\hline & Missing & $4(1.8 \%)$ \\
\hline
\end{tabular}

Note. Some participants marked multiple answers for health insurance; therefore, totals and percentages may not equal $100 \%$. 


\section{Individual Need Characteristics}

Individual need characteristics of the sample are presented in Table 4.3. Need characteristics included in the analysis were self-rated health, perceived health need, and foregone care. An equal number of participants reported excellent or very good (34.8\%) self-rated health. Most adolescents reported a self-perceived need for health care $(72.8 \%)$ in the past 12 months. A majority of participants (63.8\%) reported at least one HCP diagnosed condition, with allergies $(39.3 \%)$ being most common. Foregone care was reported by $17.4 \%$ of participants with the most common reason reported being "Thought or hoped the problem would go away" (See Table 4.3). 
Table 4.3

Need Individual Characteristics of the Sample $(N=224)$

\begin{tabular}{|c|c|c|}
\hline Variable & & $\mathrm{n}(\%)$ \\
\hline \multirow[t]{6}{*}{ Self-rated health } & Excellent & $78(34.8 \%)$ \\
\hline & Very good & $78(34.8 \%)$ \\
\hline & Good & $36(16.1 \%)$ \\
\hline & Fair & $28(12.5 \%)$ \\
\hline & Poor & $3(1.3 \%)$ \\
\hline & Missing & $1(0.4 \%)$ \\
\hline \multirow[t]{3}{*}{ Self-perceived need } & Yes & $163(72.8 \%)$ \\
\hline & No & $58(25.9 \%)$ \\
\hline & Missing & $3(1.3 \%)$ \\
\hline \multirow[t]{14}{*}{ Foregone care } & Yes & $39(17.4 \%)$ \\
\hline & No & $185(82.6 \%)$ \\
\hline & Didn't know where to go & $1(0.4 \%)$ \\
\hline & Had no transportation & $3(1.3 \%)$ \\
\hline & Couldn’t pay & $11(4.9 \%)$ \\
\hline & Hard to find the time & $7(3.1 \%)$ \\
\hline & No one available to go along & $0(0.0 \%)$ \\
\hline & Parent or guardian would not go & $9(4.0 \%)$ \\
\hline & Afraid someone might see me & $2(0.9 \%)$ \\
\hline & Didn't want my parents to know & $4(1.8 \%)$ \\
\hline & Afraid of what the doctor would say or do & $8(3.6 \%)$ \\
\hline & Thought or hoped the problem would go away & $22(9.8 \%)$ \\
\hline & I am not treated with respect there & $0(0.0 \%)$ \\
\hline & Other reason not listed & $9(4.0 \%)$ \\
\hline \multirow{12}{*}{$\begin{array}{l}\text { HCP diagnosed } \\
\text { condition }\end{array}$} & Acne & $44(19.6 \%)$ \\
\hline & ADHD & $23(10.3 \%)$ \\
\hline & Anemia & $6(2.7 \%)$ \\
\hline & Allergies & $88(39.3 \%)$ \\
\hline & Asthma & $35(15.6 \%)$ \\
\hline & Depression & $27(12.1 \%)$ \\
\hline & Diabetes & $9(4.0 \%)$ \\
\hline & HTN & $13(5.8 \%)$ \\
\hline & Overweight & $24(10.7 \%)$ \\
\hline & Obesity & $13(5.8 \%)$ \\
\hline & None & $81(36.2 \%)$ \\
\hline & Missing & $7(3.1 \%)$ \\
\hline
\end{tabular}

Note. Some participants marked multiple answers for foregone care reason and HCP diagnosed condition; therefore, totals and percentages may not equal $100 \%$. 


\section{Descriptive Statistics of Outcome Variables}

Descriptive statistics — including ranges, means, and standard deviations - were computed for all dependent variables. Research questions for this study measure the continuous variables trust of HCP, lifestyle behaviors, number of HCP visits in the past 12 months, and number of ER visits in the past months. Trust of HCP was measured by the total scale score of the Wake Forest Trust in Physician scale, lifestyle behaviors were measured by the total ALQ scale score, while the number of HCP and the number of ER visits were self-reported counts of HCP and ER visit in the past 12 months. Descriptive statistics for these central study variables are presented in Table 4.5.

Table 4.4

Descriptive Statistics for Outcome Variables $(N=224)$

\begin{tabular}{lcccc}
\hline & $\mathrm{n}$ & Range & Mean & SD \\
\hline Trust of HCP & 211 & $17-50$ & 38.68 & 7.5 \\
Lifestyle behaviors & 179 & $95-215$ & 156.54 & 24.32 \\
Number of HCP visits in past 12 months* & 211 & $0-12$ & 3.04 & 3.05 \\
Number of ER visits in past 12 months* & 218 & $0-8$ & 0.79 & 1.39 \\
& & & &
\end{tabular}

Note. Only those participants who completed all items on the respective scales were included in the descriptive statistics for trust of HCP and lifestyle behaviors. Missing data contributed to differences in sample size for each variable. *Six outliers were removed from HCP visits and five outliers were removed from ER visits. 


\section{Health Behavior}

Additional health behaviors measured were tobacco use and body mass index (BMI). Self-reported tobacco use and physical measurements were assessed to describe tobacco abuse, overweight, and obesity in the sample, which are risk-behaviors more common among rural-dwelling adolescents. The chi-square test for independence compared tobacco use and BMI group by sex. Most participants had not used tobacco in the past 30 days (75.6\%), but of those that did use tobacco, cigarette use (17.4\%) was most common among females and smokeless tobacco (20.0\%) was most common among males. Males were more likely than females to use smokeless tobacco $\left(\chi^{2}=10.92, p=\right.$ .001). BMI was calculated from self-reported height and weight, then adjusted using a formula developed from Youth Risk Behavior Surveillance results (Brener et al., 2003). Less than half (45.5\%) of adolescents reported measurements within normal limits, with nearly an equal portion reporting overweight and obese (42\%) measurements. Over eleven percent $(11.2 \%)$ chose not to report height and weight measurements (See Table 4.4).

Table 4.5

Tobacco Use and Body Mass Index of the Sample

\begin{tabular}{|c|c|c|c|c|c|}
\hline Variable & Category & $\begin{array}{c}\text { Total } \\
\mathrm{n}(\%) \\
\mathrm{N}=224\end{array}$ & $\begin{array}{c}\text { Females } \\
\mathrm{n}(\%) \\
\mathrm{n}=121\end{array}$ & $\begin{array}{c}\text { Males } \\
\mathrm{n}(\%) \\
\mathrm{n}=100\end{array}$ & $p$ \\
\hline Tobacco & Any tobacco use (\% yes) & $53(23.7 \%)$ & $25(21.7 \%)$ & $27(27.0 \%)$ & .43 \\
\hline \multirow[t]{3}{*}{ use } & Cigarettes (\% yes) & $38(17.0 \%)$ & $21(17.4 \%)$ & $17(17.0 \%)$ & .86 \\
\hline & Cigars (\% yes) & $24(10.7 \%)$ & $8(6.6 \%)$ & $15(15.0 \%)$ & .08 \\
\hline & Smokeless (\% yes) & $27(12.1 \%)$ & $6(5.0 \%)$ & $20(20.0 \%)$ & .001 \\
\hline \multirow[t]{6}{*}{ BMI } & & & & & .53 \\
\hline & Underweight & $3(1.3 \%)$ & $2(1.7 \%)$ & $1(1.0 \%)$ & \\
\hline & Healthy & $102(45.5 \%)$ & $50(41.3 \%)$ & $52(52.0 \%)$ & \\
\hline & Overweight & $55(24.6 \%)$ & $31(25.6 \%)$ & $24(24.0 \%)$ & \\
\hline & Obese & $39(17.4 \%)$ & $24(19.8 \%)$ & $15(15.0 \%)$ & \\
\hline & Missing & $25(11.2 \%)$ & $14(11.6 \%)$ & $8(8.0 \%)$ & \\
\hline
\end{tabular}




\section{Instrument Reliability}

Internal consistency reliability was calculated for the Wake Forest Trust in Physician scale, the Adolescent Lifestyle Questionnaire (ALQ), and each of the seven ALQ subscales. A Cronbach's $\alpha$ ranging from $0.80-0.90$ indicates strong internal consistency between the items in a measure and greater than 0.60 is acceptable (Polit \& Beck, 2004). This sample demonstrated good internal consistency reliability for both the Wake Forest Trust in Physician Scale $(\alpha=.90)$ and the Adolescent Lifestyle Questionnaire (ALQ) $(\alpha=.93)$ (See Table 4.6). The internal consistency reliability of the ALQ subscales ranged from acceptable to strong $(\alpha=.60-.91)$. Reliability of the Stanford Health Care Utilization Questionnaire was previously determined using comparison to medical records. Medical records were not available with this study; therefore, reliability of the Stanford Health Care Utilization Questionnaire was not calculated.

Table 4.6

Instrument Reliability

\begin{tabular}{|c|c|c|c|c|c|}
\hline Instrument & $\begin{array}{l}\text { Variable } \\
\text { measured }\end{array}$ & $\begin{array}{l}\text { Number of } \\
\text { Items }\end{array}$ & M & SD & $\begin{array}{c}\text { Cronbach's } \\
\alpha\end{array}$ \\
\hline $\begin{array}{l}\text { Wake Forest Trust in } \\
\text { Physician scale }\end{array}$ & Trust of HCP & 10 & 38.70 & 7.50 & .90 \\
\hline $\begin{array}{l}\text { Adolescent Lifestyle } \\
\text { Questionnaire (ALQ) } \\
\text { ALQ subscales: }\end{array}$ & $\begin{array}{l}\text { Lifestyle } \\
\text { behaviors }\end{array}$ & 43 & 156.54 & 24.32 & .93 \\
\hline Identity Awareness & $\begin{array}{c}\text { Identity } \\
\text { Awareness }\end{array}$ & 9 & 36.94 & 6.06 & .86 \\
\hline Nutrition & Nutrition & 8 & 22.23 & 7.58 & .91 \\
\hline Physical Participation & $\begin{array}{c}\text { Physical } \\
\text { Participation }\end{array}$ & 4 & 14.78 & 4.75 & .89 \\
\hline Safety & Safety & 7 & 29.10 & 6.43 & .87 \\
\hline Health Awareness & $\begin{array}{c}\text { Health } \\
\text { Awareness }\end{array}$ & 4 & 10.97 & 3.69 & .72 \\
\hline Social Support & Social Support & 7 & 28.56 & 4.87 & .84 \\
\hline Stress Management & $\begin{array}{c}\text { Stress } \\
\text { Management }\end{array}$ & 4 & 12.95 & 3.58 & .60 \\
\hline
\end{tabular}

Note. $\mathrm{M}=$ mean, $\mathrm{SD}=$ standard deviation 
Research Question 1What relationships exist between variables (age, sex, family structure, trust of HCP, health insurance, household income, transportation difficulty, usual source of care, self-rated health, self-perceived need, diagnosed conditions, lifestyle behaviors, HCP visits, and ER visits) in the study model? Correlations were used to evaluate relationships between variables in the model. Several significant relationships were identified. A matrix was developed in order to understand the relationships between variables (See Table 4.7).

Significant, positive correlations were found between several variables (See Table 4.7). Of interest were significant, positive correlations between study dependent variables (Trust of HCP, lifestyle behaviors, number of HCP visits, and number of ER visits) and individual characteristic variables. Significant, positive correlations were found between trust of HCP and living in a two-parent home $(\mathrm{r}=.18, \mathrm{p} \leq .01)$, usual source of care $(\mathrm{r}$ $=.21, \mathrm{p} \leq .01)$, self-rated health $(\mathrm{r}=.18, \mathrm{p} \leq .01)$, and lifestyle behaviors $(\mathrm{r}=.26, \mathrm{p} \leq .01)$. A significant, positive relationship was also found between lifestyle behaviors and living in a two-parent home $(\mathrm{r}=.23, \mathrm{p} \leq .01)$, self-rated health $(\mathrm{r}=.42, \mathrm{p} \leq .01)$. In addition, a significant, positive relationship was found between number of HCP visits in the past 12 months and $\operatorname{sex}(r=.20, p \leq .01)$, usual source of care $(r=.19, p \leq .01)$, self-perceived need $(\mathrm{r}=.33, \mathrm{p} \leq .01)$, having a HCP diagnosed condition $(\mathrm{r}=.35, \mathrm{p} \leq .01)$, and lifestyle behaviors $(\mathrm{r}=.18, \mathrm{p} \leq .01)$. Lastly, a significant, positive relationship was found between number of ER visits in the past 12 months and having a HCP diagnosed condition $(r=.15$, $\mathrm{p} \leq .05)$, and number of HCP visits in the past 12 months $(\mathrm{r}=.29, \mathrm{p} \leq .01)$.

Significant, negative correlations were found between several study variables (See Table 4.7). Of interest were significant, negative correlations between study dependent 
variables (Trust of HCP, lifestyle behaviors, number of HCP visits, and number of ER visits) and individual characteristics. A significant, negative relation was found between Trust of HCP and transportation difficulty $(r=-.25, \mathrm{p} \leq .01)$ and foregone care $(\mathrm{r}=-.19, \mathrm{p}$ $\leq .01)$. A significant, negative relationship was found between number of HCP visits in the past 12 months and foregone care $(r=-.16, p \leq .05)$. A significant, negative relationship was also found between lifestyle behaviors and age $(r=.-22, p \leq .01)$. In addition, a significant, negative relationship was also found between number of ER visits in the past 12 months and household income $(r=.-25, \mathrm{p} \leq .01)$. 
Table 4.7

Correlations between Individual Characteristic Variables and Dependent Variables

\begin{tabular}{|c|c|c|c|c|}
\hline & Trust of HCP & $\begin{array}{l}\text { Lifestyle } \\
\text { behaviors }\end{array}$ & $\mathrm{HCP}$ visits & ER visits \\
\hline Age & -.09 & $-.22 * *$ & -.12 & -.07 \\
\hline Sex & -.03 & .09 & $.20 * *$ & .04 \\
\hline Race & .01 & .05 & -.03 & .07 \\
\hline Ethnicity & -.14 & -.07 & -.06 & .03 \\
\hline $\begin{array}{l}\text { Household } \\
\text { income }\end{array}$ & .10 & .02 & .06 & $-.28 * *$ \\
\hline $\begin{array}{l}\text { Two-parent } \\
\text { family }\end{array}$ & $.18 * *$ & $.23 * *$ & .06 & -.08 \\
\hline $\begin{array}{l}\text { Transportation } \\
\text { difficulty }\end{array}$ & $-.25 * *$ & -.09 & -.02 & .03 \\
\hline $\begin{array}{l}\text { Usual source } \\
\text { of care }\end{array}$ & $.21 * *$ & .10 & $.19 * *$ & .06 \\
\hline $\begin{array}{l}\text { Self-rated } \\
\text { health }\end{array}$ & $.18 * *$ & $.42 * *$ & -.05 & -.04 \\
\hline $\begin{array}{l}\text { Self-perceived } \\
\text { need }\end{array}$ & -.08 & .06 & $.33 * *$ & .13 \\
\hline Foregone care & $-.19 * *$ & -.14 & $-.16 *$ & -.10 \\
\hline $\begin{array}{l}\text { Diagnosed } \\
\text { condition }\end{array}$ & -.11 & -.06 & $.35 * *$ & $.15 *$ \\
\hline Trust of HCP & 1.00 & $.26 * *$ & .03 & -.08 \\
\hline $\begin{array}{l}\text { Lifestyle } \\
\text { behaviors }\end{array}$ & $.26 * *$ & 1.00 & $.18^{*}$ & .02 \\
\hline $\mathrm{HCP}$ visits & .03 & $.18 *$ & 1.00 & $.29 * *$ \\
\hline ER visits & -.08 & .02 & $.29 * *$ & 1.00 \\
\hline
\end{tabular}

Note. Bold indicates significance. $* p \leq .05$ level, two-tailed $* * p \leq .01$ level, two-tailed 
One-way analysis of variance with Tukey's post hoc analysis was conducted to explore the influence of the categorical independent variables (family structure, household income, health insurance, transportation difficulty, usual source of care type, self-rated health) on the normally distributed dependent variables (trust of HCP, lifestyle behaviors). Significant differences between groups were found with trust of HCP and family structure - father, indicating that having the biological father or stepfather in the home was associated with higher levels of trust of HCP. Significant differences between groups were found with trust of $\mathrm{HCP}$ and transportation difficulty, indicating that increasing levels of transportation difficulty were associated with lower levels of trust of HCP. Significant differences between groups were also found with lifestyle behaviors and family structure — mother, family structure — father, health insurance, and self-rated health. These results indicated that adolescents reported higher levels of healthy lifestyle behaviors when living with their biological mother or biological father compared to other family structures, living with a non-specified male, when having Medicaid or private health insurance as compared to no health insurance, and when reporting excellent or very good health as compared to reporting good, fair, or poor health. Results of these group comparisons are presented in Table 4.8. 
Table 4.8

One-way Analysis of Variance with Categorical Independent Variables

\begin{tabular}{|c|c|c|c|c|}
\hline $\begin{array}{l}\text { Variable } \\
\text { Category }\end{array}$ & $\begin{array}{l}\text { Trust of HCP } \\
\text { M (SD) }\end{array}$ & $\begin{array}{l}\text { Tukey's post } \\
\text { hoc analysis }\end{array}$ & $\begin{array}{c}\text { Lifestyle behaviors } \\
\text { M (SD) }\end{array}$ & $\begin{array}{l}\text { Tukey's post hoc } \\
\text { analysis }\end{array}$ \\
\hline Family structure-mother & & NS & & I, III \\
\hline I. Biological mother & $38.84(7.53)$ & & $158.89(24.71)^{*}$ & \\
\hline II. Stepmother & $34.20(6.46)$ & & $158.67(14.33)$ & \\
\hline III. Someone else & $38.49(21.64)$ & & $146.15(7.52)^{*}$ & \\
\hline Family structure - father & & I, III; II, III & & I, III \\
\hline I. Biological father & $39.69(7.11)^{* *}$ & & $159.97(24.55)^{*}$ & \\
\hline II. Stepfather & $40.09(8.21) * *$ & & $159.48(20.56)$ & \\
\hline III. Someone else & $35.87(7.23)^{* *}$ & & $148.14(23.78)^{*}$ & \\
\hline Household income & & NS & & NS \\
\hline I. Free lunch & $37.17(7.28)$ & & $155.82(25.62)$ & \\
\hline II. Reduced lunch & $38.95(7.96)$ & & $156.42(14.75)$ & \\
\hline III. Pays for lunch & $39.26(7.49)$ & & $156.98(25.24)$ & \\
\hline Health insurance & & NS & & I, V; III, V \\
\hline I. Medicaid & $36.77(7.69)$ & & $161.78(19.31)^{* *}$ & \\
\hline II. Military insurance & $33.50(11.15)$ & & $160.00(12.65)$ & \\
\hline III. Private insurance & $39.84(7.26)$ & & $158.21(21.97)^{*}$ & \\
\hline IV. Other insurance & $36.47(8.22)$ & & $157.00(36.73)$ & \\
\hline V. No insurance & $32.88(7.94)$ & & $131.71(20.77)^{*}$ & \\
\hline Transportation difficulty & & $\begin{array}{l}\text { I, III; II, III; } \\
\text { III, IV }\end{array}$ & & NS \\
\hline I. Not at all difficult & $40.28(6.85)^{*}$ & & $158.57(26.30)$ & \\
\hline II. Not too difficult & $37.69(7.51)^{*}$ & & $155.30(22.41)$ & \\
\hline III. Somewhat difficult & $32.76(7.63)^{*}$ & & $150.47(17.40)$ & \\
\hline IV. Very difficult & $46.00(2.00)^{*}$ & & $157.00(39.89)$ & \\
\hline Usual source of care type & & NS & & NS \\
\hline I. Health care provider & $40.17(7.21)$ & & $156.65(24.43)$ & \\
\hline II. Health clinic & $37.27(7.49)$ & & $160.33(24.36)$ & \\
\hline III. Urgent care center & $36.75(7.46)$ & & $157.54(28.68)$ & \\
\hline IV. Emergency room & $35.20(7.43)$ & & $147.00(16.64)$ & \\
\hline V. No usual source of care & $35.38(8.51)$ & & $148.64(21.24)$ & \\
\hline Self rated health & & NS & & $\begin{array}{l}\text { I, V; I, IV; II, IV; } \\
\text { I, III; II, III }\end{array}$ \\
\hline I. Excellent health & $40.49(6.76)$ & & $172.40(28.34)^{*}$ & \\
\hline II. Very good health & $39.49(7.68)$ & & $140.41(25.13)^{*}$ & \\
\hline III. Good health & $38.10(7.04)$ & & $150.09(20.64)^{*}$ & \\
\hline IV. Fair health & $35.67(8.49)$ & & $140.41(25.13)^{*}$ & \\
\hline V. Poor health & $37.67(8.51)$ & & $123.50(26.16)^{*}$ & \\
\hline
\end{tabular}


Kruskal-Wallis tests were conducted to explore the influence of the categorical independent variables (family structure, household income, health insurance, transportation difficulty, usual source of care type, self-rated health) on the non-normally distributed continuous dependent variables (number of $\mathrm{HCP}$ visits and number of ER visits). The Kruskal-Wallis test is the non-parametric alternative to the one-way ANOVA. With the Kruskal-Wallis test, the median number of HCP visits and ER visits are reported for each category, along with the mean rank. Mean rank indicates which group on the categorical variable had the highest overall ranking corresponding to the highest score on the continuous variables number of HCP visits and number of ER visits. No significant differences between groups were found with number of $\mathrm{HCP}$ visits. Significant differences between groups were found with number of ER visits in the past 12 months and family structure - mother, indicating that adolescents living with a stepmother had more ER visits than other family structures. Results of these group comparisons are presented in Table 4.9. 
Table 4.9

Kruskal-Wallis Tests

\begin{tabular}{|c|c|c|c|c|}
\hline $\begin{array}{l}\text { Variable } \\
\text { Category }\end{array}$ & $\begin{array}{c}\text { HCP visits } \\
\text { Median (Rank) }\end{array}$ & $\begin{array}{c}\chi^{2} \\
(p \text { value })\end{array}$ & $\begin{array}{c}\text { ER visits } \\
\text { Median (Rank) }\end{array}$ & $\begin{array}{c}\chi^{2} \\
(p \text { value })\end{array}$ \\
\hline $\begin{array}{l}\text { Family structure-mother } \\
\text { I. Biological mother } \\
\text { II. Stepmother } \\
\text { III. Someone else }\end{array}$ & $\begin{array}{l}2.00(104.82) \\
2.00(105.30) \\
3.00(109.25)\end{array}$ & NS & $\begin{array}{l}0.00(103.47)^{*} \\
2.00(162.08)^{*} \\
0.00(112.72)^{*}\end{array}$ & $\begin{array}{c}7.35 \\
(p=.025)\end{array}$ \\
\hline $\begin{array}{l}\text { Family structure-father } \\
\text { I. Biological father } \\
\text { II. Stepfather } \\
\text { III. Someone else }\end{array}$ & $\begin{array}{c}2.00(93.94) \\
3.00(115.23) \\
2.00(98.10)\end{array}$ & NS & $\begin{array}{c}0.00(93.50) \\
0.00(103.23) \\
0.00(115.37)\end{array}$ & NS \\
\hline $\begin{array}{l}\text { Household income } \\
\text { I. Free lunch } \\
\text { II. Reduced lunch } \\
\text { III. Pays for lunch }\end{array}$ & $\begin{array}{l}2.50(27.50) \\
1.00(11.00) \\
2.00(68.00)\end{array}$ & NS & $\begin{array}{l}1.00(27.00) \\
1.00(12.00) \\
0.00(69.00)\end{array}$ & NS \\
\hline $\begin{array}{l}\text { Health insurance } \\
\text { I. Medicaid } \\
\text { II. Military insurance } \\
\text { III. Private insurance } \\
\text { IV. Other insurance } \\
\text { V. No insurance }\end{array}$ & $\begin{array}{l}2.00(24.00) \\
4.00(4.00) \\
2.00(30.00) \\
2.00(8.00) \\
1.00(1.00)\end{array}$ & NS & $\begin{array}{c}1.00(24.50) \\
0.00(4.00) \\
0.00(30.00) \\
0.00(8.50) \\
0.00(1.00)\end{array}$ & NS \\
\hline $\begin{array}{l}\text { Transportation difficulty } \\
\text { I. Not at all difficult } \\
\text { II. Not too difficult } \\
\text { III. Somewhat difficult } \\
\text { IV. Very difficult }\end{array}$ & $\begin{array}{c}2.00(55.50) \\
3.00(39.00) \\
2.00(10.50) \\
1.00(2.50)\end{array}$ & NS & $\begin{array}{c}0.00(55.00) \\
0.00(39.50) \\
0.00(12.00) \\
0.50(2.50)\end{array}$ & NS \\
\hline $\begin{array}{l}\text { Usual source of care type } \\
\text { I. Health care provider } \\
\text { II. Health clinic } \\
\text { III. Urgent care center } \\
\text { IV. Emergency room } \\
\text { V. None/I don't know }\end{array}$ & $\begin{array}{l}2.00(64.50) \\
2.00(22.50) \\
2.50(8.50) \\
0.00(3.00) \\
2.00(5.50)\end{array}$ & NS & $\begin{array}{l}0.00(65.50) \\
0.00(22.00) \\
1.00(8.50) \\
1.00(3.00) \\
2.00(6.50)\end{array}$ & NS \\
\hline $\begin{array}{l}\text { Self rated health } \\
\text { I. Excellent health } \\
\text { II. Very good health } \\
\text { III. Good health } \\
\text { IV. Fair health } \\
\text { V. Poor health }\end{array}$ & $\begin{array}{l}2.00(18.00) \\
2.00(38.00) \\
2.00(37.00) \\
3.00(13.50) \\
3.00(1.50)\end{array}$ & NS & $\begin{array}{c}0.00(17.50) \\
0.00(37.50) \\
0.00(38.50) \\
0.00(14.50) \\
0.00(1.50)\end{array}$ & NS \\
\hline
\end{tabular}

Note. Significant differences between groups are identified by group number in the $\chi^{2}$ post hoc analysis column, $\mathrm{p} \leq .05$, NS $=$ non-significant. 
Adolescent Lifestyle Questionnaire (ALQ) subscales. In addition to measuring the correlations between study variables, correlations between the ALQ subscales [identity awareness, nutrition, physical participation, safety, social support, health awareness, and stress management) (Gillis, 1997)] and study variables were also examined. Pearson's $r$ was used to compare the relationship between ALQ subscales and the normally distributed continuous variables (age, trust of HCP). Point biserial correlations were used to explore the relationship between each of the ALQ subscales and dichotomous variables (sex, family structure, health insurance, usual source of care, selfperceived need, has any HCP diagnosed condition), while Spearman's rho was used to compare ALQ subscales to non-normally distributed continuous variables (number of HCP visits, number of ER visits) and ordinal variables (transportation, self-rated health status). A matrix was developed to in order to understand the relationships between variables (See Table 4.9).

Significant, positive correlations were found between ALQ subscales and several variables (See Table 4.9). Of interest were significant, positive correlations between the ALQ physical participation subscale and self-rated health $(r=.42, p \leq .01)$. A significant, positive relationship was also found between the ALQ nutrition subscale and family structure-father $(r=.15, p \leq .05)$, self-rated health $(r=.15, p \leq .05)$, and number of $\mathrm{HCP}$ visits $(r=.15, \mathrm{p} \leq .05)$. In addition, a significant positive relationship was found between the ALQ social support subscale and trust of $\operatorname{HCP}(r=.38, p \leq .01)$ and self-rated health $(\mathrm{r}=.30, p \leq .01)$. With the ALQ stress management subscale, significant relationships were found with female $\operatorname{sex}(r=.20, p \leq .01)$ and self-rated health $(r=.22, p$ $\leq .01)$. Furthermore, the ALQ subscale identity awareness was significantly, positively 
related to family structure — mother $(r=.16, p \leq .05)$, family structure—-father $(r=.23, p$ $\leq .01)$, trust of $\mathrm{HCP}(r=.42, p \leq .01)$, and self-rated health $(r=.46, p \leq .01)$. Additionally, the ALQ subscale health awareness had a significant, positive relationship to trust of HCP $(r=.25, p \leq .01)$, self-rated health $(r=.21, p \leq .01)$, and number of HCP visits in the past 12 months $(r=.16, p \leq .05)$. Finally, the ALQ subscale safety had a significant relationship with female sex $(r=.15, p \leq .05)$, family structure - mother $(r=.16, p \leq .05)$, Trust of HCP $(r=.20, p \leq .01)$, and self-rated health $(r=.20, p \leq .01)$.

Significant, negative correlations were found between ALQ subscales and several variables (See Table 4.9). Of interest were significant, negative correlations between the ALQ physical participation subscale and age $(r=-.25, p \leq .01)$, male sex $(r=-.13, p$ $\leq .05)$, and transportation $(r=-.13, p \leq .05)$. A significant, negative relationship was also found between the ALQ nutrition subscale and health insurance $(r=-.18, p \leq .05)$. In addition, a significant negative relationship was found between the ALQ social support subscale and age ( $r=.-20, p \leq .01)$, transportation $(r=.-15, p \leq .05)$, and having a HCP diagnosed condition $(r=.-16, p \leq .05)$. With the ALQ stress management subscale, a significant, negative relationship was found with age $(r=-.16, p \leq .05)$. Furthermore, the ALQ subscale identity awareness was significantly, negatively related to transportation ( $r$ $=-.24, p \leq .01)$ and having a HCP diagnosed condition $(r=-.23, p \leq .01)$. Additionally, the ALQ subscale health awareness had a significant, negative relationship to age $(r=-.17, p$ $\leq .05)$ and health insurance $(r=-.17, p \leq .05)$. Finally, the ALQ subscale safety had a significant, negative relationship with age $(r=-.15, p \leq .05)$ and ER visits $(r=-.18, p$ $\leq .01)$. 
Table 4.10

Correlations between ALQ Subscales and Variables

\begin{tabular}{|c|c|c|c|c|c|c|c|c|}
\hline & $\begin{array}{l}\text { Total } \\
\text { ALQ }\end{array}$ & $\begin{array}{l}\text { ALQ physical } \\
\text { participation }\end{array}$ & $\begin{array}{c}\text { ALQ } \\
\text { nutrition }\end{array}$ & $\begin{array}{c}\text { ALQ } \\
\text { social } \\
\text { support }\end{array}$ & $\begin{array}{l}\text { ALQ stress } \\
\text { management }\end{array}$ & $\begin{array}{l}\text { ALQ identity } \\
\text { awareness }\end{array}$ & $\begin{array}{l}\text { ALQ health } \\
\text { awareness }\end{array}$ & $\begin{array}{l}\text { ALQ } \\
\text { safety }\end{array}$ \\
\hline Age & $-.25^{* * *}$ & $-.25^{* *}$ & -.003 & $-.20^{* *}$ & $-.16^{*}$ & -.08 & $-.17^{*}$ & $-.15^{*}$ \\
\hline Sex & .11 & $-.13^{*}$ & .10 & .12 & $.20^{* *}$ & .07 & .08 & $.15^{*}$ \\
\hline Race & .06 & -.01 & .06 & .005 & -.03 & .06 & -.12 & .06 \\
\hline Ethnicity & -.06 & -.09 & -.04 & -.07 & .05 & -.002 & .06 & -.08 \\
\hline $\begin{array}{l}\text { Family structure- } \\
\text { mother }\end{array}$ & $.20^{* *}$ & .11 & .13 & .08 & .11 & $.16^{*}$ & .06 & $.16^{*}$ \\
\hline $\begin{array}{l}\text { Family structure- } \\
\text { father }\end{array}$ & $.16^{*}$ & .11 & $.15^{*}$ & .11 & .10 & $.23^{* *}$ & .06 & .07 \\
\hline Trust of HCP & $.26^{* *}$ & .06 & -.04 & $.38^{* *}$ & $.19^{* *}$ & $.42^{* *}$ & $.25^{* *}$ & $.20^{* *}$ \\
\hline $\begin{array}{l}\text { Household } \\
\text { income }\end{array}$ & .01 & -.04 & .09 & .08 & .03 & .09 & -.07 & .06 \\
\hline Health insurance & -.12 & .01 & $-.18^{*}$ & .04 & -.12 & -.04 & $-.17^{*}$ & -.02 \\
\hline Transportation & -.09 & $-.13^{*}$ & .06 & $-.15^{*}$ & -.08 & $-.24^{* *}$ & -.03 & -.03 \\
\hline $\begin{array}{l}\text { Usual source of } \\
\text { care }\end{array}$ & .13 & -.04 & .08 & .06 & .10 & .07 & .12 & .08 \\
\hline Self-rated health & $.42^{* *}$ & $.42^{* * *}$ & $.15^{*}$ & $.30^{* *}$ & $.22^{* *}$ & $.46^{* *}$ & $.21^{* *}$ & $.20^{* *}$ \\
\hline $\begin{array}{l}\text { Self-perceived } \\
\text { need }\end{array}$ & .07 & -.06 & .04 & .00 & .06 & .03 & .13 & .08 \\
\hline $\begin{array}{l}\text { Diagnosed } \\
\text { condition }\end{array}$ & -.06 & -.10 & .08 & $-.16^{*}$ & -.06 & $-.23^{* *}$ & -.05 & .12 \\
\hline $\mathrm{HCP}$ visits & $.18^{*}$ & .02 & $.15^{*}$ & .06 & .07 & .04 & $.16^{*}$ & .09 \\
\hline ER visits & .02 & .07 & .02 & -.13 & .08 & .06 & .02 & $-.18^{* *}$ \\
\hline
\end{tabular}




\section{Research Question 2}

Which variables in the model were predictive of trust of $\mathrm{HCP}$ among adolescents attending a public high school in a rural area? Hierarchical multiple regression was used to evaluate predictors of adolescents' trust of HCP. Trust of HCP was treated as both a predictor variable and an outcome variable in this study. In this research question, trust of $\mathrm{HCP}$ was treated as the outcome variable of interest; therefore, trust of $\mathrm{HCP}$ was not included as a predictor variable in this regression model. With hierarchical multiple regression, blocks of variables were entered into the regression model based on Andersen's Behavioral Model (ABM). The first block of variables entered included predisposing characteristics (age, sex, family structure), followed by individual enabling characteristics (household income, health insurance, transportation difficulty, usual source of care), then individual need characteristics (self-rated heath, foregone care, HCP diagnosed conditions), and finally health behavior (lifestyle behavior, HCP visits, ER visits). After the first block of variables were entered, family structure—-father was significant. In the second block, health insurance, transportation difficulty, and USOC were significant, while family structure—-father became non-significant. With the addition of the third block of variables, household income became significant, while health insurance and USOC remained significant, and transportation difficulty became non-significant. In the final model, lifestyle behavior was significant, USOC and health insurance remained significant, and transportation difficulty returned to significance.

Data indicated that the overall model was statistically significant, $F(16,160)=$ $2.96, p<.001$ and explained $25 \%$ of the variance. In the final model, four predictor variables remained significant (ordered by strength of contribution assessed by 
standardized beta value): USOC, health insurance, lifestyle behavior, and transportation difficulty. Participants having a HCP as a usual source of care had higher levels of trust of HCP compared to those that did not have a HCP as the USOC (beta $=.28, p<.001$ ). Those individuals with Medicaid insurance had lower levels of trust compared to those with private/other health insurance (beta $=-.26, p=.005$ ). Adolescents reporting higher levels of healthy lifestyle behavior also reported higher levels of trust of HCP (beta $=.18$, $p=.04)$. Finally, those participants reporting transportation difficulty had lower levels of trust of $\mathrm{HCP}$ as compared to those reporting no transportation difficulty (beta $=-.16, p=$ .04) (See Table 4.10). 
Table 4.11

Model Predicting Trust of HCP using Hierarchical Linear Regression $(n=161)$

\begin{tabular}{|c|c|c|c|c|c|c|c|c|}
\hline & $\mathrm{F}$ & $\begin{array}{c}p \text { value } \\
\text { of } \mathrm{F}\end{array}$ & $\mathrm{R}^{2}$ & $\operatorname{Adj} R^{2}$ & $\begin{array}{c}\mathrm{F} \text { for } \\
\mathrm{R}^{2} \text { change }\end{array}$ & $\begin{array}{l}p \text { value of } \\
\mathrm{R}^{2} \text { change }\end{array}$ & $\begin{array}{c}\text { Standardized } \\
\beta\end{array}$ & $\begin{array}{c}p \\
\text { value }\end{array}$ \\
\hline Step 1 & 1.90 & .11 & .05 & .02 & 1.90 & .11 & & \\
\hline Age & & & & & & & -.05 & .53 \\
\hline Sex & & & & & & & .03 & .73 \\
\hline Family structure-mother & & & & & & & -.03 & .72 \\
\hline Family structure - father & & & & & & & .08 & .38 \\
\hline Step 2 & 3.43 & $<.001$ & .19 & .13 & 4.29 & .001 & & \\
\hline Household income & & & & & & & -.18 & .08 \\
\hline No health insurance* & & & & & & & -.11 & .17 \\
\hline Medicaid* & & & & & & & -.26 & .005 \\
\hline Military insurance* & & & & & & & -.07 & .37 \\
\hline Transportation difficulty & & & & & & & -.16 & .04 \\
\hline Usual source of care & & & & & & & .28 & $<.001$ \\
\hline Step 3 & 3.21 & $<.001$ & .22 & .15 & 2.20 & .09 & & \\
\hline Self-rated health & & & & & & & .04 & .62 \\
\hline Foregone care & & & & & & & -.08 & .33 \\
\hline HCP diagnosed depression & & & & & & & -.11 & .18 \\
\hline Step 4 & 2.96 & $<.001$ & .25 & .16 & 1.67 & .18 & & \\
\hline Lifestyle behaviors & & & & & & & .18 & .04 \\
\hline Any HCP visit within year & & & & & & & -.06 & .44 \\
\hline Any ER visit within year & & & & & & & .07 & .42 \\
\hline
\end{tabular}

Note: Bold indicates significance. ${ }^{*}=$ private/other health insurance used as reference category. 


\section{Research Question 3}

Which variables in the model were predictive of lifestyle behaviors among adolescents attending a public high school in a rural area? Hierarchical multiple regression was used to evaluate predictors of adolescents' lifestyle behaviors using the ALQ scale. With hierarchical multiple regression, blocks of variables were entered into the regression model based on ABM. The first block of variables included predisposing characteristics (age, sex, family structure, trust of HCP), followed by individual enabling characteristics (household income, health insurance, transportation difficulty, usual source of care), then individual need characteristics (self-rated heath, foregone care, HCP diagnosed conditions), and finally health behavior (HCP visits, ER visits) were entered. After the first block of variables were entered, age and trust of HCP were significant. In the second block, no new variables were significant, but age and trust of HCP remained significant. With the addition of the third block of variables, self-rated health was significant, sex became significant when it had not been previously, and age and trust of HCP remained significant. In the final model, none of the added variables were significant, but age, sex, trust of HCP, and self-rated health remained significant.

Data indicated that the overall model was statistically significant, $F(16,161)=$ 4.97, $p<.001$ and explained $36 \%$ of the variance. Although the fourth step did not add any significant change in $\mathrm{R}^{2}$, the final model was significant with four significant predictor variables (ordered by strength of contribution assessed by beta value): selfrated health, age, trust of HCP, and sex. Participants reporting excellent or very good self-rated health as compared to good, fair, or poor self-rated health had higher levels of healthy lifestyle behaviors (beta $.41, p<.001$ ). Younger participants had higher levels of 
healthy lifestyle behaviors as compared to older participants (beta $=.21, \mathrm{p}=.004$ ).

Higher levels of trust of HCP compared to lower levels of trust of HCP predicted higher levels of healthy lifestyle behaviors (beta $.17, p=.03$ ). Finally, females had higher levels of healthy lifestyle behaviors (beta $=.15, p=.04$ ) compared to males (See Table 4.11). 
Table 4.12

Model Predicting Lifestyle Behaviors using Hierarchical Linear Regression $(N=161)$

\begin{tabular}{|c|c|c|c|c|c|c|c|c|}
\hline & $\mathrm{F}$ & $\begin{array}{c}p \text { value } \\
\text { of } \mathrm{F}\end{array}$ & $\mathrm{R}^{2}$ & $\operatorname{Adj} R^{2}$ & $\begin{array}{c}\mathrm{F} \text { for } \\
\mathrm{R}^{2} \text { change }\end{array}$ & $\begin{array}{l}p \text { value of } \\
\mathrm{R}^{2} \text { change }\end{array}$ & $\begin{array}{c}\text { Standardized } \\
\beta \\
\end{array}$ & $\begin{array}{c}p \\
\text { value }\end{array}$ \\
\hline Step 1 & 6.01 & $<.001$ & .16 & .14 & 6.01 & $<.001$ & & \\
\hline Age & & & & & & & -.21 & .004 \\
\hline Sex & & & & & & & .15 & .04 \\
\hline Family structure - mother & & & & & & & .04 & .61 \\
\hline Family structure - father & & & & & & & .12 & .13 \\
\hline Trust of HCP & & & & & & & .17 & .03 \\
\hline Step 2 & 3.48 & $<.001$ & .20 & .15 & 1.31 & .26 & & \\
\hline Household income & & & & & & & -.08 & .41 \\
\hline No health insurance* & & & & & & & -.09 & .24 \\
\hline Medicaid* & & & & & & & .09 & .32 \\
\hline Military insurance* & & & & & & & .08 & .28 \\
\hline Transportation difficulty & & & & & & & .08 & .27 \\
\hline Usual source of care & & & & & & & -.02 & .79 \\
\hline Step 3 & 5.53 & $<.001$ & .35 & .28 & 10.58 & $<.001$ & & \\
\hline Self-rated health & & & & & & & .41 & $<.001$ \\
\hline Any foregone care & & & & & & & .01 & .88 \\
\hline HCP diagnosed condition & & & & & & & .00 & .99 \\
\hline Step 4 & 4.97 & $<.001$ & .36 & .28 & 1.04 & .36 & & \\
\hline Any HCP visit within year & & & & & & & .10 & .19 \\
\hline Any ER visit within year & & & & & & & -.05 & .49 \\
\hline
\end{tabular}

Note: Bold indicates significance. ${ }^{*}=$ private/other health insurance used as reference category. 


\section{Research Question 4a}

Which variables in the model were predictive of utilization of health services (number of HCP visits) among adolescents attending a public high school in a rural area? Negative binomial regression was used to evaluate the over-dispersed data measuring number of HCP visits in the past 12 months. The independent variables entered into the negative binomial regression model for number of HCP visits were age, sex, family structure, trust of HCP, household income, health insurance, transportation, usual source of care, self-rated heath, self-perceived need, HCP diagnosed conditions, lifestyle behaviors, and number ER visits within the last 12 months. The omnibus test of the main effect was statistically significant using the Likelihood ratio test, $\chi 2(18, \mathrm{n}=105)=$ $31.59, p=.03$. This result indicates that the negative binomial model provides a significantly better fit than the Poisson model and that the estimate of $\alpha$ was significantly different from zero. The deviance model fit statistic $(86, \mathrm{n}=105)=53.97, p=.99$ indicated adequate fit of the model to the data. With this fit index, a non-significant, small deviance fit statistic was preferred (Coxe et al., 2009). The model contained six significant predictors after controlling for the influence of all other variables (See Table 4.12): $\operatorname{sex}\left(\chi^{2}=3.70, p=.05\right)$, household income $\left(\chi^{2}=4.44, p=.04\right)$, self-rated health $\left(\chi^{2}=20.91, p<.001\right)$, self-perceived need $\left(\chi^{2}=12.77, p<.001\right)$, health insurance $(\chi 2=$ $8.29, p=.02)$, and number of ER visits $(\chi 2=17.95, p<.001)$. The rate ratios were calculated for the following variables: (1) males — compared to females - were .75 times less likely to have a HCP visit (RR: $0.75 ; 95 \% \mathrm{CI}=0.55-1.01, p=.05)$, (2) those living in a low income household — compared to those living in a high income household — were approximately 0.60 times less likely of having a $\mathrm{HCP}$ visit (RR: $0.58 ; 95 \% \mathrm{CI}=0.35$ - 
$0.96, p=.035),(3)$ poor self-rated health — compared to excellent, very good, good, or fair self-rated health—was 0.23 times less likely to have a HCP visit (RR: 0.23 ; 95\% CI $=0.11-.50, p \leq .001),(4)$ having no self-perceived need was 0.48 times less likely to have a $\mathrm{HCP}$ visit (RR: $0.48 ; 95 \% \mathrm{CI}=0.32-.72, p \leq .001),(5)$ having no health insurancecompared to having Medicaid, military insurance, or private/other health insurance-was 0.31 times less likely to have a HCP visit (RR: $0.31 ; 95 \% \mathrm{CI}=0.14-.70, p=.005)$, and (6) for each ER visit, HCP visits increase by 0.41 times (RR: 1.41; 95\% CI = 1.20-1.66, $p$ $\leq .001)($ See Table 4.12). 
Table 4.13

Model Predicting Number of HCP Visits using Negative Binomial Regression $(N=105)$

\begin{tabular}{|c|c|c|c|c|c|c|}
\hline Parameter & $\mathrm{B}$ & Std. Error & Rate Ratio & $\begin{array}{l}95 \% \text { Wald } \\
\text { Lower }\end{array}$ & $\begin{array}{l}\text { r Rate Ratio } \\
\text { Upper }\end{array}$ & $p$ \\
\hline Intercept & 1.886 & 1.5425 & 6.596 & .321 & 135.611 & .22 \\
\hline Sex (male) & -.295 & .1532 & .745 & .552 & 1.005 & .05 \\
\hline Sex (female) & ref & . & 1 & . & . & . \\
\hline Does not live with biological mother & .022 & .2179 & 1.022 & .667 & 1.567 & .92 \\
\hline Lives with biological mother & ref & 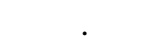 & 1 & . & . & . \\
\hline Does not live with biological father & -.083 & .1741 & .920 & .654 & 1.294 & .63 \\
\hline Lives with biological father & ref & . & 1 & . & . & . \\
\hline Household income (low) & -.547 & .2595 & .579 & .348 & .962 & .04 \\
\hline Household income (higher) & ref & . & 1 & . & . & . \\
\hline Health insurance (none) & -1.180 & .4191 & .307 & .135 & .699 & .005 \\
\hline Health insurance (Medicaid or Military) & .033 & .2376 & 1.034 & 649 & 1.647 & .88 \\
\hline Health insurance (Private insurance or other) & ref & . & 1 & . & . & . \\
\hline Usual source of care (no) & -.186 & .2619 & .830 & .497 & 1.387 & .48 \\
\hline Usual source of care (yes) & ref & . & 1 & . & . & . \\
\hline Self-rated health status (poor) & -1.463 & .3876 & .232 & .108 & .495 & $<.001$ \\
\hline Self-rated health status (fair) & -.447 & .3915 & 639 & .297 & 1.377 & .25 \\
\hline Self-rated health status (good) & -.220 & .2426 & .803 & .499 & 1.291 & .37 \\
\hline Self-rated health status (very good) & -.190 & .2477 & .827 & .509 & 1.343 & .44 \\
\hline Self-rated health status (excellent) & ref & . & 1 & . & . & . \\
\hline Self-perceived health need (no) & -.741 & .2074 & .477 & .317 & .716 & $<.001$ \\
\hline Self-perceived health need (yes) & ref & . & 1 & . & . & . \\
\hline HCP diagnosed health condition (no) & -.324 & .2077 & .723 & .481 & 1.086 & .12 \\
\hline HCP diagnosed health condition (yes) & ref & . & 1 & . & . & . \\
\hline Transportation (some other way) & .098 & .1816 & 1.103 & .773 & 1.574 & .59 \\
\hline Transportation (drives self) & ref & . & 1 & . & . & . \\
\hline Age & -.009 & .0722 & .991 & .860 & 1.141 & .90 \\
\hline Trust of HCP & .008 & .0124 & 1.008 & .984 & 1.033 & .52 \\
\hline Lifestyle behaviors (total ALQ score) & -.003 & .0043 & .997 & .989 & 1.006 & .52 \\
\hline Number of ER visits & .345 & .0814 & 1.412 & 1.204 & 1.656 & $<.001$ \\
\hline
\end{tabular}




\section{Research Question 4b}

Which variables in the model were predictive of utilization of health services (number of ER visits) among adolescents attending a public high school in a rural area? Predictors of adolescents' reported number of ER visits within the past 12 months were evaluated using negative binomial regression. The independent variables entered into the negative binomial regression model for number of ER visits were age, sex, family structure, trust of $\mathrm{HCP}$, household income, health insurance, transportation, usual source of care, self-rated heath, perceived health need, HCP diagnosed health conditions, lifestyle behaviors, and number of HCP visits within the last 12 months. The omnibus test of the main effect was statistically significant using the Likelihood ratio test, $\chi^{2}(15, \mathrm{n}=$ 106) $=35.13, p=.002$. This result indicates that the negative binomial model provides a significantly better fit than the Poisson model and it also indicates that the estimate of $\alpha$ was significantly different from zero. The deviance model fit statistic $(90, \mathrm{n}=106)=$ $76.44, p=.85$ indicated adequate fit of the model to the data. The model contained two significant predictors after controlling for the influence of all other variables (See Table 4.13): household income $\left(\chi^{2}=8.46, p=.004\right)$ and number of HCP visits $(\chi 2=8.925, p=$ $.003)$. The rate ratios were calculated for the following variables: 1) those living in low income household — compared to higher income households — were 3.3 times more likely to have an ER visit (RR: 3.30; 95\% CI $=1.481-7.38, p=.004)$ and 2 ) for each HCP visit, ER visits increased by 0.06 times (RR: $1.06 ; 95 \% \mathrm{CI}=1.02-1.10, p=.003$ ) (See Table 4.13). 
Table 4.14

Model Predicting Number of ER Visits using Negative Binomial Regression $(N=106)$

\begin{tabular}{|c|c|c|c|c|c|c|}
\hline \multirow[b]{2}{*}{ Parameter } & \multirow[b]{2}{*}{$\beta$} & \multirow[b]{2}{*}{ Std. Error } & \multirow[b]{2}{*}{ Rate Ratio } & \multirow{2}{*}{\multicolumn{2}{|c|}{$\begin{array}{l}\text { 95\% Wald C.I. for Rate } \\
\text { Ratio }\end{array}$}} & \multirow[b]{2}{*}{$p$} \\
\hline & & & & & & \\
\hline Intercept & -1.688 & 2.6886 & .185 & .001 & 35.935 & .53 \\
\hline Sex (male) & .409 & .2713 & 1.506 & .885 & 2.562 & .13 \\
\hline Sex (female) & ref & . & 1 & . & . & . \\
\hline Lives with biological mother & -.178 & .3469 & .837 & .424 & 1.652 & .61 \\
\hline Does not live with biological mother & ref & . & 1 & . & . & . \\
\hline Lives with biological father & .429 & .3158 & 1.536 & .827 & 2.852 & .17 \\
\hline Does not live with biological father & ref & . & 1 & . & . & . \\
\hline Household income (low income) & 1.194 & .4105 & 3.300 & 1.476 & 7.377 & .004 \\
\hline Household income (not low income) & ref & . & 1 & . & . & . \\
\hline Health insurance (Private or other) & .209 & .4376 & 1.232 & .523 & 2.905 & .63 \\
\hline Health insurance (no insurance) & .302 & 6312 & 1.353 & .393 & 4.662 & .63 \\
\hline Health insurance (Medicaid or Military) & ref & . & 1 & . & . & . \\
\hline Usual source of care (no) & -.183 & .4618 & .833 & .337 & 2.059 & .69 \\
\hline Usual source of care (yes) & ref & . & 1 & . & . & . \\
\hline Self-perceived need (yes) & .681 & .4235 & 1.975 & .861 & 4.529 & .11 \\
\hline Self-perceived need (no) & ref & . & 1 & . & . & . \\
\hline HCP diagnosed condition (yes) & -.127 & .3213 & .881 & .469 & 1.654 & .69 \\
\hline HCP diagnosed condition (no) & ref & . & 1 & . & . & . \\
\hline Transportation (drives self) & .447 & .3918 & 1.564 & .726 & 3.371 & .25 \\
\hline Transportation (some other way) & ref & . & 1 & . & . & . \\
\hline Age & -.033 & .1339 & .968 & .744 & 1.258 & .81 \\
\hline Trust of HCP & -.015 & .0190 & .985 & .949 & 1.022 & .43 \\
\hline Lifestyle behaviors (total ALQ) & .003 & .0080 & 1.003 & .987 & 1.018 & .75 \\
\hline Number of HCP visits in 12 months & .059 & .0198 & 1.061 & 1.020 & 1.103 & .003 \\
\hline Self-rated health (Excellent/very good) & .403 & .3195 & 1.497 & .800 & 2.799 & .21 \\
\hline Self-rated health (poor/fair/good) & ref & . & 1 & . & . & . \\
\hline
\end{tabular}

Note: ref = reference category; $\mathrm{M}=.79, \mathrm{SD}=1.39$, Variance $=1.92$ 


\section{Summary}

A number of statistical analyses were completed to test the four research questions in this chapter. For Research Question 1, the study found multiple significant associations between individual characteristics and dependent variables trust of HCP, lifestyle behaviors, number of HCP visits, and number ER visits. With Research Question 2, the model predicted $27 \%$ of the variance in trust of HCP with trust of HCP predicted by USOC, health insurance, lifestyle behavior, and transportation difficulty. In addition, the model predicted $34 \%$ of lifestyle behaviors with lifestyle behaviors being predicted by self-rated health, age, trust of HCP, and sex. The models were also significant for predicting HCP visits and ER visits with Research Question 4. Predictors of number of HCP visits were sex, household income, self-rated health, self-perceived need, health insurance, and number of ER visits, while household income and number of HCP visits predicted number of ER visits. The following and final chapter will discuss these finding in depth. 


\section{CHAPTER V}

\section{DISCUSSION}

In this chapter, a discussion of the study findings is provided. The purpose of this study was to examine individual characteristic variables and determine the extent to which these variables influence trust of HCP, lifestyle behaviors, and utilization of health services among adolescents attending public high school in rural Indiana. In this chapter, Andersen's Behavioral Model of Health Services Use (ABM) was employed to present and organize a discussion of study findings. In addition to a discussion of study findings, limitations of the study are presented, along with implications of the study, and finally recommendations for future research are addressed.

\section{Andersen's Behavioral Model of Health Services Use}

Andersen's Behavioral Model (ABM) served as a foundation for the research design of this study. In this section, individual characteristic findings of the study are compared and contrasted to both the contextual characteristics of the population from which the sample was drawn (presented in Chapter 3 with the study setting section), as

well as findings of other previous studies. The ABM defines contextual characteristics as the circumstances and environment of health services access. Because there was little variability in the rural population from which this sample was drawn, contextual characteristics were not included in the analysis. However, the contextual characteristics of the community in which the data were collected provided a picture of the 
circumstances and environment in which the research participants live and may be important to interpreting the findings of this study. Contextual characteristics were presented in Chapter 3 as a description of the study setting. These contextual characteristics helped to elucidate the findings.

\section{Individual Characteristics}

In this study of adolescents' age 15-19 attending a public high school in rural Indiana, significant associations were found between individual characteristic variables and the dependent variables trust of HCP, lifestyle behaviors, and utilization of health services. Findings related to each research question are discussed.

\section{Research Questions}

In this study involving adolescents' attending a public high school in rural Indiana, variables identified in the literature as significantly associated with the dependent variables were applied to an adapted version of Andersen's Behavioral Model of Health Services Use (ABM). Independent variables in this study included individual characteristics of health care users as described in the ABM (age, sex, family structure, health insurance, household income, transportation, usual source of care, self-rated health, self-perceived need, foregone care, diagnosed conditions, trust of $\mathrm{HCP}$ ), which in turn influence health behavior. The ABM describes health behavior as lifestyle behaviors and health utilization. This study examined the effect of individual characteristics on the outcome of health behavior, indicated by lifestyle behaviors, and health services utilization, measured as number of HCP visits, and number of ER visits.

In addition, the individual characteristic of trust in $\mathrm{HCP}$ was examined as both a predictor of health behavior, as described in the ABM, and also as an outcome of other 
independent variables. However, because there is so little known about interactions among these factors in adolescents living in rural areas, analysis was not limited to examining only the effects of independent variables on dependent variables. Instead, all possible associations among study variables were explored to extract the maximum amount of information from the data. Correlations were examined and analysis of variance was used to identify significant relationships among variables (Research question 1), and then multiple regression was used to identify factors that were predictors of trust of HCP (Research question 2), lifestyle behaviors (Research question 3), and health services utilization (Research question 4).

Research Question 1. What relationships exist between variables (age, sex, race, ethnicity, family structure, trust of $\mathrm{HCP}$, health insurance, household income, transportation, usual source of care, self-rated health, self-perceived need, diagnosed conditions, lifestyle behaviors, HCP visits, and ER visits) in the study model?

Age and sex. The biological variables age and sex are predictors of health service use. Typically, older female adolescents utilize more health services (Hoover et al., 2010; Simpson et al., 2005; Simpson et al., 2004), related to contraceptive, STD, and obstetric care among older adolescent females (Hoover et al., 2010). Overall—in both the U.S. and internationally — males tend to utilize fewer health services than females (Hoover et al., 2010; Ma et al., 2005; Mulye et al., 2009; Spleen et al., 2014). In this study, females were more likely than males to have a HCP visit, but no difference was seen between males and females for ER visits. This study found no relationship between age and HCP visit or ER visit. As mentioned above, increased rates of HCP visits with age are usually related to older females obtaining sexual health services. The absence of a relationship between 
age and HCP visits may be related to the lack of low cost sexual health services-such as Planned Parenthood-in this community.

Race and ethnicity. Race and ethnicity are known to have a significant effect on utilization of health services. The majority of participants reported race as white $(95.0 \%)$ and ethnicity as non-Hispanic (92.0\%). Data provided by school administrators portrayed race (white $=97.2 \%$ ) similarly, but revealed some discrepancy concerning ethnicity (nonHispanic ethnicity $=99.7 \%)($ Personal communication with J. Martin, June 4, 2014). Nevertheless, the sample was racially and ethnically homogenous, which was supported by county level data and is common in rural areas. Studies of health services utilization indicate adolescents who identify as racial and ethnic minorities are less likely to utilize health services (Ma et al., 2005; Simpson et al., 2004). This study did not find any significant difference between races or ethnicities, but that is likely due to the lack of variability in the sample $(\mathrm{n}=26)$.

Family structure. Family structure influences utilization of health services among adolescents. In this study, most adolescents reported living in a two-parent home with at least one of their biological parents, which was also supported by county level data. Other studies of adolescent health services utilization have demonstrated that HCP visits tend to decrease across family structure, with the two-parent family having the highest rates (Probst et al., 2005), followed by the single-mother family, then the single-father family (Gorman \& Braverman, 2008; Leininger \& Ziol-Guest, 2008). In this study, families including the biological mother made significantly fewest ER visits compared to families not including the biological mother. Father in the family did not have a significant influence on utilization of health services.. The lack of differences between family 
structure groups in health services utilization may be related to the avoidance of health services utilization by rural people (Weinert \& Long, 1989; Winters \& Lee, 2004).

Health insurance. Having health insurance is the factor most likely to provide access to health services among most Americans (Institute of Medicine, 2004). More than a third of participants in this study reported not knowing what kind of health insurance they had. Among the participants in this study reporting knowledge of their health insurance status, this sample of adolescents included a smaller proportion of privately insured individuals, a greater proportion of publicly insured individuals, and fewer reporting no insurance than compared to the county overall-likely due to increased Medicaid coverage of minors because children are eligible for the Child Health Insurance Program (CHIP). An evaluation of HCP office visits among adolescents demonstrates that the privately insured adolescents received the most HCP visits, followed by the publicly insured, with uninsured adolescents being least likely to receive a HCP visit (Simpson, 2004). In this study, no difference was seen in number of HCP visits or ER visits according to insurance type. Another consideration is that most of the 9 th graders in this study were unaware of their insurance status and therefore, evaluations could not be made for them.

Household income. Lack of financial resources and underserved populations are both common themes in health services research. Participation in the National School Lunch Program (NSLP) was used as a proxy measure for household income in this study. In this sample, $36.6 \%$ of participants reported free or reduced lunch status, which was similar to the figure $(36.4 \%)$ provided by school administrators reflecting the NSLP participation rate of the entire 9th and 12th grades (personal communication, J. Martin, 
June 4, 2014). Alternatively, the overall county participation rate in the NLSP was higher (43\%) than indicated with this sample and national participation rates were much higher (70\%) than indicated with this sample. School administrators mentioned that many parents do not apply for the program and that it is likely that many eligible students do not receive benefits (personal communication, J. Martin, June 4, 2014). The reluctance of rural dwellers to accept public assistance (Lee \& Winters, 2004; Long \& Weinert, 1989) was demonstrated in both the low NSLP participation rates found among this study's participants and across the county overall. Other studies have found that children in lowincome families are less likely to receive HCP visits and ER visits (Probst et al., 2005; Simpson et al., 2005; Simpson et al., 2004). In this study, a significant negative relationship existed with number of ER visits between participation and non-participation in the NSLP, but no significant differences in number of HCP visits were found between NSLP groups. It was possible that the non-significant difference in number of HCP visits was related to non-participation of eligible households, resulting in incorrect household income group assignment. Since rural people (Weinert \& Long, 1988) are known to avoid the use of social services, NSLP participation may not be an appropriate proxy measure of household income with adolescents living in a rural area.

Transportation. Transportation barriers are frequently reported in health services literature. Rural areas are defined by a small population in a broad geographic area (Klugman, 2008b), which results in more transportation barriers since distances are greater and rural areas typically lack public transportation. Overall, more than $80 \%$ of the adolescents that reported transportation difficulty also reported they relied on others for transportation to appointments. Among those participants who reported foregone care, 
$8.82 \%$ reported transportation as a barrier to HCP visits—all of whom reported relying others for transportation to appointments. These results were similar to a study of foregone mental health services among adolescents in rural Minnesota $(n=497)$, in which $7.8 \%$ of those reporting foregone care also reported transportation difficulty as a barrier to utilization of health services (Samargia et al., 2006). Most of the participants who reported transportation difficulty rely on others for transportation to appointments. However, the high school in this study was located directly next door to the local hospital with a HCP office complex —including a pediatrician, two family providers, and two internal medicine providers - across the street. Although several HCP offices are within a short walking distance of the school, adolescents continued to report transportation difficulties. This suggests that transportation difficulties may be related to age, driver's licensure, and independent transportation to and from school.

Usual source of care. Most adolescents in this study reported having a usual source of care (USOC), but the proportion remained below national rates of USOC. A USOC means that an individual identifies a particular HCP or clinic as the typical supplier of health services when needed and recent evidence has indicated that having a USOC is as important as having health insurance when measuring minors' access to health care (DeVoe, Tillostson, Wallace, Lesko, \& Angier, 2012). In this study, 81.7\% of adolescents reported having a USOC, which was similar to other studies of USOC reported by underserved adolescents. For example, $80 \%$ of minority adolescent females in New York (McKee \& Fletcher, 2006) and $81 \%$ of adolescent CHIP recipients in Florida and New York reported a USOC (Klein et al., 2006). In comparison, a large national sample of adolescents in general reported $92.8 \%$ had a USOC (Adams, et al., 
2013). These results support other studies that indicate underserved adolescents were somewhat less likely to have a USOC.

Self-rated health. Results of this study supported previous research concerning adolescent self-rated health. Self-rated health is a global measure of wellness, which has been shown to be a valid and stable measurement of health among adolescents (Fosse \& Haas, 2009). More than a third of participants (34.8\%) in this study reported excellent health, which was higher than found with a large national sample in the Youth Risk Behavior Surveillance (15.5\%) (Foti \& Eaton, 2010). This sample also reported a much higher number of HCP diagnosed health conditions than typically found in adolescent populations - the combination of which seems puzzling. However, other studies have indicated that adolescents consider physical health, mental health, social functioning, personal factors, and environmental factors when determining self-rated health (Foti \& Eaton, 2010). In this study, $13.8 \%$ of adolescents reported fair or poor health, which was less than the county's adults, of whom $21.2 \%$ reported fair or poor health. This difference is likely related to the participants' young age. With this sample, self-rated health had a significant negative relationship with having a HCP diagnosed condition, which means that poorer health was associated with having at least one HCP-diagnosed condition. In other studies, fair or poor self-rated health has been associated with increased rates of chronic health conditions such as asthma, diabetes, overweight, and obesity (Fosse \& Haas, 2009), as well as increased rates of health services utilization (Bradford, 2007). In this study, fair or poor self-rated health was also positively associated with diabetes, overweight, and obesity, in addition to depression and hypertension. Furthermore, reporting poor health was a predictor of number of HCP visits in this study. 
Foregone care. Foregone care is not seeking health services when there was a subjective need for health services (Rew et al., 1999). The item used to measure foregone care in this study also seeks to describe barriers to utilization of health services. In this study, $17.4 \%$ of adolescents reported foregone care in the past 12 months. Other studies have reported higher levels of foregone care: $28.9 \%$ among Hispanic adolescents in Connecticut (Rew, 1999), 37\% at a school-based health center in rural Mississippi (Bradford, 2006), and 34.3\% among urban minority females in New York (McKee \& Fletcher, 2006). The most common reasons cited explaining foregone care in this study were: (1) thought my problem would go away, (2) couldn't pay, (3) parent would not go, (4) afraid of what the doctor might say or do. Other studies of foregone care among adolescents have reported similar reasons for foregone care (Bradford \& O'Sullivan, 2006; Elliott \& Larson, 2004; McKee \& Fletcher, 2006; Rew et al., 1999). For example, Elliott and Larson (2004) found that female sex was positively associated with not wanting parents to know about HCP visit as a reason for foregone care. In this study, no significant association was found between sex and not wanting parents to know, because a minimum of five responses was necessary to complete chi square analysis. However, only females $(n=4)$ chose not wanting parents to know about HCP visit as reason for foregone care. The results of this study seem to support the work of other studies concerning foregone care. The comparatively low rate of foregone care may be related to adolescent's (Rew, 2007) and rural dweller's (Lee \& Winters, 2004; Long \& Weinert, 1989) reliance on informal sources of health care information — such as the internet or a knowledgeable friend or family member-for the treatment of health concerns, especially since adults in this county reported similar rates of foregone care (20\%). 
Diagnosed conditions. Adolescents living in rural areas report HCP-diagnosed conditions at higher rates than do adolescents in urban and national studies (Adams et al., 2013; Elliott, 2004; Fosse \& Haas, 2009; Klein et al., 2006; Youngblade, 2006). With self-reported surveys, evaluated need has typically been determined by reported HCP diagnosed conditions. This study assessed for the following HCP diagnosed conditions: acne, allergies, ADHD, anemia, asthma, depression, diabetes, high blood pressure, overweight, and obesity, because these diagnoses are commonly found among adolescents (Fosse \& Haas, 2009). In this study, 60.7\% of participants reported having at least one HCP diagnosed condition — which is greater than has been found in other studies. The most common HCP diagnosed conditions in this study were allergies (39.3\%), acne (19.6\%), asthma (15.6\%), and overweight/obesity (15.5\%). A nationwide study evaluating data from 2007 found that $19 \%$ of adolescents reported a HCP diagnosed condition (Adams et al., 2013), while adolescents in Florida (12.2\%) and New York (17.7\%) (Klein et al., 2006) reported fewer HCP diagnosed conditions. One study of adolescents living in rural Missouri reported $43 \%$ had a HCP diagnosed condition (Elliott \& Larson, 2004). The rate of diagnosed health conditions in this sample is concerning. As indicated in the contextual characteristics described in Chapter 3, the rural area under study has water quality and air quality concerns, in addition to a high smoking prevalence, which may contribute to the high levels of allergies and asthma reported in this study. The drinking water contaminants identified in the Municipal Water Report (2013) have known associations with asthma and atopic dermatitis (Richardson et al., 2010), both of which are associated with allergies. In addition, adolescents living in rural areas have greater problems with overweight, obesity, and respiratory problems than 
urban adolescents (Curtis et al., 2011; Lutfiyya et al., 2007). Results of this study support previous work reporting high rates of diagnosed health conditions among adolescents living in a rural area.

Trust of health care provider. This was the first study to measure trust of HCP among adolescents using a valid and reliable instrument. In this study, trust of HCP was defined as a patient's accepted vulnerability to the HCP's possible but not expected ill will, made up of four overlapping domains: fidelity, competence, honesty, and global trust (Hall et al., 2002). Among five previous quantitative studies, trust of HCP was measured among adolescents using one or two investigator-developed survey items (Chandra, 2006; Cheng, 1993; Farrant \& Wilson, 2004; McKee, O’Sullivan, \& Weber, 2006; Ingram \& Salmon, 2007). In this study, use of the Wake Forest Trust in Physician Scale allowed a quantitative measurement of trust of HCP that can be compared to other studies. With this sample, the mean trust of HCP score $(\mathrm{M}=38.7)$ was lower than found within a national sample of diverse American adults not defined by residential area $(\mathrm{M}=$ 40.8) (Hall, 2002), but higher than found with a sample of low-income African-American parents of small children $(\mathrm{M}=36.5, \mathrm{SD}=3.4$ ) (Horn, Mitchell, Wang, Joseph, \& Wissow, 2012). In addition, this study found a significant relationship between trust of HCP among adolescents living in a two-parent household and living with either their biological father or step-father, suggesting that adolescents living with a consistent male role model report greater trust of HCP. Since trust of HCP has never been measured among adolescents with a psychometrically sound instrument, this relationship had not been demonstrated previously. There were no significant differences in trust of HCP by mother in the family structure. There is evidence that adolescents living in a family 
structure with either a father or stepfather benefit from improved household income, family stability, supervision, and role modeling as compared to other family structures (Sweeney, 2007) — which may influence trust of HCP — but in this study, trust of HCP was not associated with household income. Perhaps an additional benefit adolescents receive from living with either their fathers or stepfathers is developing trusting relationships with a HCP. Future research should explore the relationship between father in the family structure and trust of HCP.

Lifestyle behaviors. The participants in this study reported low rates of healthy lifestyle behaviors. Lifestyle behaviors are a multidimensional pattern of discretionary activities and perceptions that significantly affect health status and make up one's daily approach to living (Gillis, 1997). Lifestyle behaviors were measured with the ALQ, which contained seven subscales: identity awareness, nutrition, physical participation, safety, social support, health awareness, and stress management (Gillis, 1997). Higher total scores suggest higher levels of healthy lifestyle behavior. In this study, the mean total ALQ score was $156.54(\mathrm{SD}=24.32)$, which was lower-indicating poorer lifestyle behaviors - than found among a diverse group $(\mathrm{N}=28)$ of older adolescents ages $18-21$ at a university in the American Southwest $(\mathrm{M}=186.06, \mathrm{SD}=27.56)(\mathrm{Rew}$, Wong, Torres, \& Howell, 2007). A significant negative relationship was demonstrated in this study between age and lifestyle behavior, suggesting that younger age is associated with healthier lifestyle behavior. Overall, the middle to late adolescents in this study reported less healthy lifestyle behaviors than the late adolescents living in urban Texas (Rew, et al., 2007). These results in combination with previous results (Rew, et al., 2007), suggest that healthy lifestyle behaviors may be lowest at approximately ages 17-19. Steinberg 
posits that high-risk reward-seeking behavior associated with normal cognitive development peaks around age 15 and declines with further cognitive development that improves adolescents' self-regulation abilities (Steinberg, 2010). The lowest point of healthy lifestyle behaviors measured with this sample occurred around ages 17-19, which may be related to the independence that accompanies driver's licensure and the use of products that require legal adult status to purchase, such as tobacco, cough medicine, energy drinks, and fireworks. In addition, adolescents living with their biological mothers reported healthier lifestyle behaviors compared to family structures without the biological mother present. Previous work (Rew, Arheart, Thompson, \& Johnson, 2011) had demonstrated that parental monitoring has a positive association with lifestyle behaviors among adolescents.

HCP visits. The adolescents in this sample demonstrated less utilization of health services when compared to national samples of adolescents, not defined by residential area. In 2001, according to a secondary analysis of the Medical Expenditure Survey, adolescents ages 15-17 made nearly five HCP visits annually $(\mathrm{M}=4.7)$ (Simpson et al., 2005). According to a study analyzing National Health Interview Survey data (Mulye et al., 2009), in $200684.2 \%$ of adolescents ages 10-17 had at least one HCP visit in the past year. With this sample of rural dwelling adolescents, the mean number of HCP visits in the past 12 months was $3.04(\mathrm{SD}=3.05)$, with $81.3 \%$ of participants having had at least one HCP visit in the past 12 months. In this study, participants received 1.66 fewer HCP visits per adolescent annually than national figures. Although the proportion of adolescents receiving at least one HCP visit annually was similar, this study found fewer mean HCP visits than the most recent national data. People living in rural areas avoid the 
utilization of health services (Spleen et al., 2014) and the sample in this study was consistent with this pattern. It seems unlikely that adolescents living in a rural area would have less need for HCP visit than urban adolescents—especially considering the high rates of HCP diagnosed conditions reported by this sample. Perhaps this sample of adolescents receive informal means of health care information common among people living in rural areas (Lee \& Winters, 2004; Long \& Weinert, 1989), such as from a knowledgeable and trusted family member or friend or the internet.

$\boldsymbol{E} \boldsymbol{R}$ visits. Utilization of the emergency room tends to increase during adolescence, due to risk-taking behaviors that result in unintentional injuries. In 2001, according to a secondary analysis of the Medical Expenditure Survey, the mean number of ER visits per year for adolescents age 15-17 was 1.4 ER visits (Simpson et al., 2005). In 2006, $17.5 \%$ of adolescents ages 10-17 used the emergency room at least once (Mulye et al., 2009). In this study, the mean number of ER visits in the past 12 months was 0.79 $(\mathrm{SD}=1.39)$, with $38.4 \%$ of participants having made at least one ER visit in the past 12 months. This study found fewer mean ER visits in the past 12 months than the most recent national data, but a greater proportion using the ER at least once. Once again, these results support previous research that has reported rural residence as a risk factor for avoidance of health services (Spleen et al., 2014).

\section{Predictive Models}

The significant findings in this study included both correlations and predictive regression models. This study found significant results for all four research questions. A discussion of the results from the predictive models is presented here. 
Research question 2. Which variables in the model were predictive of trust of HCP among adolescents attending a public high school in a rural area?

Predictors of trust of HCP among adolescents living in a rural area were modeled according to ABM. In the final model, three of the four steps were significant, suggesting that $\mathrm{ABM}$ is moderately useful for predicting trust of $\mathrm{HCP}$ among rural adolescents, but needs additional testing. Significant predictors of trust of HCP among this sample of adolescents include usual source of care (USOC), health insurance, lifestyle behavior, and transportation difficulty. In this study, having Medicaid insurance and having transportation difficulty resulted in lower levels of trust of $\mathrm{HCP}$, while having a $\mathrm{HCP}$ as a usual source of care and engaging in healthier lifestyle behaviors predicted higher trust of HCP.

The most significant positive predictor of trust of $\mathrm{HCP}$ was having a HCP as the usual source of care. Having a HCP as the USOC reflects continuity of care and an opportunity to develop a relationship with a HCP. Continuity of care from the patient perspective is the experience of a continuous caring relationship with an individual HCP (Gulliford, Naithani, \& Morgan, 2006). Trust of HCP has been demonstrated as developing as a result of continuity with a HCP, among both adults (Horn et al., 2012) and adolescents (van Staa, Jedeloo, \& van der Stege, 2011). These results suggest that having a HCP as the USOC allows for continuity of care and the development of a trusting relationship with a HCP. Rural people are more likely to accept health care from a HCP that is an insider - or long-standing member of the rural community (Weinert \& Long, 1989). In addition, rural-dwellers use five criteria to choose a HCP (distance, road conditions, perceived quality of care, familiarity with $\mathrm{HCP}$, and availability of family and 
friends near the HCP's office) (Winters \& Lee, 2004). Familiarity with the HCP is similar to both of the concepts of insider and USOC. Rural individuals may be more likely identify a HCP as the USOC and develop a trusting relationship with the HCP when the $\mathrm{HCP}$ is an insider to the rural community.

Another significant predictor of trust of HCP was having Medicaid health insurance. The relationship between Medicaid and trust of health care provider may be related to household income and lack of choice in HCP. As discussed above, participation in the NSLP was not an effective measure of household income since many eligible families did not participate. Medicaid is also a low-income program and may be a better indicator of household income for this population. A study measuring trust of physician among low-income individuals indicated that low-income individuals were more likely to perceive they were being discriminated against and have lower trust of physicians (Born et al., 2009). Other studies have also found a significant relationship between patients' choice of HCP on trust of HCP (Chu-Weininger \& Balkrishnan, 2006; Kao, Green, Davis, Koplan, \& Cleary, 1998). Without choice of HCP, individuals likely feel trapped in the relationship with the HCP. Medicaid typically has limited HCP provider choices for the purpose of cost containment. The Indiana Medicaid website encourages participants to choose their Medicaid plan based on which plan their existing HCP participates in, because choice of HCP was severely limited within each plan (Indiana Family and Social Services, 2014). The effect of Medicaid health insurance on trust of HCP was likely related to household income and choice of HCP.

The predictive relationship between healthy lifestyle behaviors and trust of $\mathrm{HCP}$ in this study was likely a combination of factors. As discussed previously, a number of 
qualitative studies have reported that adolescents distrust HCP when accessing health services for risk behavior (Breland-Noble, Burriss, \& Poole, 2010; Klostermann, Slap, Nebrig, Tivorsak, \& Britto, 2005; Leavey, Rothi, \& Paul, 2011; Renker, 2006; Tinnafalt, Eriksson, \& Brunnberg, 2011). Risk behaviors were indirectly measured in this study as the lower scores on the Adolescent Lifestyle Questionnaire when assessing lifestyle behavior. A systematic review of 52 papers described having a USOC with a trusted HCP as a facilitator of healthy lifestyle behavior (Dennis et al., 2012). Both healthy lifestyle behaviors and trust of $\mathrm{HCP}$ were associated with many factors such as female sex, household income, higher education, and better physical and mental health (Ahnquist, Wamala, \& Lindström, 2010). In addition, evidence demonstrates that HCPs that have the skills necessary to build a trusting relationship with an adolescent patient could also provide more effective assessment and counseling concerning lifestyle behaviors. A study measuring alcohol treatment for rural adolescents found that HCPs that make an effort to develop a trusting relationship with the adolescent could more effectively assess for alcohol abuse and provide counseling concerning healthy lifestyle behaviors (Gordon, Ettaro, Rodriguez, Mocik, \& Clark, 2011). A combination of individual characteristics and HCP qualities may result in healthier lifestyle behaviors among adolescents.

Transportation difficulty also predicted trust of HCP among this sample of rural dwelling adolescents. Another study has also reported a relationship between transportation difficulty and lower levels of trust of HCP (Shoff and Yang, 2012). Individuals with transportation difficulty tend to be marginalized and marginalized populations often demonstrate lower levels of trust of HCP. 
Research question 3. Which variables in the model were predictive of lifestyle behaviors among adolescents attending a public high school in a rural area? Predictors of lifestyle behaviors among adolescents living in a rural area were modeled according to ABM. The significance of the first three theory-based levels of the model suggests ABM was a moderately useful foundation for conceptualizing lifestyle behaviors, but needs additional testing. Significant predictors of lifestyle behaviors among this sample of adolescents include self-rated health, age, trust of HCP, and sex. In this study, reporting excellent or very good health, reporting higher levels of trust of HCP, younger age, higher levels of trust of HCP, and female sex predicted higher levels of healthy lifestyle behaviors. Each predictive variable was described below.

This study identified self-rated health as a predictor of lifestyle behaviors. It seems logical that self-rated health would predict lifestyle behaviors. In a secondary data analysis of YRBS data, Foti \& Eaton found that various lifestyle behaviors such as nutrition, physical activity have a positive relationship with self-rated health, while risk behaviors such as tobacco use, alcohol use, and violence have an inverse relationship with self-rated health among adolescents (2010). Similar results were found with this sample.

After identifying lifestyle behaviors as a predictor of trust of HCP, it was not surprising to find trust of $\mathrm{HCP}$ was a predictor of lifestyle behaviors. Other studies have used the ALQ to measure lifestyle behaviors and found lifestyle behaviors were predicted by other pro-social variables such as social connectedness (Rew et al., 2013) and religious commitment (Rew et al., 2007). Rew and others (2007) suggest that adolescents with strong social bonds— such as those trusting their $\mathrm{HCP}$ — may also engage in healthy 
lifestyle behaviors because they feel a sense of responsibility to others and to following pro-social guidelines.

Sex and age have known associations with lifestyle behaviors. Among adolescents, females were less likely to engage in risk behaviors and more likely to engage in healthy lifestyle behaviors (Centers for Disease Control and Prevention, 2012; Mattila et al., 2008; Steinberg, 2010a). Adolescent risk behavior typically peaks around mid-adolescence at age 15, then decreases over time (Steinberg, 2010b). Adolescents tend to maintain lower levels of healthy lifestyle behaviors through age 18 (Centers for Disease Control and Prevention, 2013), likely related to the greater independence resulting from driver's licensure and availability of controlled products such as cigarettes at age 18 .

Research question 4a. Which variables in the model were predictive of number of HCP visits within the past 12 months among adolescents attending a public high school in a rural area? Predictors of the number of HCP visits in the past 12 months among adolescents living in a rural area were modeled according to ABM. Significant predictors of HCP visits among this sample of adolescents included sex, household income, self-rated health, self-perceived need, health insurance, and number of ER visits. In this study, neither trust of HCP or lifestyle behaviors were a significant predictor of number of HCP visits. Previous research has shown that females tend to utilization more health services than males, and that household income and health insurance predict the financial access to health services (Berdahl et al., 2013; Blackwell et al., 2009; Hoover et al., 2010; Probst et al., 2005; Simpson et al., 2005; Simpson et al., 2004). Self-rated health and self-perceived need were subjective indicators of health, which also have 
known associations to health service utilization (Fosse \& Haas, 2009; Foti \& Eaton, 2010; Klein et al., 2006). Number of ER visits was also a logical predictor of HCP visits, since utilization of the ER suggests a serious health condition requiring ongoing treatment and patients were instructed to follow up with their HCP after discharge from the ER.

Research question $4 \mathrm{~b}$. Which variables in the model were predictive of number of ER visits within the past 12 months among adolescents attending a public high school in a rural area? Predictors of the number of HCP visits in the past 12 months among adolescents living in a rural area were modeled according to ABM. Significant predictors of ER visits among this sample of adolescents include household income and number of HCP visits. In this study, low household income resulted in a 3.3 times increased risk of using the ER. Lack of socioeconomic resources may result in care delayed until the health condition becomes urgent or unbearable (Roos, Walld, Uhanova, \& Bond, 2005). In addition, people living in rural areas are known to avoid health service utilization (Spleen et al., 2014), often resulting in urgent conditions that require more aggressive treatment than if it had been treated earlier in an outpatient setting (Laditka et al., 2009). The relationship between ER visits and HCP visits is a logical one, since utilization of the ER suggests a serious health condition requiring ongoing treatment and patients are usually instructed to follow up with their HCP after discharge from the ER. However, the small relationship $(\mathrm{RR}=1.06)$ seen with this sample may not be clinically significant.

\section{Limitations}

This study characterizes important mechanisms in the relationship between individual characteristics, trust of HCP, lifestyle behaviors, and health services use. 
However, there were multiple limitations in the research design and methods used in this study to be acknowledged and discussed. These limitations included a relatively small, non-random sample, cross-sectional study design, a homogenous group of research participants, self-report data, and the influence of health policy changes related to the recent implementation of the Affordable Care Act.

The small, non-random, mostly White, non-Hispanic convenience sample may limit the generalizability of study findings. To offset these limitations, the principal investigator offered participation to all adolescents in the $9^{\text {th }}$ and $12^{\text {th }}$ grades by collecting data in required courses — that enrolls all students within the given grade — to provide a sample similar to the community from which it was drawn. While the sample was representative of the population from which it was drawn, the population was homogenous. Future research efforts should involve a national, multi-site, rural school study to improve understanding of individual characteristics, trust of HCP, lifestyle behaviors, and utilization of health services across the United States.

Disadvantages of cross-sectional study are risk for recall bias, confounding variables that are unequally distributed, and inability to determine causation. In addition, many individual characteristic variables were unequally distributed, with unequal group sizes resulting in difficulty comparing groups. The cross-sectional nature of this study prevents causal inferences between the variables. In order to make causal inferences in a study, a temporal, empirical relationship between variables (Polit \& Beck, 2008) must be established which could be accomplished with a longitudinal study.

Self-report measures are at risk for both recall bias and social desirability bias. When comparing self-reported HCP visits across six months, medical record reviews 
demonstrate that adults tend to underestimate the number of $\mathrm{HCP}$ visits by one, although number of ER visits were accurate (Ritter et al., 2001). The magnitude of the difference between reported health service utilization and actual utilization among adolescents in this study is unknown. In this study, many $9^{\text {th }}$ graders were unaware of their health insurance status, which led to a large quantity of missing data and limited use of the health insurance variable. A previous study has indicated that approximately half of adolescents are unaware of their health insurance status and knowledge of health insurance status is positively associated with age (Robertson, et al., 1998). Future studies could include parents for improved recall of information, or data could be obtained from a medical record review in addition to self-report. In addition, the risk for social desirable responses was also a factor, since the topics under study included risk behaviors and beliefs about an authority figure, which may present confidentiality and anonymity concerns. The principal investigator made efforts to relieve concerns about confidentiality and anonymity with the informed consent process by verbally explaining that no personally identifying information was being collected from the participants, that all data collected was anonymous and confidential, and directing the classroom instructors to refrain from pacing the room or positioning themselves in view of participant surveys. Finally, the influence of health policy changes on participants' health insurance status and utilization of health services related to the implementation of the Patient Protection and Affordable Care Act (2010) are unknown. The implementation of the Affordable Care Act created a health insurance mandate beginning March 2014. The data in this study were collected in May 2014; therefore, it is likely that some participants may have had changes in their health insurance status, which may have in turn influenced 
health services utilization. Future studies could include a retrospective data collection from parents of adolescents or from medical records, in order to provide concerning health insurance status changes and its effect on health services utilization.

\section{Conclusions}

This study used Andersen's Behavioral Model of Health Service Use to examine individual characteristic variables among adolescents' and determine the extent to which these variables influence trust of health care provider, lifestyle behaviors, and utilization of health services among adolescents attending public high school in rural Indiana. With this sample, $27 \%$ of the variance in trust of $\mathrm{HCP}$ was predicted by having a $\mathrm{HCP}$ as a usual source of care, having health insurance, healthier lifestyle behaviors, and little to no difficulty with transportation. Higher self-rated health, younger age, higher levels of trust of $\mathrm{HCP}$, and female sex predicted $34 \%$ of the variance in lifestyle behaviors. Number of HCP visits in the past 12 months was predicted by female sex, higher household income, excellent or very good self-rated health, self-perceived need, having health insurance, and number of ER visits in the past 12 months. Finally, number of ER visits was predicted by low household income and number of HCP visits in the past 12 months. Another important finding in this study was that adolescents attending public school in this rural area had higher prevalence of asthma, overweight, and obesity, but lower rates of health service utilization than adolescents in general across the United States.

\section{Implications}

Having a $\mathrm{HCP}$ as a usual source of care must become a priority for rural dwelling adolescents. Having a HCP as the USOC allows for continuity of care and the development of a trusting relationship with the HCP. Recent evidence indicates that 
having a $\mathrm{HCP}$ as the USOC is as important as having health insurance when measuring minors' access to health care (DeVoe, et al., 2012). Since Medicaid health insurance limits choice of provider, Medicaid caseworkers should be trained to encourage enrollees to choose a health plan that includes coverage of the participants USOC HCP. This study demonstrated that having a trusting relationship with a USOC HCP predicts improved healthy lifestyle behaviors. Perhaps with improved rates of HCP as USOC, especially among Medicaid recipients, some of the negative health effects associated with low socioeconomic status — such as risky lifestyle behaviors and reliance on the emergency room for ambulatory sensitive conditions_ — could be mediated.

In addition, the results of this study demonstrate the need for school-based health services among adolescents attending rural high schools. Access to health services was shown to be a concern in this sample, with approximately one-fifth of the sample without a $\mathrm{HCP}$ as a usual source of care and more than $12 \%$ reporting some level of transportation difficulty. A school-based health clinic (SBHC) resolves many barriers to utilization of health services among adolescents (Guo, Wade, Pan, \& Keller, 2010; Wade \& Guo, 2010). SBHCs provide comprehensive medical and mental health treatment for adolescents at their schools. SBHCs are designed to overcome barriers that inhibit young people from getting needed health care, including lack of confidentiality or fear that confidentiality will not be maintained, transportation issues, fear that parents will be notified by insurer, inconvenient appointment times, costs, and anxiety about discussing personal health problems (Schlitt, Juszczak, \& Eichner, 2008). 


\section{Recommendations for Future Research}

This study utilized a valid and reliable instrument to quantify trust of HCP among adolescents where others have not. Several studies have focused on qualitative measurement of trust of HCP (Breland-Noble, Burriss, \& Poole, 2010; Cogswell, 1985; Klostermann, Slap, Nebrig, Tivorsak, \& Britto, 2005; Leavey, Rothi, \& Paul, 2011; Renker, 2006; Tinnfault, Eriksson, \& Brunnberg, 2011) and a few studies have attempted to measure trust of $\mathrm{HCP}$ with one or two investigator-developed questions (Ingram \& Salmon, 2007; McKee, O'Sullivan, Weber, 2006). Future studies should use the Wake Forest Interpersonal Trust in Physician Scale among diverse adolescent populations to compare and contrast the results between samples and further support the validity and reliability of the instrument.

This study found a significant relationship between trust of HCP between adolescents living with their biological father or stepfather and adolescents in other family structures. The relationship between trust of HCP and family structure has not been demonstrated previously. Adolescents living in a family structure with either a father or stepfather are known to benefit from improved household income, family stability, supervision, and role modeling as compared to other family structures (Sweeney, 2007). While this study found that two-parent families are associated with higher incomes, there was no association between household income and trust of HCP. Future research should explore the relationship between family structure and trust of HCP.

This instrument used in this study to measure trust of HCP excluded the concept of confidentiality. Previous qualitative research concerning adolescents' trust of HCP 
frequently mentions trust in healthcare provider's reliable protection of confidentiality and the issue of confidentiality was frequently included in theoretical models, conceptual analyses, and instruments measuring trust of HCP. In order to disentangle these interrelated concepts, trust was measured in this study using an instrument (Hall et al., 2002) that did not include items related to confidentiality. Future research should focus on measuring trust in HCP's reliable protection of confidentiality among rural dwelling adolescents.

The beliefs subsection of the ABM could include a variety of health beliefs relevant to adolescents living in rural areas. There is evidence (Marcell \& HalpernFelsher, 2005) that adolescents struggle to identify conditions necessitating a HCP's assistance, such as sexual activity or tobacco cessation. Measuring adolescents' health beliefs concerning intentions to seek care may help to explain health services utilization.

It has been suggested that both adolescents (Rew et al., 1999) and rural people (Lee \& Winters, 2004; Long \& Weinert, 1989) use informal resources for health care information rather than utilizing health services. Since this study found fewer mean HCP visits per adolescent than the most recent national data and considering the high rates of HCP diagnosed conditions reported by this sample, it seems likely that this sample of adolescents may have received informal means of health information, such as from the internet or from a knowledgeable and trusted family member or friend. This study did not address informal sources of health information, but informal sources of health information among adolescents living in a rural area should be investigated in future. 


\section{Summary}

This study used Andersen's Behavioral Model of Health Service Use to examine individual characteristic variables among adolescents' and determine the extent to which these variables influence trust of health care provider, lifestyle behaviors, and utilization of health services among adolescents attending public high school in rural Indiana. Multiple significant associations were found between individual characteristics and the dependent variables trust of $\mathrm{HCP}$, lifestyle behaviors, number of $\mathrm{HCP}$ visits, and number ER visits. Models predicted $27 \%$ of the variance in trust of $\mathrm{HCP}$ and $34 \%$ of the variance in lifestyle behaviors. Individual characteristics were predictors of number of HCP visits and ER visits among adolescent living in a rural area. Contextual characteristics specific to this rural area and individual characteristics of this sample helped to explain these results. Another important finding was that adolescents living in this rural area had higher prevalence of asthma, overweight, and obesity, but lower rates of health service utilization. Approximately $22 \%$ of American adolescents live in rural areas. With such a large portion of the adolescent population at risk for poor outcomes, it is imperative that the research community place greater attention on the health of rural dwelling adolescents. 


\section{REFERENCES}

Adams, S. H., Newacheck, P. W., Park, M. J., Brindis, C. D., \& Irwin, C. E., Jr. (2013). Medical home for adolescents: Low attainment rates for those with mental health problems and other vulnerable groups. Academic Pediatrics, 13(2), 113-121. doi: 10.1016/j.acap.2012.11.004

Aday, L., \& Andersen, R. M. (1974). A framework for the study of access to medical care. Health Services Research, 9(3), 208-220.

Aday, L., Begley, C. E., Lairson, D. R., \& Balkrishnan, R. (2004). Evaluating the healthcare system: Effectiveness, efficiency, and equity (3rd ed.). Chicago: Health Administration Press.

Aday, L., Quill, B. E., \& Reyes-Gibby, C. C. (2010). Equity in rural health and health care. In S. Loue \& B. E. Quill (Eds.), Handbook of rural health (pp. 45-72). New York: Kluwer Academic/Plenum Publishing.

Afilalo, J., Marinovich, A., Afilalo, M., Colacone, A., Leger, R., Unger, B., \& Giguere, C. (2004). Nonurgent emergency department patient characteristics and barriers to primary care. Academic Emergency Medicine, 11(12), 1302-1310. doi: 10.1197/j.aem.2004.08.032

Agency for Healthcare Research and Quality. (2012). 2012 National healthcare disparities report. Agency for Healthcare Research and Quality. Washington, DC. 
Ahnquist, J., Wamala, S. P., \& Lindström, M. (2010). What has trust in the health-care system got to do with psychological distress? Analyses from the national Swedish survey of public health. International Journal for Quality in Health Care, 22(4), 250-258. doi: 10.1093/intqhe/mzq024

Akinbami, L. J., Gandhi, H., \& Cheng, T. L. (2003). Availability of adolescent health services and confidentiality in primary care practices. Pediatrics, 111(2), 394401.

American Psychological Association. (2000). Diagnostic and statistical manual (IV Text Revision ed.). Arlington, VA: American Psychological Association.

Andersen, R. M. (1968). Families' use of health services: A behavioral model of predisposing, enabling, and need Components. Dissertation, Purdue University, West Lafayette, IN. Retrieved from http://docs.lib.purdue.edu/dissertations/AAI6902884/

Andersen, R. M. (1995). Revisiting the Behavioral Model and access to medical care: Does it matter? Journal of Health and Social Behavior, 36(1), 1-10. doi: $10.2307 / 2137284$

Andersen, R. M. (2008). National health surveys and the behavioral model of health services use. Medical Care, 46(7), 647-653. doi:

10.1097/MLR.0b013e31817a835d

Andersen, R. M., Davidson, P. L., \& Ganz, P. A. (1994). Symbiotic relationships of quality of life, health services research, and other health research. Quality of Life Research, 3(5), 365-371. 
Andersen, R. M., \& Newman, J. F. (2005). Societal and individual determinants of medial care utilization in the United States. The Milbank Quarterly, 83(4), 1-28.

Andersen, R. M., Rice, T. H., \& Kominski, G. F. (2007). Changing the U.S. health care system: Key issues in health services policy and management. Hoboken, NJ: John Wiley \& Sons.

Andersen, R. M., Yu, H., Wyn, R., Davidson, P. L., Brown, E. R., \& Teleki, S. (2002). Access to medical care for low-income persons: How do communities make a difference? Medical Care Research and Review, 59(4), 384-411.

Anderson, L. A., \& Dedrick, R. F. (1990). Development of the Trust in Physician scale: A measure to assess interpersonal trust in patient-physician relationships. Psychological Reports, 67(3), 1091-1100.

Arcury, T. A., Preisser, J. S., Gesler, W. M., \& Powers, J. M. (2005). Access to transportation and health care utilization in a rural region. The Journal of Rural Health, 21(1), 31-38. doi: 10.1111/j.1748-0361.2005.tb00059.x

Armstrong, K., Ravenell, K. L., McMurphy, S., \& Putt, M. (2007). Racial/ethnic differences in physician distrust in the United States. American Journal of Public Health, 97(7), 1283-1289. doi: 10.2105/AJPH.2005.080762

Atav, S. \& Spencer, G. A. (2002). Health risk behaviors among adolescents attending rural, suburban, and urban schools: A comparative study. Family \& Community Health, 25(2), 53-64.

Atkins, D. C., \& Gallop, R. J. (2007). Rethinking how family researchers model infrequent outcomes: A tutorial on count regression and zero-inflated models. Journal of Family Psychology, 21(4), 726-735. doi: 10.1037/0893-3200.21.4.726 
Babitsch, B., Gohl, D., \& von Lengerke, T. (2012). Re-visiting Andersen's behavioral model of health services use: A systematic review of studies from 1998-2011. Psychosocial Medicine, 9, 1-15. doi: 10.3205/psm000089

Baier, A. (1986). Trust and antitrust. Ethics, 96(2), 231-260.

The Balanced Budget Act. Title XXI: The State Childrens Health Insurance Program, Pub. L. No. 105-33 (1997).

Bennett, K. J., Olatosi, B., \& Probst, J. C. (2008). Health disparities: A rural-urban chartbook. South Carolina Rural Health Research Center.

Berdahl, T. A., Friedman, B. S., McCormick, M. C., \& Simpson, L. (2013). Annual report on health care for children and youth in the United States: Trends in racial/ethnic, income, and insurance disparities over time, 2002-2009. Academic Pediatrics, 13(3), 191-203. doi: 10.1016/j.acap.2013.02.003

Bethea, T. N., Lopez, R. P., Cozier, Y. C., White, L. F., \& McClean, M. D. (2012). The relationship between rural status, individual characteristics, and self-rated health in the Behavioral Risk Factor Surveillance System. The Journal of Rural Health, 28(4), 327-338. doi: 10.1111/j.1748-0361.2012.00414.x

Blackwell, D. L., Martinez, M. E., Gentleman, J. F., Sanmartin, C., \& Berthelot, J. M. (2009). Socioeconomic status and utilization of health care services in Canada and the United States: Findings from a bi-national health survey. Medical Care, 47(11), 1136-1146. doi: 10.1097/MLR.0b013e3181adcbe9

Blake, B., Robley, L., \& Taylor, G. (2012). A lion in the room: Youth living with HIV. Pediatric Nursing, 38(6), 311-318. 
Born, W., Engelman, K., Greiner, K. A., Bhattacharya, S. B., Hall, S., Hou, Q., \& Ahluwalia, J. S. (2009). Colorectal cancer screening, perceived discrimination, and low-income and trust in doctors: A survey of minority patients. BMC Public Health, 9, 363. doi: 10.1186/1471-2458-9-363

Bradford, J. Y., \& O'Sullivan, P. S. (2006). Use of health services by ninth grade adolescents in rural Mississippi. Journal of the Mississippi State Medical Association, 47(10), 295-300.

Bradford, J. Y., \& O'Sullivan, P. S. (2007). The relationship between the use of health clinics in rural Mississippi schools and the CHIP-AE adolescent health profile. Journal of School Nursing, 23(5), 293-298. doi: 10.1622/10598405(2007)23[293:TRBTUO]2.0.CO;2

Brady, J. E., \& Weitzman, B. C. (2007). Inconsistencies in place definition: How different operational place definitions affect estimates of adolescent smoking and drinking risk. Health \& Place, 13(2), 562-568. doi:

10.1016/j.healthplace.2006.05.001

Breland-Noble, A. M., Burriss, A., \& Poole, H. K. (2010). Engaging depressed African American adolescents in treatment: Lessons from the AAKOMA PROJECT. Journal of Clinical Psychology, 66(8), 868-879.

Brener, N. D., McManus, T., Galuska, D. A., Lowry, R., \& Wechsler, H. (2003). Reliability and validity of self-reported height and weight among high school students. The Journal of Adolescent Health, 32(4), 281-287. 
Britto, M. T., DeVellis, R. F., Hornung, R. W., DeFriese, G. H., Atherton, H. D., \& Slap, G. B. (2004). Health care preferences and priorities of adolescents with chronic illnesses. Pediatrics, 114(5), 1272-1280. doi: 10.1542/peds.2003-1134-L

Brook, R. H., Ware, J. E., Jr., Rogers, W. H., Keeler, E. B., Davies, A. R., Donald, C. A., ... Newhouse, J. P. (1983). Does free care improve adults' health? Results from a randomized controlled trial. New England Journal of Medicine, 309(23), 14261434. doi: 10.1056/NEJM198312083092305

Brook, R. H., Ware, J. E., Rogers, W. H., Keeler, E. B., Davies, A. R., Sherbourne, C. D., ... Newhouse, J. P. (1984). The effect of coinsurance on the health of adults: Results from the Rand Health Insurance Experiement. Santa Monica, CA: Rand Corporation.

Broome, M. E., \& Richards, D. J. (2003). The influence of relationships on children's and adolescents' participation in research. Nursing Research, 52(3), 191.

Brown, K. E., Arden, M. A., \& Hurst, K. M. (2007). A qualitative analysis of accounts of hormonal contraceptive use: Experiences and beliefs of British adolescents. European Journal of Contraception \& Reproductive Health Care, 12(3), 269-278. doi: $10.1080 / 13625180701440719$

Bushy, A. (2012). The rural context and nursing practice. In D. Molinari \& A. Bushy (Eds.), The Rural Nurse: Transition to Practice. New York: Springer.

Bushy, A., \& Leipert, B. D. (2005). Factors that influence students in choosing rural nursing practice: A pilot study. Rural and Remote Health, 5(2), 387.

Centers for Disease Control and Prevention. (2012). Youth Risk Behavior SurveillanceUnited States, 2011. Centers for Disease Control and Prevention. Atlanta, GA. 
Centers for Disease Control and Prevention. (2013, June 4, 2013). Other at risk populations Retrieved October 21, 2013, from http://www.cdc.gov/minorityhealth/populations/atrisk.html

Chandler, M. (1987). The Othello effect: Essay on the emergence and eclipse of skeptical doubt. Human Development, 30, 137-159.

Chandra, A., \& Minkovitz, C. S. (2006). Stigma starts early: Gender differences in teen willingness to use mental health services. Journal of Adolescent Health, 38(6), e751-758. doi: 10.1016/j.jadohealth.2005.08.011

Charman, D., Harms, C., \& Myles-Pallister, J. (2010). Help and e-help: Young people's perspectives of mental health care. Australian Family Physician, 39(9), 663-665.

Cheng, T. L., Savageau, J. A., Sattler, A. L., \& DeWitt, T. G. (1993). Confidentiality in health care. A survey of knowledge, perceptions, and attitudes among high school students. Journal of the American Medical Association, 269(11), 1404-1407.

Chu-Weininger, M. Y., \& Balkrishnan, R. (2006). Consumer satisfaction with primary care provider choice and associated trust. BMC Health Services Research, 6, 139. doi: 10.1186/1472-6963-6-139

Cogswell, B. E. (1985). Cultivating the trust of adolescent patients. Family Medicine, 17(6), 254.

Cohen, J. (1988). Statistical power analysis for the behavioral sciences. (Vol. 2). New York: Lawrence Erlbaum Associates.

Coker, T. R., Sareen, H. G., Chung, P. J., Kennedy, D. P., Weidmer, B. A., \& Schuster, M. A. (2010). Improving access to and utilization of adolescent preventive health 
care: The perspectives of adolescents and parents. Journal of Adolescent Health, 47(2), 133-142. doi: 10.1016/j.jadohealth.2010.01.005

Community Health Status Indicators. (2009). Measures of health: W County, IN Retrieved June 27, 2014, from http://wwwn.cdc.gov/CommunityHealth/SummaryMeasuresOfHealth.aspx?Geog $\mathrm{CD}=18175 \&$ PeerStrat $=29 \&$ state $=$ Indiana $\&$ count $y=W$

Continelli, T., McGinnis, S., \& Holmes, T. (2010). The effect of local primary care physician supply on the utilization of preventive health services in the United States. Health \& Place, 16(5), 942-951. doi: 10.1016/j.healthplace.2010.05.010

County Health Rankings \& Roadmaps. (2014). W County Snapshot Retrieved June 27, 2014, from http://www.countyhealthrankings.org/app/indiana/2014/rankings/ w____county/outcomes/overall/snapshot

Coxe, S., West, S. G., \& Aiken, L. S. (2009). The analysis of count data: A gentle introduction to poisson regression and its alternatives. Journal of Personality Assessment, 91(2), 121-136. doi: 10.1080/00223890802634175

Cullen, E., \& Salganicoff, A. (2011). Adolescent health: Coverage and access to care. Washington, DC: The Henry J. Kaiser Family Foundation.

Curtis, A. C., Waters, C. M., \& Brindis, C. (2011). Rural adolescent health: The importance of prevention services in the rural community. Journal of Rural Health, 27(1), 60-71. doi: 10.1111/j.1748-0361.2010.00319.x

Danaei, G., Rimm, E. B., Oza, S., Kulkarni, S. C., Murray, C. J. L., \& Ezzati, M. (2010). The promise of prevention: The effects of four preventable risk factors on national 
life expectancy and life expectancy disparities by race and county in the United States. PLoS Medicine, 7(3), 1-13. doi: 10.1371/journal.pmed.1000248

Danis, M. (2013). The ethics of allocating resources toward rural health and health care. In C. M. Klugman \& P. M. Dalinis (Eds.), Ethical issues in rural health care (pp. 71-96). Baltimore, MD: Johns Hopkins University Press.

Davis, A. M., Bennett, K. J., Befort, C., \& Nollen, N. (2011). Obesity and related health behaviors among urban and rural children in the United States: Data from the National Health And Nutrition Examination Survey 2003-2004 and 2005-2006. Journal of Pediatric Psychology, 36(6), 669-676. doi: 10.1093/jpepsy/jsq117

Deck, D., \& Ley, K. V. (2006). Medicaid eligibility and access to mental health services among adolescents in substance abuse treatment. Psychiatric Services, 57(2), 263265. doi: 10.1176/appi.ps.57.2.263

Dennis, S., Williams, A., Taggart, J., Newall, A., Denney-Wilson, E., Zwar, N., . . . Harris, M. F. (2012). Which providers can bridge the health literacy gap in lifestyle risk factor modification education: A systematic review and narrative synthesis. BMC Family Practice, 13, 44. doi: 10.1186/1471-2296-13-44

DeParle, J., \& Gebeloff, R. (2009, November 28). Food stamp use soars, and stigma fades, New York Times. Retrieved from http://www.nytimes.com/2009/11/29/us/29foodstamps.html?pagewanted=1\&_r=2

DeVoe, J. E., Tillotson, C. J., Wallace, L. S., Lesko, S. E., \& Angier, H. (2012). The effects of health insurance and a usual source of care on a child's receipt of health care. Journal of Pediatric Health Care, 26(5), e25-e35. doi:

10.1016/j.pedhc.2011.01.003 
Duncan, S. C., Duncan, T. E., \& Strycker, L. A. (2005). Sources and types of social support in youth physical activity. Health Psychology, 24(1), 3-10. doi:

10.1037/0278-6133.24.1.3

Eaton, D. K., Kann, L., Kinchen, S., Shanklin, S., Flint, K. H., Hawkins, J., . . Wechsler, H. (2012). Youth Risk Behavior Surveillance: United States, 2011. Atlanta, GA: Centers for Disease Control and Prevention.

Elliott, B. A., \& Larson, J. T. (2004). Adolescents in mid-sized and rural communities: Foregone care, perceived barriers, and risk factors. Journal of Adolescent Health, 35(4), 303-309.

Ensminger, M. E., Forrest, C. B., Riley, A. W., Kange, M., Green, B. F., Starfield, B., \& Ryan, S. A. (2000). The validity of measures of socioeconomic status of adolescents. Journal of Adolescent Research, 15(3), 392-419.

Environmental Protection Agency. (2014). Facilty detail report: Lake J__ Water Plant. Facility Registry Service. Retrieved on September 8, 2014 from http://oaspub.epa.gov/enviro/fii_query_dtl.disp_program_facility?p_registry_id=1 1000XXXXXXX

Erikson, E. H. (1963). Childhood in society. New York: W.W. Norton.

Farrant, B., \& Watson, P. D. (2004). Health care delivery: Perspectives of young people with chronic illness and their parents. Journal of Paediatrics and Child Health, 40(4), 175-179.

Fawcett, J. (1984). The metaparadigm of nursing: Present status and future refinements. Journal of Nursing Scholarship, 16(3), 77-87. 
Fosse, N. E., \& Haas, S. A. (2009). Validity and stability of self-reported health among adolescents in a longitudinal, nationally representative survey. Pediatrics, 123(3), 496-501. doi: 10.1542/peds.2008-1552

Foti, K., \& Eaton, D. (2010). Associations of selected health risk behaviors with selfrated health status among U.S. high school students. Public Health Reports, 125(5), 771-781.

Garside, R., Ayres, R., Owen, M., Pearson, V. A., \& Roizen, J. (2002). Anonymity and confidentiality: Rural teenagers' concerns when accessing sexual health services. Journal of Family Planning and Reproductive Health Care, 28(1), 23-26. doi: $10.1783 / 147118902101195965$

Geyman, J. P., Norris, T. E., \& Hart, L. G. (2001). Textbook of rural medicine. New York: McGraw-Hill.

Gillis, A. J. (1997). The Adolescent Lifestyle Questionnaire: Development and psychometric testing. Canadian Journal of Nursing Research, 29(1), 29-46.

Gordon, A. J., Ettaro, L., Rodriguez, K. L., Mocik, J., \& Clark, D. B. (2011). Provider, patient, and family perspectives of adolescent alcohol use and treatment in rural settings. Journal of Rural Health, 27(1), 81-90. doi: 10.1111/j.17480361.2010.00321.x

Gorman, B. K., \& Braverman, J. (2008). Family structure differences in health care utilization among U.S. children. Socal Science \& Medicine, 67(11), 1766-1775. doi: 10.1016/j.socscimed.2008.09.034

Grenklo, T. B., Kreicbergs, U. C., Valdimarsdottir, U. A., Nyberg, T., Steineck, G., \& Furst, C. J. (2013). Communication and trust in the care provided to a dying 
parent: A nationwide study of cancer-bereaved youths. Journal of Clinical Oncology, 31(23), 2886-2894. doi: 10.1200/jco.2012.46.6102

Gulliford, M., Naithani, S., \& Morgan, M. (2006). What is 'continuity of care'? Journal of Health Services Research \& Policy, 11(4), 248-250. doi: $10.1258 / 135581906778476490$

Guo, J. J., Wade, T. J., Pan, W., \& Keller, K. N. (2010). School-based health centers: cost-benefit analysis and impact on health care disparities. American Journal of Public Health, 100(9), 1617-1623. doi: 10.2105/AJPH.2009.185181

Guttmacher Institute. (2013). An overview of minors' consent law. Guttmacher Institute. Washington, D.C.

Haas, J. S., Lee, L. B., Kaplan, C. P., Sonneborn, D., Phillips, K. A., \& Liang, S. Y. (2003). The association of race, socioeconomic status, and health insurance status with the prevalence of overweight among children and adolescents. American Journal of Public Health, 93(12), 2105-2110.

Hall, M. A. (2001). Do patients trust their doctors? Does it matter? North Carolina Medical Journal, 62(4), 188-191.

Hall, M. A., Dugan, E., Zheng, B., \& Mishra, A. K. (2001). Trust in physicians and medical institutions: What was it, can it be measured, and does it matter? Milbank Quarterly, 79(4), 613-639.

Hall, M. A., Zheng, B., Dugan, E., Camacho, F., Kidd, K. E., Mishra, A., \& Balkrishnan, R. (2002). Measuring patients' trust in their primary care providers. Medical Care Research \& Review, 59(3), 293-318. 
Halpern-Felsher, B. L., \& Cauffman, E. (2001). Costs and benefits of a decision: Decision-making competence in adolescents and adults. Journal of Applied Developmental Psychology, 22(3), 257-273.

Hammond, W. P., Matthews, D., \& Corbie-Smith, G. (2010). Psychosocial factors associated with routine health examination scheduling and receipt among African American men. Journal of the National Medical Association, 102(4), 276-289.

Harju, B. L., Wuensch, K. L., Kuhl, E. A., \& Cross, N. J. (2006). Comparison of rural and urban residents' implicit and explicit attitudes related to seeking medical care. The Journal of Rural Health, 22(4), 359-363. doi: 10.1111/j.17480361.2006.00058.x

Health Resources and Services Administration. (n.d.[a]). Defining the rural population. Federal Office of Rural Health Policy. Retrieved March 3, 2014, from http://www.hrsa.gov/ruralhealth/policy/definition_of_rural.html

Health Resources and Services Administration. (n.d.[b]). Shortage designation: Health Professional Shortage Areas \& Medically Underserved Areas and Populations. Retrieved March 1, 2014, from http://www.hrsa.gov/shortage/

Healthy People 2010. (2000). Twenty-one critical health objectives for adolescents and young adults. Washington, D.C.: U.S. Department of Health and Human Services.

Heron, M. (2012). Deaths: Leading causes for 2009. Center for Disease Control and Prevention. 
Holt, M. K., \& Espelage, D. L. (2005). Social support as a moderator between dating violence victimization and depression/anxiety among African American and Caucasian adolescents. School Psychology Review, 34(3), 309-328.

Hoover, K. W., Tao, G., Berman, S., \& Kent, C. K. (2010). Utilization of health services in physician offices and outpatient clinics by adolescents and young women in the United States: Implications for improving access to reproductive health services. Journal of Adolescent Health, 46(4), 324-330. doi:

10.1016/j.jadohealth.2009.09.002

Horn, I. B., Mitchell, S. J., Wang, J., Joseph, J. G., \& Wissow, L. S. (2012). AfricanAmerican parents' trust in their child's primary care provider. Academic Pediatrics, 12(5), 399-404. doi: 10.1016/j.acap.2012.06.003

Hudson, A. L., Nyamathi, A., \& Sweat, J. (2008). Homeless youths' interpersonal perspectives of health care providers. Issues in Mental Health Nursing, 29(12), 1277-1289.

Idler, E. L., \& Angel, R. J. (1990). Self-rated health and mortality in the NHANES-I epidemiologic follow-up study. American Journal of Public Health, 80(4), 446452.

Indiana Coalition to Improve Adolescent Health. (2009). Picturing a healthier future: A state stragegic plan for Indiana's adolescents. Indianapolis, IN: Indiana Coalition to Improve Adolescent Health.

Indiana Family and Social Services. (2014). Working with your health plan. Indiana Medicaid. Retrieved July 5, 2014, from http://member.indianamedicaid.com/ 
programs - benefits/important-things-to-know/working-with-your-healthplan.aspx

Ingram, J., \& Salmon, D. (2007). 'No worries!': Young people's experiences of nurse-led drop-in sexual health services in south west England. Journal of Research in Nursing, 12(4), 305-315.

Institute of Medicine. (2004). Insuring America's health: Principles and recommendations. Washington, D.C.: National Academy Press.

Institute of Medicine. (2005). Quality through collaboration: The future of rural health care. Washington, DC: The National Academies Press.

Institute of Medicine \& National Research Council. (2011). The science of adolescent risk-taking: Workshop report. Washington, DC: The National Academies Press.

Kao, A. C., Green, D. C., Davis, N. A., Koplan, J. P., \& Cleary, P. D. (1998). Patients' trust in their physicians: Effects of choice, continuity, and payment method. Journal of General Internal Medicine, 13(10), 681-686.

Kerpelman, J. L., \& Mosher, L. S. (2004). Rural African American adolescents' future orientation: The importance of self-efficacy, control, responsibility, and identity development. Identity, 4(2), 187-208. doi: 10.1207/s1532706xid0402_5

Kilbourne, A. M., Switzer, G., Hyman, K., Crowley-Matoka, M., \& Fine, M. J. (2006). Advancing health disparities research within the health care system: A conceptual framework. American Journal of Public Health, 96(12), 2113-2121. doi: 10.2105/AJPH.2005.077628

Klein, J. D., Shenkman, E., Brach, C., Shone, L. P., Col, J., Schaffer, V. A., . . Szilagyi, P. G. (2006). Prior health care experiences of adolescents who enroll in SCHIP. 
Journal of Health Care for the Poor and Underserved, 17(4), 789-807. doi: 10.1353/hpu.2006.0127

Klostermann, B. K., Slap, G. B., Nebrig, D. M., Tivorsak, T. L., \& Britto, M. T. (2005). Earning trust and losing it: Adolescents' views on trusting physicians. Journal of Family Practice, 54(8), 679-687.

Klugman, C. M. (2008a). Vast tracts of land: Rural health care culture. American Journal of Bioethics, 8(4), 57-58. doi: 10.1080/15265160802147082

Kraag, G., Van Breukelen, G. J. P., Kok, G., \& Hosman, C. (2009). ‘Learn young, learn fair,' a stress management program for fifth and sixth graders: Longitudinal results from an experimental study. Journal of Child Psychology and Psychiatry, 50(9), 1185-1195. doi: 10.1111/j.1469-7610.2009.02088.x

Laditka, J. N., Laditka, S. B., \& Probst, J. C. (2009). Health care access in rural areas: Evidence that hospitalization for ambulatory care-sensitive conditions in the United States may increase with the level of rurality. Health \& Place, 15(3), 731740. doi: $10.1016 /$ j.healthplace.2008.12.007

Lawrence, R., Gootman, J., \& Sim, L. (2009). Adolescent health services : Missing opportunities. Washington, DC: National Academies Press.

Leavey, G., Rothi, D., \& Paul, R. (2011). Trust, autonomy and relationships: The helpseeking preferences of young people in secondary level schools in London. Journal of Adolescence, 34(4), 685-693. doi: 10.1016/j.adolescence.2010.09.004

Lee, H. J., \& Winters, C. A. (2004). Testing rural nursing theory: Perceptions and needs of service providers. Online Journal of Rural Nursing and Health Care, 4(1), 5163. 
Lehrer, J. A., Pantell, R. T., Tebb, K., \& Shafer, M. (2007). Forgone health care among U.S. adolescents: Associations between risk characteristics and confidentiality concern. Journal of Adolescent Health, 40(3), 218-226. doi:

10.1016/j.jadohealth.2006.09.015

Leight, S. B. (2001). The application of a vulnerable populations conceptual model to rural health. Public Health Nursing, 20(6), 440-448.

Leininger, L. J., \& Ziol-Guest, K. M. (2008). Reexamining the effects of family structure on children's access to care: The single-father family. Health Services Research, 43(1 Pt 1), 117-133. doi: 10.1111/j.1475-6773.2007.00758.x

Leonard, A. D., Markham, C. M., Bui, T., Shegog, R., \& Paul, M. E. (2010). Lowering the risk of secondary HIV transmission: Insights from HIV-positive youth and health care providers. Perspectives on Sexual and Reproductive Health, 42(2), 110-116. doi: 10.1363/4211010PSRH4211010

Long, K. A., Ewing, L. J., Cohen, S., Skoner, D., Gentile, D., Koehrsen, J., . . Marsland, A. L. (2011). Preliminary evidence for the feasibility of a stress management intervention for 7- to 12-year-olds with asthma. Journal of Asthma, 48(2), 162 170. doi: 10.3109/02770903.2011.554941

Long, K. A., \& Weinert, C. (1989). Rural nursing: Developing the theory base. Scholarly Inquiry for Nursing Practice, 3(2), 113-127.

Lovett, J., \& Wald, M. S. (1985). Physician attitudes toward confidential care for adolescents. The Journal of Pediatrics, 106(3), 517-521. doi: 10.1016/S0022$3476(85) 80696-X$ 
Lutfiyya, M. N., Lipsky, M. S., Wisdom-Behounek, J., \& Inpanbutr-Martinkus, M. (2007). Is rural residency a risk factor for overweight and obesity for U.S. children? Obesity, 15(9), 2348-2356. doi: 10.1038/oby.2007.278

Ma, J., Wang, Y., \& Stafford, R. S. (2005). U.S. adolescents receive suboptimal preventive counseling during ambulatory care. The Journal of Adolescent Health, $36(5)$, e441-447.

MacDowell, M., Glasser, M., Fitts, M., Nielsen, K., \& Hunsaker, M. (2010). A national view of rural health workforce issues in the USA. Rural Remote Health, 10(3), 1531.

MacKay, A. P., \& Duran, C. (2007). Adolescent health in the United States. Washington, DC: National Center for Health Statistics.

Manning, W. G., Newhouse, J. P., Duan, N., Keeler, E. B., Benjamin, B., Leibowitz, A., ...Zwanziger, J. (1988). Health insurance and the demand for medical care: Evidence from a randomized experiment. The RAND Corportation.

Manning, W. G., Newhouse, J. P., \& Ware, J. E. (1982). The status of health in demand estimation: Beyond excellent, good, fair, and poor. In V. R. Fuchs (Ed.), Economic Aspects of Health (pp. ix, 333 p.). Chicago: University of Chicago Press.

Marcell, A. V., Ford, C. A., Pleck, J. H., \& Sonenstein, F. L. (2007). Masculine beliefs, parental communication, and male adolescents' health care use. Pediatrics, 119(4), e966-975. 
Marcell, A. V., \& Halpern-Felsher, B. L. (2005). Adolescents' health beliefs are critical in their intentions to seek physician care. Preventive Medicine, 41(1), 118-125. doi: 10.1016/j.ypmed.2004.10.016

Mattila, V. M., Parkkari, J., Koivusilta, L., Nummi, T., Kannus, P., \& Rimpela, A. (2008). Adolescents' health and health behaviour as predictors of injury death: A prospective cohort follow-up of 652,530 person-years. BMC Public Health, 8, 90. doi: 10.1186/1471-2458-8-90

Maulik, P. K., Mendelson, T., \& Tandon, S. D. (2011). Factors associated with mental health services use among disconnected African-American young adult population. Journal of Behavioral Health Services Research, 38(2), 205-220. doi: $10.1007 / \mathrm{s} 11414-010-9220-0$

Mazzaferro, K. E., Murray, P. J., Ness, R. B., Bass, D. C., Tyus, N., \& Cook, R. L. (2006). Depression, stress, and social support as predictors of high-risk sexual behaviors and STIs in young women. The Journal of Adolescent Health, 39(4), 601-603.

McKee, M. D., \& Fletcher, J. (2006). Primary care for urban adolescent girls from ethnically diverse populations: Foregone care and access to confidential care. Journal of Health Care for the Poor and Underserved, 17(4), 759-774. doi: 10.1353/hpu.2006.0131

McKee, M. D., Fletcher, J., \& Schechter, C. B. (2006). Predictors of timely initiation of gynecologic care among urban adolescent girls. Journal of Adolescent Health, 39(2), 183-191. doi: 10.1016/j.jadohealth.2005.11.022 
McKee, M. D., O'Sullivan, L. F., \& Weber, C. M. (2006). Perspectives on confidential care for adolescent girls. Annals of Family Medicine, 4(6), 519-526. doi: $10.1370 /$ afm. 601

Mollborn, S., Stepanikova, I., \& Cook, K. S. (2005). Delayed care and unmet needs among health care system users: When does fiduciary trust in a physician matter? Health Services Research, 40(6), 1898-1917. doi: 10.1111/j.1475$6773.2005 .00457 . x$

Mulye, T. P., Park, M. J., Nelson, C. D., Adams, S. H., Irwin, C. E., Jr., \& Brindis, C. D. (2009). Trends in adolescent and young adult health in the United States. Journal of Adolescent Health, 45(1), 8-24. doi: 10.1016/j.jadohealth.2009.03.013

Murimi, M. W., \& Harpel, T. (2010). Practicing preventive health: The underlying culture among low-income rural populations. The Journal of Rural Health, 26(3), 273-282. doi: 10.1111/j.1748-0361.2010.00289.x

Murray, C. J., Kulkarni, S. C., Michaud, C., Tomijima, N., Bulzacchelli, M. T., Iandiorio, T. J., \& Ezzati, M. (2006). Eight Americas: Investigating mortality disparities across races, counties, and race-counties in the United States. PLoS Medicine, 3(9), e260. doi: 10.1371/journal.pmed.0030260

Nasim, A., Fernander, A., Townsend, T. G., Corona, R., \& Belgrave, F. Z. (2011). Cultural protective factors for community risks and substance use among rural African American adolescents. Journal of Ethnicity and Substance Abuse, 10(4), 316-336. doi: 10.1080/15332640.2011.623510

National Center for Chronic Disease Prevention and Health Promotion, \& Division of Adolescent and School Health. (2009). Healthy youth topics: Alcohol and drug 
use. Retrieved July 14, 2009, from

http://www.cdc.gov/HealthyYouth/alcoholdrug/

National Institutes of Health. (2001). Policy on reporting race and ethnicity data:

Subjects in clinical research. Washington, DC: National Institutes of Health.

National Quality Measures Clearinghouse. (2014). Ambulatory care sensitive conditions.

Retrieved 4/2/2014 from

http://www.qualitymeasures.ahrq.gov/content.aspx?id=47604

National Research Council, \& Institute of Medicine. (2007). Challenges in adolescent health care. Committee on Adolescent Health Care Services and Models of Care for Treatment, Prevention, and Healthy Development. Board on Children, Youth, and Families, Division of Behavioral and Social Sciences and Education. Washington, D.C.: The National Academies Press.

Neinstein, L. S. (2009). Handbook of adolescent health care. Philadelphia: Wolters Kluwer Health/Lippincott Williams \& Wilkins.

Nelms, E., Wang, L., Pennelli, M., Wewers, M. E., Seiber, E., Adolph, M. D., .. . Ferketich, A. K. (2013). Trust in physicians among rural Medicaid-enrolled smokers. The Journal of Rural Health, 30(2), 214-220. doi: 10.1111/jrh.12046

Nelson, W. A. (2008). The challenges of rural health care. In C. M. Klugman \& P. M. Dalinis (Eds.), Ethical Issues in Rural Health. Baltimore: Johns Hopkins University Press.

Newhouse, J. P. (1974). A design for a health insurance experiment. Inquiry, 11(1), 5-27. 
Niemira, D. (2010). Ethical dimensions of the quality of rural health care. In C. M. Klugman \& P. M. Dalinis (Eds.), Ethical Issues in Rural Health. Baltimore: Johns Hopkins University Press.

Patient Protection and Affordable Care Act and the Health Care and Education Reconciliation Act of 2010. 42 U.S.C. § 18001 (2010).

Penchansky, R., \& Thomas, J. W. (1981). The concept of access: Definition and relationship to consumer satisfaction. Medical Care, 19(2), 127-140.

Pender, N. J. (1996). Health promotion in nursing practice (3rd ed.). Stamford, CT: Appleton \& Lange.

Pender, N. J., Murdaugh, C. L., \& Parsons, M. A. (2011). Health promotion in nursing practice (6th ed.). Upper Saddle River, NJ: Prentice Hall.

Polit, D.F. \& Beck, C. T. Nursing research: Principles and methods. (2004). 7th ed. Philadelphia, PA: Lippincott, Williams \& Wilkins.

Potter, N. (2002). How can I be trusted? A virtue theory of trustworthiness. Oxford, England: Rowman \& Littlefield Publishers, Inc.

Probst, J. C., Moore, C. G., \& Baxley, E. G. (2005). Update: Health insurance and utilization of care among rural adolescents. Journal of Rural Health, 21(4), 279287.

Rand, C. M., Shone, L. P., Albertin, C., Auinger, P., Klein, J. D., \& Szilagyi, P. G. (2007). National health care visit patterns of adolescents: Implications for delivery of new adolescent vaccines. Archives of Pediatrics \& Adolescent Medicine, 161(3), 252-259. doi: 10.1001/archpedi.161.3.252 
Renker, P. R. (2006). Perinatal violence assessment: Teenagers' rationale for denying violence when asked. Journal of Obstetric, Gynecologic \& Neonatal Nursing, 35(1), 56-67. doi: 10.1111/j.1552-6909.2006.00018.x

Resnick, M. D., Litman, T. J., \& Blum, R. W. (1992). Physician attitudes toward confidentiality of treatment for adolescents: Findings from the Upper Midwest Regional Physicians Survey. Journal of Adolescent Health, 13(7), 616-622.

Rew, L. (2005). Adolescent health : A multidisciplinary approach to theory, research, and intervention. Thousand Oaks: Sage Publications.

Rew, L., Arheart, K. L., Thompson, S., \& Johnson, K. (2013). Predictors of adolescents' health-promoting behaviors guided by primary socialization theory. Journal for Specialists in Pediatric Nursing, 18(4), 277-288. doi: 10.1111/jspn.12036

Rew, L., Resnick, M., \& Beuhring, T. (1999). Usual sources, patterns of utilization, and foregone health care among Hispanic adolescents. Journal of Adolescent Health, 25(6), 407-413.

Rew, L., Wong, Y. J., Torres, R., \& Howell, E. (2007). A linguistic investigation of mediators between religious commitment and health behaviors in older adolescents. Issues Comprehensive Pediatric Nursing, 30(3), 71-86. doi: $10.1080 / 01460860701525147$

Richardson, S. D., DeMarini, D. M., Kogevinas, M., Fernandez, P., Marco, E., Lourencetti, C., .. V Villanueva, C. M. (2010). What's in the pool? A comprehensive identification of disinfection by-products and assessment of mutagenicity of chlorinated and brominated swimming pool water. Environmental Health Perspectives, 118(11), 1523-1530. doi: 10.1289/ehp.1001965 
Ritter, P. L., Stewart, A. L., Kaymaz, H., Sobel, D. S., Block, D. A., \& Lorig, K. R. (2001). Self-reports of health care utilization compared to provider records. Journal of Clinical Epidemiology, 54(2), 136-141. doi: S0895-4356(00)00261-4

Robertson, L. M. et al. (1998). Knowledge of health insurance coverage by adolescents and young adults attending a hospital-based clinic. (1998). Journal of Adolescent Health, 22(6): 439-445.

Roos, L. L., Walld, R., Uhanova, J., \& Bond, R. (2005). Physician visits, hospitalizations, and socioeconomic status: Ambulatory care sensitive conditions in a Canadian setting. Health Services Research, 40(4), 1167-1185. doi: 10.1111/j.14756773.2005.00407.x

Rural Institute at The University of Montana. (2005). Population distribution by urbanized areas and urban clusters. Missoula, MT: The University of Montana. S___ Municipal Utilities. (2013). 2013 consumer confidence report. S__, Indiana.

Samargia, L. A., Saewyc, E. M., \& Elliott, B. A. (2006). Foregone mental health care and self-reported access barriers among adolescents. Journal of School Nursing, $22(1), 17-24$.

Sayles, J. N., Macphail, C. L., Newman, P. A., \& Cunningham, W. E. (2010). Future HIV vaccine acceptability among young adults in South Africa. Health Education \& Behavior, 37(2), 193-210.

Schreier, H. M., \& Chen, E. (2013). Socioeconomic status and the health of youth: A multilevel, multidomain approach to conceptualizing pathways. Psychology Bulliten, 139(3), 606-654. doi: 10.1037/a0029416 
Schlitt, J. J., Juszczak, L. J., \& Eichner, N. H. (2008). Current status of state policies that support school-based health centers. Public Health Reports, 123(6), 731-738.

Scoggins, J. F., Fedorenko, C. R., Donahue, S. M. A., Buchwald, D., Blough, D. K., \& Ramsey, S. D. (2012). Is distance to provider a barrier to care for Medicaid patients with breast, colorectal, or lung cancer? The Journal of Rural Health, 28(1), 54-62. doi: 10.1111/j.1748-0361.2011.00371.x

Scott, L. D. \& Davis, L. E. (2006). Young, black, and male in foster care: Relationship of negative social contextual experiences to factors relevant to mental health service delivery. Journal of Adolescence, 29(5), 721-736.

Shoff, C. \& Yang, T. (2012). Untangling the associations among distrust, race, and neighborhood social environment: A social disorganization perspective. Social Science and Medicine, 74(9): 1342-1352. doi: 10.1016/j.socscimed.2012.01.012

Simpson, L., Owens, P. L., Zodet, M. W., Chevarley, F. M., Dougherty, D., Elixhauser, A., \& McCormick, M. C. (2005). Health care for children and youth in the United States: Annual report on patterns of coverage, utilization, quality, and expenditures by income. Ambulatory Pediatrics, 5(1), 6-44. doi: 10.1367/A04119R.1

Simpson, L., Zodet, M. W., Chevarley, F. M., Owens, P. L., Dougherty, D., \& McCormick, M. (2004). Health care for children and youth in the United States: 2002 report on trends in access, utilization, quality, and expenditures. Ambulatory Pediatrics, 4(2), 131-153. doi: 10.1367/1539409(2004)4<131:HCFCAY>2.0.CO;2 
Spleen, A. M., Lengerich, E. J., Camacho, F. T., \& Vanderpool, R. C. (2014). Health care avoidance among rural populations: Results from a nationally representative survey. The Journal of Rural Health, 30(1), 79-88. doi: 10.1111/jrh.12032

Steinberg, L. (2008). A social neuroscience perspective on adolescent risk-taking. Developmental Reveiw, 28(1), 78-106. doi: 10.1016/j.dr.2007.08.002

Steinberg, L. (2010a). Adolescence. New York, NY: McGraw-HIll.

Steinberg, L. (2010b). A dual systems model of adolescent risk-taking. Developmental Psychobiology, 52(3), 216-224. doi: 10.1002/dev.20445

Stroud, L. R., Foster, E., Papandonatos, G. D., Handwerger, K., Granger, D. A., Kivlighan, K. T., \& Niaura, R. (2009). Stress response and the adolescent transition: Performance versus peer rejection stressors. Development and Psychopathology, 21(01), 47-68. doi: doi:10.1017/S0954579409000042

Sweeney, M. M. (2007). Stepfather families and the emotional well-being of adolescents. Journal of Health and Social Behavior, 48(1), 33-49. doi: 10.2307/27638689

Tabachnick, B. G., \& Fidell, L. S. (2007). Using multivariate statistics (5th ed.). Boston: Allyn and Bacon.

Thomas, E. (2010). Structural violence in rural context. In C. M. Klugman \& P. M. Dalinis (Eds.), Ethical issues in rural health. Baltimore: Johns Hopkins University Press.

Tinnfält, A., Eriksson, C., \& Brunnberg, E. (2011). Adolescent children of alcoholics on disclosure, support, and assessment of trustworthy adults. Child and Adolescent Social Work Journal, 28(2), 133-151. 
Title X of the Public Health Service Act of 1970, Pub. L. No. 91-572 § 1001 et seq. (1970).

United States Census Bureau. (2013). American Community Survey 2008-2012 five-year estimates. Retrieved June 27, 2014, from United States Census Bureau http://factfinder2.census.gov/faces/tableservices/jsf/pages/productview.xhtml?pid =ACS_12_5YR_DP05\&prodType=table

USDA Food and Nutrition Service. (2014). National School Lunch Program. Retrieved June 30, 2014 from http://www.fns.usda.gov/nslp/national-school-lunch-programnslp

Viner, R. M., Ozer, E. M., Denny, S., Marmot, M., Resnick, M., Fatusi, A., \& Currie, C. (2012). Adolescence and the social determinants of health. Lancet, 379(9826), 1641-1652. doi: 10.1016/S0140-6736(12)60149-4

Vingilis, E., Wade, T., \& Seeley, J. (2007). Predictors of adolescent health care utilization. Journal of Adolescence, 30(5), 773-800. doi: 10.1016/j.adolescence.2006.10.001

Wade, T. J., \& Guo, J. J. (2010). Linking improvements in health-related quality of life to reductions in Medicaid costs among students who use school-based health centers. American Journal of Public Health, 100(9), 1611-1616. doi: 10.2105/AJPH.2009.185355

Washington, H. A. (2008). Medical apartheid: The dark history of medical experimentation on Black Americans from colonial times to the present. New York: Anchor Books. 
Weiler, R. M. (1997). Adolescents' perceptions of health concerns: An exploratory study among rural midwestern youth. Health Education and Behavior, 24(3), 287-299.

Weinert, C., \& Long, K. (1987). Understanding the health care needs of rural families. Family Relations, 36, 450-455.

Weinert, C., \& Long, K. (1990). Rural families and health care: Refining the knowledge base. Marriage and Family Review, 15, 57-75.

Wu, L. T., Blazer, D. G., Li, T. K., \& Woody, G. E. (2011). Treatment use and barriers among adolescents with prescription opioid use disorders. Addictive Behaviors, $36(12), 1233-1239$.

Wu, L. T., Pilowsky, D. J., Schlenger, W. E., \& Hasin, D. (2007). Alcohol use disorders and the use of treatment services among college-age young adults. Psychiatric Services, 58(2), 192-200. doi: 10.1176/appi.ps.58.2.192

Youngblade, L. M., Curry, L. A., Novak, M., Vogel, B., \& Shenkman, E. A. (2006). The impact of community risks and resources on adolescent risky behavior and health care expenditures. Journal of Adolescent Health, 38(5), 486-494. doi:

10.1016/j.jadohealth.2005.07.016

Ziller, E. C., Coburn, A. F., Loux, S. L., Hoffman, C., \& McBride, T. D. (2003). Health insurane coverage in rural America chartbook. Institute for Health Policy Muskie School of Public Service University of Southern Maine \& The Kaiser Commission on Medicaid and the Uninsured. Washington, DC: The Henry J. Kaiser Family Foundation. 


\section{APPENDICES}

\section{A. Parental Passive Consent Letter}

\section{UN I VER S I T Y OF LOUISVILLE.} SCHOOL OF NURSING

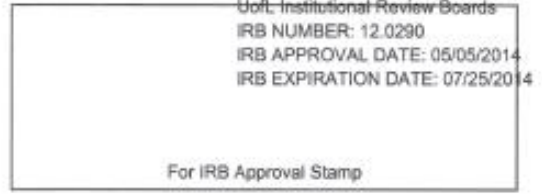

\section{EXPLORING TRUST IN HEALTH CARE PROVIDERS AMONG RURAL ADOLESCENTS}

Dear Parent or Guardian:

Next week, your Salem High School child will be invited to participate in a research study by answering a survey about their trust of doctors and nurses. There are no known risks for your child's participation in this research study. The information collected may not benefit your child directly. The information learned in this study may be helpful to others. The information your child provides will help us understand how teenagers trust their doctor or nurse practitioner. The completed surveys will be stored at the University of Louisville, School of Nursing. The survey will take approximately 30 minutes to complete.

Individuals from the School of Nursing, the Institutional Review Board (IRB), the Human Subjects Protection Program Office (HSPPO), and other regulatory agencies may inspect these records. In all other respects, however, the data will be held in confidence to the extent permitted by law. Should the data be published, your child's identity will not be disclosed.

Taking part in this study is voluntary. On the day of the survey, your child may choose to take or not take the survey. Your child does not have to answer any questions that make her/him uncomfortable. Your child may choose not to take part at all. If your child decides to be in this study $\mathrm{s} /$ he may stop taking part at any time. If s/he decides not to be in this study or if s/he stops taking part at any time, s/he will not lose any benefits for which s/he may qualify. Your child may choose to skip any questions s/he does not wish to answer.

If you have any questions, concerns, complaints, or would like to decline your child's participation in the research study, please contact: Heather Hardin, RN at 812-620-3816, hkhard02@louisville.edu or Dr Barbara Speck at 502-852-8513, bispec01@louisville.edu.

If you have any questions about your child's rights as a research subject, you may call the Human Subjects Protection Program Office at (502) 852-5188. You can discuss any questions about your child's rights as a research subject, in private, with a member of the Institutional Review Board (IRB) You may also call this number if you have other questions about the research, and you cannot reach the research staff, or want to talk to someone else. The IRB is an independent committee made up of people from the University community, staff of the institutions, as well as people from the community not connected with these institutions. The IRB has reviewed this research study,

If you have concems or complaints about the research or research staff and you do not wish to give your name, you may call 1-877-852-1167. This is a 24 -hour hot line answered by people who do not work at the University of Louisville.

Sincerely,

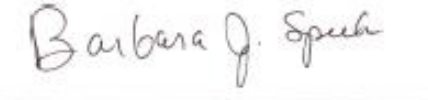

Barbara J. Speck, PhD, RN

Research Investigator

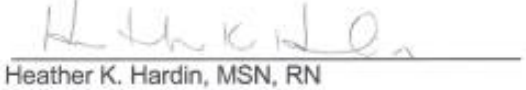

Research Co-Investigator 


\section{B. Institutional Review Board Approval Letter}

\section{unveresiriv of LOUISVILLE}

Human Subjects Protection Program Office

MedCenter One - Suite 200

501 E. Broadway

Louisville, KY 40202-1798

Office: 502.852 .5188 Fax: 502.852 .2164
DATE:

TO:

FROM:

IRB NUMBER:

STUDY TITLE:

REFERENCE \#

IRB STAFF CONTACT:
May 07, 2014

Barbara J Speck

The University of Louisville Institutional Review Board

12.0290

Exploring Trust in Health Care Providers among Rural Adolescents 334110

Name: Jacqueline S. Powell

Phone: 852-4101

Email: jspowe01@Louisville.edu

The amendment request has been received by the Human Subjects Protection Program Office and approved by the Chair of the Institutional Review Board (IRB) on 05/05/2014 through the expedited review procedure according to 45 CFR 46.110(B). The following documents have been reviewed and approved:

\begin{tabular}{|c|c|c|c|}
\hline \multicolumn{4}{|l|}{ Submission Components } \\
\hline \multicolumn{4}{|l|}{ Submission Form } \\
\hline \multicolumn{2}{|l|}{ Form Name } & \multicolumn{2}{|l|}{ Outcome } \\
\hline \multicolumn{2}{|c|}{ IRB Amendment Form } & \multicolumn{2}{|c|}{ Approved as Submitted } \\
\hline \multicolumn{2}{|c|}{ Review Response Submission Form } & \multicolumn{2}{|c|}{ Approved as Submitted } \\
\hline \multicolumn{4}{|c|}{ Study Document } \\
\hline Title & Version Number & Version Date & Outcome \\
\hline Research proposal & Version 1.0 & $04 / 28 / 2014$ & \\
\hline $\begin{array}{l}\text { Preamble Parents info } \\
\text { letter amendment }\end{array}$ & Version 1.0 & $04 / 25 / 2014$ & Approved \\
\hline $\begin{array}{l}\text { Protocol amendment } \\
\text { clean copy }\end{array}$ & Version 1.0 & $04 / 25 / 2014$ & \\
\hline $\begin{array}{l}\text { Demographic survey } \\
\text { amendment }\end{array}$ & Version 1.0 & $04 / 25 / 2014$ & \\
\hline Alternative activity & Version 1.0 & $04 / 25 / 2014$ & \\
\hline $\begin{array}{l}\text { Preamble participant } \\
\text { letter amend }\end{array}$ & Version 1.0 & $04 / 24 / 2014$ & Approved \\
\hline $\begin{array}{l}\text { Preamble minor info } \\
\text { letter amend }\end{array}$ & Version 1.0 & $04 / 24 / 2014$ & Approved \\
\hline $\begin{array}{l}\text { Preamble adult info } \\
\text { letter amend }\end{array}$ & Version 1.0 & $04 / 24 / 2014$ & Approved \\
\hline
\end{tabular}




\begin{tabular}{|l|l|l|l|}
\hline $\begin{array}{l}\text { Proposal amendment } \\
\text { clean copy }\end{array}$ & Version 1.0 & $04 / 24 / 2014$ & \\
\hline $\begin{array}{l}\text { Stanford Utilization of } \\
\text { Health Care Survey }\end{array}$ & Version 1.0 & $04 / 23 / 2014$ & \\
\hline Salem High School LOS & Version 1.0 & $04 / 23 / 2014$ & \\
\hline Recruitment flyer & Version 1.0 & $04 / 23 / 2014$ & Approved \\
\hline $\begin{array}{l}\text { Adolescent Lifestyle } \\
\text { Questionnaire }\end{array}$ & Version 1.0 & $04 / 23 / 2014$ & \\
\hline
\end{tabular}

The modifications include: 1 . Changing the demographics survey, 2. Adding the Adolescent Lifestyle Questionnaire, 3. Adding the Stanford Utilization of Health Care Survey, 4. Removed the GTB-LA and HCR scales, 5. Updated protocol to reflect change of surveys, 6 . Updated protocol to include alternative activity for non-participants, 7 . Sponsor is a $\$ 500$ grant from the Rural Nurses Organization-no changes from sponsor.

Please begin using your newly stamped approved documents with any new subjects. The committee will be advised of this action at a regularly scheduled meeting.

If you have any questions, please contact the HSPPO at (502) 852-5188 or hsppofc@louisville.edu.

Thank you for your submission.

Sincerely,

Pate $n$ dinsed

Peter M. Quesada, Ph.D., Chair

Social/Behavioral/Educational Institutional Review Board

PMQ/jsp 


\section{Minor's Survey Informational Cover Sheet}

\section{U N I VER S I T Y OF LOUISWHLE. E.} SCHOOL OF NURSING
Uoh. Institutonal Review Boards IRB APPROVAL DATE 05105/201 IRB EXPIRATION DATE: 07/25/2014

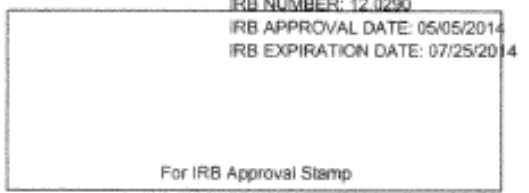

Exploring Trust in Health Care Providers Among Rural Adolescents

Mary 1, 2014

Dear Student

You are being invited to participate in a research study by answering the attached survey about your trust of doctors and nurses. Your parents have recently received a letter of information about this survey. There are no known risks for your participation in this research study. The information collected may not benefit you directly. The information learned in this study may be helpful to others. The information you provide will help us to understand how teenagers trust their doctor or nurse practitioner. Your completed survey will be stored at the University of Louisville School of Nursing. The survey will take approximately 30 minutes to complete.

Individuals from the Department of Nursing, the institutional Review Board (IRB), the Human Subjects Profection Program Offica (HSPPO), and other regulatory agencies may inspect these records. in all other respects, however, the data will be heid in confidence to the extent permitted by law. Should the data be published, your identity will not be disclosed.

Taking part in this study is voluntary. By completing this survey you agree to take part in this research study. You do not have to answer any questions that make you uncomfortable. You may choose not to take part at all. If you decide to be in this study you may stop taking part at any time. If you decide not to be in this study or if you stop taking part at any time, you will not lose any benefits for which you may qualify.

If you have any questions, concerns, or complaints about the research study, please contact: Heather Hardin, RN at 812-620-3816, hkhard02@louisville,edu or Dr Barbara Speck at 502-852-8513. bjspec01@louisville.edu.

If you have any questions about your rights as a research subject, you may call the Human Subjects Protection Program Office at (502) 852-5188. You can discuss any questions about your rights as a research subject, in private, with a member of the Institutional Review Board (IRB). You may also call this number if you have other questions about the research, and you cannot reach the research staff, or want to talk to someone else. The IRB is an independent committee made up of people from the University community, staff of the institutions, as well as people from the community not connected with these institutions. The IRB has reviewed this research study.

If you have concems or complaints about the research or research staff and you do not wish to give your name, you may call 1-877-852-1167. This is a 24 hour hot line answered by people who do not work at the University of Louisville.

Sincerely

Barbara Q. Sput

Barbara J. Speck, PhD, RN 


\section{Adult Participant Passive Consent Letter and Coversheet}

UNIVERSITY OF
LOUS

SCHOOL OF NURSING

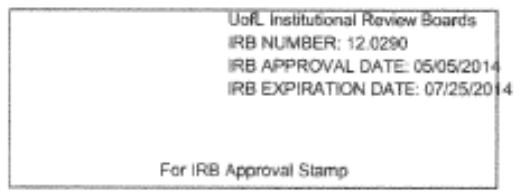

For IRB Approval Stamp

EXPLORING TRUST IN HEALTH CARE PROVIDERS AMONG RURAL ADOLESCENTS

May 1, 2014

Dear Student:

You are being invited to participate in a research study by answering the attached survey about your trust of doctors and nurses. There are no known risks for your participation in this research study. The information collected may not benefit you directly. The information leamed in this study may be helpful to others. The information you provide will help us understand how teenagers trust their doctor or nurse practitioner. Your completed survey will be stored at the University of Louisville, School of Nursing. The survey will take approximately 30 minutes to complete.

Individuals from the School of Nursing, the Institutional Review Board (IRB), the Human Subjects Protection Program Office (HSPPO), and other regulatory agencies may inspect these records. In all other respects, however, the data will be heid in confidence to the extent permitted by law. Should the data be published, your identity will not be disciosed.

Taking part in this study is voluntary. By completing this survey you agree to take part in this research study. On the day of the survey, you may choose to take or not take the survey. If you wish to take this survey, you may do so beginning on the next page. You do not have to answer any questions that make you uncomfortable. You may choose not to take part at all. If you decide to take this survey, you may stop taking part at any time. If you decide not to be in this study or if you stop taking part at any time, you will not lose any benefits for which you may qualify. You may choose to skip any questions you do not wish to answer.

If you have any questions, concerns, or complaints about the research study, please contact: Heather Hardin, RN at812-620-3816, hkhard02@louisville.edu or Dr Barbara Speck at 502-852-8513. bjspec01@olouisville.edu.

If you have any questions about your rights as a research subject, you may call the Human Subjects Protection Program Office at (502) 852-5188. You can discuss any questions about your rights as a research subject, in private, with a member of the Institutional Review Board (IRB). You may also call this number if you have other questions about the research, if you cannot reach the research staff, or want to talk to someone else. The IRB is an independent committee made up of people from the University community, staff of the institutions, as well as people from the community not connected with these institutions. The IRB has reviewed this research study.

If you have concerns or complaints about the research or research staff and you do not wish to give your name, you may call 1-877-852-1167. This is a 24-hour hot line answered by people who do not work at the University of Louisville.

Sincerely,

$$
\text { Babara of span }
$$

Barbara J. Speck, PhD, RN

Research Investigator

Heather K, Hardin, MSN, RN

Research Co-Investigator 


\section{E. Wake Forest Interpersonal Trust in Physician Scale}

Directions: I'd like you to think about how well your doctor cares for your medical needs. For each statement that I read, please tell me whether you Strongly Agree, Agree, Neutral, Disagree, Strongly Disagree.

\begin{tabular}{|c|c|c|c|c|c|}
\hline & $\begin{array}{l}\text { Strongly } \\
\text { Disagree }\end{array}$ & Disagree & Neutral & Agree & $\begin{array}{c}\text { Strongly } \\
\text { Agree }\end{array}$ \\
\hline $\begin{array}{l}\text { 1. [Your doctor] will do } \\
\text { whatever it takes to get you all } \\
\text { the care you need. }\end{array}$ & 1 & 2 & 3 & 4 & 5 \\
\hline $\begin{array}{l}\text { 2. Sometimes [your doctor] } \\
\text { cares more about what is } \\
\text { convenient for [him/her] than } \\
\text { about your medical needs. }\end{array}$ & 1 & 2 & 3 & 4 & 5 \\
\hline $\begin{array}{l}\text { 3. [Your doctor]'s medical } \\
\text { skills are not as good as they } \\
\text { should be. }\end{array}$ & 1 & 2 & 3 & 4 & 5 \\
\hline $\begin{array}{l}\text { 4. [Your doctor] is extremely } \\
\text { thorough and careful. }\end{array}$ & 1 & 2 & 3 & 4 & 5 \\
\hline $\begin{array}{l}\text { 5. You completely trust [your } \\
\text { doctor's] decisions about } \\
\text { which medical treatments are } \\
\text { best for you. }\end{array}$ & 1 & 2 & 3 & 4 & 5 \\
\hline $\begin{array}{l}\text { 6. [Your doctor] is totally } \\
\text { honest in telling you about all } \\
\text { of the different treatment } \\
\text { options available for your } \\
\text { condition. }\end{array}$ & 1 & 2 & 3 & 4 & 5 \\
\hline $\begin{array}{l}\text { 7. [Your doctor] only thinks } \\
\text { about what is best for you. }\end{array}$ & 1 & 2 & 3 & 4 & 5 \\
\hline $\begin{array}{l}\text { 8. Sometimes [your doctor] } \\
\text { does not pay full attention to } \\
\text { what you are trying to tell } \\
\text { [him/her] }\end{array}$ & 1 & 2 & 3 & 4 & 5 \\
\hline $\begin{array}{l}\text { 9. You have no worries about } \\
\text { putting your life in [your } \\
\text { doctor]'s hands. }\end{array}$ & 1 & 2 & 3 & 4 & 5 \\
\hline $\begin{array}{l}\text { 10. All in all, you have } \\
\text { complete trust in [your } \\
\text { doctor]. }\end{array}$ & 1 & 2 & 3 & 4 & 5 \\
\hline
\end{tabular}




\section{F. Adolescent Lifestyle Questionnaire}

Welcome to a survey about YOU! There are no right or wrong answers. Please circle the answer that is honest for you. No one else will ever know how you answered.

\begin{tabular}{|c|c|c|c|c|c|}
\hline & Never & Rarely & Sometimes & Often & $\begin{array}{l}\text { Almost } \\
\text { Always }\end{array}$ \\
\hline $\begin{array}{l}\text { 1. In an average week, I exercise } \\
\text { 3-4 times such as running, taking } \\
\text { long walks, dancing, playing ball, } \\
\text { swimming. }\end{array}$ & 1 & 2 & 3 & 4 & 5 \\
\hline $\begin{array}{l}\text { 2. I discuss problems and } \\
\text { concerns with people close to me. }\end{array}$ & 1 & 2 & 3 & 4 & 5 \\
\hline 3. I like who I am. & 1 & 2 & 3 & 4 & 5 \\
\hline $\begin{array}{l}\text { 4. When riding in an automobile, } \\
\text { I wear a seatbelt. }\end{array}$ & 1 & 2 & 3 & 4 & 5 \\
\hline $\begin{array}{l}\text { 5. I participate in a regular } \\
\text { program sports or exercise at } \\
\text { school. }\end{array}$ & 1 & 2 & 3 & 4 & 5 \\
\hline $\begin{array}{l}\text { 6. I enjoy spending time with my } \\
\text { friends. }\end{array}$ & 1 & 2 & 3 & 4 & 5 \\
\hline 7. I avoid doing drugs. & 1 & 2 & 3 & 4 & 5 \\
\hline $\begin{array}{l}\text { 8. I read labels on packaged foods } \\
\text { I eat. }\end{array}$ & 1 & 2 & 3 & 4 & 5 \\
\hline $\begin{array}{l}\text { 9. I express my concerns to } \\
\text { others. }\end{array}$ & 1 & 2 & 3 & 4 & 5 \\
\hline $\begin{array}{l}10 . \text { I know my strengths and } \\
\text { weaknesses. }\end{array}$ & 1 & 2 & 3 & 4 & 5 \\
\hline $\begin{array}{l}\text { 11. I refuse to get into a car if the } \\
\text { driver is drinking or taking } \\
\text { drugs. }\end{array}$ & 1 & 2 & 3 & 4 & 5 \\
\hline $\begin{array}{l}\text { 12. I exercise vigorously for } 20-30 \\
\text { minutes at least } 3 \text { times per week. }\end{array}$ & 1 & 2 & 3 & 4 & 5 \\
\hline $\begin{array}{l}\text { 13. I have good friendships with } \\
\text { girls and guys my age. }\end{array}$ & 1 & 2 & 3 & 4 & 5 \\
\hline $\begin{array}{l}\text { 14. If I had a problem, I have } \\
\text { people I could turn to }\end{array}$ & 1 & 2 & 3 & 4 & 5 \\
\hline 15. I am happy and content. & 1 & 2 & 3 & 4 & 5 \\
\hline 16. I look forward to the future. & 1 & 2 & 3 & 4 & 5 \\
\hline $\begin{array}{l}\text { 17. I avoid use of tobacco in } \\
\text { cigarette and chewable forms. }\end{array}$ & 1 & 2 & 3 & 4 & 5 \\
\hline
\end{tabular}


18. I report any unusual changes in my body to others such as a nurse, my parents, friends, or physician.

\begin{tabular}{|c|c|c|c|c|c|}
\hline $\begin{array}{l}\text { 19. I play sports at least } 3 \text { times } \\
\text { per week. }\end{array}$ & 1 & 2 & 3 & 4 & 5 \\
\hline 20. I usually follow a healthy diet. & 1 & 2 & 3 & 4 & 5 \\
\hline $\begin{array}{l}\text { 21. I try not to eat too many foods } \\
\text { high in fats. }\end{array}$ & 1 & 2 & 3 & 4 & 5 \\
\hline $\begin{array}{l}\text { 22. I try not to eat too many } \\
\text { foods high in salt. }\end{array}$ & 1 & 2 & 3 & 4 & 5 \\
\hline $\begin{array}{l}\text { 23. I try not to eat too many foods } \\
\text { high in sugar. }\end{array}$ & 1 & 2 & 3 & 4 & 5 \\
\hline
\end{tabular}

24. If I needed help, I have someone to turn to such as my family, friends, teachers, or

$\begin{array}{lllll}1 & 2 & 3 & 4 & 5\end{array}$
coaches.

25. I can express my feelings to others, such as my family or friends.

26. I exercise (walk, jog, play sports) to control my stress.

27. I talk to my friends about my stress.

28. I set goals for myself in life.

1

2

$3 \quad 4$

5

29. I examine my beliefs and values in life.

1

2

$\begin{array}{lll}3 & 4 & 5\end{array}$

30. I avoid drinking alcohol.

1

\section{I talk to the health} teacher/nurse about ways to improve my health.

1

2

32. I read pamphlets, teen

\begin{tabular}{|c|c|c|c|c|c|}
\hline $\begin{array}{l}\text { magazines about health topics of } \\
\text { interest. }\end{array}$ & 1 & 2 & 3 & 4 & 5 \\
\hline $\begin{array}{l}\text { 33. I discuss health concerns with } \\
\text { others such as friends, family, } \\
\text { coach, health nurse, or teacher. }\end{array}$ & 1 & 2 & 3 & 4 & 5 \\
\hline $\begin{array}{l}\text { 34. I often choose salads, fruits, \& } \\
\text { vegetables for snacks. }\end{array}$ & 1 & 2 & 3 & 4 & 5 \\
\hline $\begin{array}{l}\text { 35. I usually limit my intake of } \\
\text { "junk food" for snacks. }\end{array}$ & 1 & 2 & 3 & 4 & 5 \\
\hline $\begin{array}{l}\text { 36. I believe my life has a } \\
\text { purpose. }\end{array}$ & 1 & 2 & 3 & 4 & 5 \\
\hline
\end{tabular}


37. I usually use helpful strategies to help me deal with stress.

1

38. I usually make informed

choices about sexual

1

relationships.

39. I use prayer or spiritual beliefs to help me deal with stress.

2

3

$4 \quad 5$

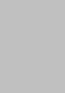

40. If I was going to be sexually

active, I would use protection against pregnancy or sexually transmitted diseases, such as

AIDS.

41. I usually choose foods without additives.

1

42. I try to do my best each day.

1

2

2

3

4

5

43. I am confident about my

beliefs and values in life.

1

2

3

3

$4 \quad 5$

5

$\begin{array}{lll}3 & 4 & 5\end{array}$




\section{G. Stanford Health Care Utilization Questionnaire}

1. In the past 12 months, how many times did you visit a doctor? Do NOT include visits while in the hospital or the hospital emergency room visits. times

2. In the past 12 months, how many times did you go to a hospital emergency room? times 


\section{H. Demographic and Individual Characteristic Survey}

1. What is your sex?
A. Female
B. Male

2. Are you Hispanic or Latino?
A. Yes
B. No

3. What is your race? If you are of more than one race, you may select more than one.
A. American Indian or Alaska Native
B. Asian
C. Black or African American
D. Native Hawaiian or other Pacific Islander
E. White

4. How old are you?
A. 14 years old
B. 15 years old
C. 16 years old
D. 17 years old
E. 18 years old
F. 19 years old

5. In what grade are you in now?
A. 9 th grade
B. 10th grade
C. $11^{\text {th }}$ grade
D. $12^{\text {th }}$ grade

6. Do you live with your...
A. Biological mother
B. Step-mother
C. Foster mother
D. Adoptive mother
E. Grandmother
F. Someone else
G. No mother figure 
7. Do you live with your...
A. Biological father
B. Step-father
C. Foster father
D. Adoptive father
E. Grandfather
F. Someone else
G. No father figure

8. Do you receive free or reduced lunch at school?
A. Yes, I receive free lunch
B. Yes, I receive reduced lunch
C. No, I pay for my lunch

9. What kind of health insurance do you have?
A. Medicaid or Hoosier Healthwise
B. Military insurance
C. Private insurance (like insurance from your parent's job)
D. Other insurance
E. I do not have health insurance
F. I don't know

10. In general, would you say your health is:
A. Excellent
B. Very good
C. Good
D. Fair
E. Poor

11. Is there a particular doctor's office, clinic, health center, or other place that you usually go if you are sick or need advice about your health?
A. Yes
B. No

12. Which of these places best describes where you USUALLY go when you are sick or need advice about your health?
A. Clinic or health center
B. Doctor's office
C. Hospital emergency room
D. Urgent care center
E. Some other place
F. I don't go to the one place most often
G. I don't know 
13. How do you usually get to the doctor's office or health clinic?
A. Drive
B. Driven by someone else
C. Taxi, bus, train, or other public transportation
D. Walk
E. Some other way

15. How difficult is it for you to get to the doctor's office or health clinic?
A. Very difficult
B. Somewhat difficult
C. Not too difficult
D. Not at all difficult

16. In the past year, was there a time when you thought you should see a doctor or nurse about your health?
A. Yes
B. No

17. Did you go see a doctor or nurse about your health at that time?
A. Yes
B. No

18. If not, why? (Choose all that apply)
A. Didn't know where to go
B. Had no transportation
C. Couldn't pay
D. Hard to find the time
E. No one available to go along
F. Parent or guardian would not go
G. Afraid someone I know might see me
H. Didn't want parents to know
I. Afraid of what the doctor would say or do
J. Thought or hoped the problem would go away
K. I am not treated with respect there
L. Other reason not listed

19. What was your height without your shoes on? feet, inches

20. What was your weight without your shoes on? pounds

21. In the past 30 days,

A. How many cigarettes have you smoked?

B. How many cigars or mini-cigars have you smoked?

C. How many times have you dipped, chewed, or used smokeless tobacco? 
22. Have you ever been diagnosed with any of these conditions? Mark all that apply:
A. Acne
B. ADHD
C. Anemia
D. Allergies
E. Asthma
F. Depression
G. Diabetes
H. High blood pressure
J. Overweight
L. Obese
M. None of the above 


\section{CURRICULUM VITA}

\section{Heather K. Hardin, MSN, RN, PhD candidate}

555 South Floyd Street

Louisville, KY 40202

heather.hardin@louisville.edu

\section{Education}

PhD in Nursing, December 2014

University of Louisville School of Nursing, Louisville, KY

University Graduate Fellowship

Dissertation Title: Lifestyle behaviors, trust of health care providers, and utilization of health services among adolescents living in a rural area.

Dissertation Chair: Barbara J. Speck, PhD, RN

Certificate in Health Professions Education, May 2012

University of Louisville School of Education, Louisville, KY

Master of Science in Nursing, May 2012

University of Louisville School of Nursing, Louisville, KY

Dean's Award for Highest Scholarship

Certified Lactation Specialist, May 2012

Lactation Education Consultants, Wheaton, IL

Bachelor of Science in Nursing, May 2007

Indiana University Southeast School of Nursing, New Albany, IN

Associate of Science in Nursing, May 2005

IVY Tech State College School of Nursing, Sellersburg, IN

Cum Laude Honors 


\section{RN Licensure}

\section{Registered Nurse}

State of Kentucky, License 1106494, 2005-present.

\section{Registered Nurse}

State of Indiana, License 28167218A, 2006-present.

\section{Research Experience}

Principal Investigator, Doctoral Dissertation, Spring 2014

Health behaviors, trust of health care providers, and utilization of health services among adolescents living in a rural area.

The purpose of this study was to examine individual characteristic variables among adolescents' and determine the extent to which these variables influence trust of health care provider, health behaviors, and utilization of health services.

\section{Project Director, Clinical Trial, Fall 2014}

Improving outcomes for children with special needs and their caregivers using CBT. The purposes of this project were to provide brief cognitive behavior therapy for lowincome female caregivers with depressive symptoms who have a child with special health care needs and to evaluate its effects in levels of depressive symptoms.

\section{Principal Investigator, Pilot Study, Spring 2014}

Trust of health care providers among adolescents living in a rural area.

The purpose of this study was to test three instruments and to assess school administrators' willingness to participate in recruitment of subjects in preparation for the dissertation study.

\section{Co-Investigator, Pilot Feasibility Study, Fall 2012}

Testing Rotenberg's framework of interpersonal trust among adolescents using structural equation modeling

The purpose of this study was to test Rotenberg's Framework of Interpersonal Trust among adolescents using structural equation modeling in order evaluate its potential in planning the dissertation study.

\section{Co-Investigator, Secondary Data Analysis, Spring 2011}

Utility analysis of HPV vaccine mandate for public school entry.

The purpose of this study was to conduct a utility analysis of mothers' preferences for HPV vaccine mandate for public school entry. 


\section{Professional Nursing Experience}

\section{Research Assistant}

University of Louisville School of Nursing, Louisville, KY, 2012-2014

Acted as Editor-in-Chief of the Cutting Edge research newsletter

Conducted content analysis of qualitative data related to advanced nursing curriculum Prepared manuscripts for publication in scientific journals

Provided electronic literature search training to School of Nursing faculty

Designed floor-to-ceiling advertising banners for the School of Nursing Research

Office

Designed award-winning research presentations and posters

\section{Adjunct Clinical Faculty}

Spalding University School of Nursing, Louisville, KY 2011-2011

Facilitated demonstrations in basic nursing skills such as physical assessment and medication administration

Responsible for the implementation of the medical/surgical clinical at University of Louisville Hospital

\section{Teaching Assistant}

University of Louisville School of Nursing, Louisville, KY, 2011-2012

Responsible for didactic lectures for undergraduate Research \& Evidence Based

Practice course

Designed and implemented online assignments for undergraduate Research \&

Evidence Based Practice course

Moderated online discussions in undergraduate Professional Issues course

Responsible for the implementation of the community portion of the mother-baby clinical at the Teenage Pregnancy and Parenting high school in Louisville, KY

Facilitated simulation of obstetrical emergencies

\section{Registered Nurse \& Nutritionist}

WIC, Salem, IN, 2011-present

Acted as a certifying professional authority for the federal program Women, Infants, \& Children

Assessed nutritional needs of pregnant women, infants, and children under age five Provided nutritional education to families

Provided breastfeeding education, assessment, and counseling 


\section{University Graduate Fellow}

University of Louisville School of Interdisciplinary and Graduate Studies,

Louisville, KY, 2009-2011

Enrolled in additional statistics courses to broaden my analytical skill set (structural equation modeling and utility analysis)

Conducted secondary analysis study using structural equation modeling

Conducted secondary analysis study using utility analysis

Designed and produced a national award-winning podcast about nurse researchers

Completed a health policy internship on Capitol Hill in Washington, DC

\section{Research Assistant}

University of Louisville School of Nursing, Louisville, KY, 2008-2009

Prepared manuscripts for publication in scientific journals

Assisted with grant preparation procedures

Entered quantitative data into statistical software databases

Conducted basic quantitative statistical analysis

Provided qualitative interview transcription

Conducted content analysis of qualitative data related to health services research

Organized and assisted in conduction of focus groups related to health services

research and advanced nursing curriculum

\section{Registered Nurse, Medical/Surgical Telemetry Unit}

\section{Washington County Memorial Hospital, Salem, IN, 2006-2006}

Managed pre-operative care for patients with cataract removal or epidural

Provided primary nursing care for pediatric and adult patients with acute care needs such as pneumonia or post-operative observation complicated by conditions such as diabetes or cancer-related compromised immunity

\section{Registered Nurse, Medical/Surgical Telemetry Unit \\ Jewish Hospital, Louisville, KY, 2005-2008}

Provided complex primary nursing for adult patients with acute post-operative care needs such as bowel resection, TURP, or hysterectomy with patient controlled analgesia, epidural, or insulin drip complicated by chronic conditions such as diabetes, hepatitis $\mathrm{C}, \mathrm{MRSA}$, chronic renal failure, and/or solid organ transplant Developed a unit-specific training manual for newly hired nurses Provided charge-nurse responsibilities for 22-bed cardiac monitored unit 


\section{Publications}

Wang, X., Robinson, K., \& Hardin, H. (2014). The impact of caregiving on caregivers' medication adherence and appointment keeping. Western Journal of Nursing Research. Published online ahead of print. doi: 10.1177/0193945914533158

Abusalem, S. \& Hardin, H. (2011). Predictors of home health nurses' change in practice after experiencing care errors. Rehabilitation Nursing, 36(3): 98-105, 128.

Berger, J., Hardin, H. \& Topp, R. (2011). Implementation of a virtual journal club in a clinical setting. Journal for Nurses in Staff Development, 27(3): 116-120.

Hardin, H. \& McKillip, C. (Producers). (2010). The Role of Nurse as Scientist (Still media and audio podcast). Council for the Advancement of Nursing Science \& American Academy of Nursing: Washington, D.C. Available at www.nursingscience.org.

\section{Editorial Position}

Editor-in-Chief, The Cutting Edge: Research \& Scholarship Newsletter for the University of Louisville School of Nursing, 2013-2014.

\section{Presentations at Professional Meetings}

Hardin, H. \& Hetland, B. (2014). New student member orientation. Conference programming presentation at the Midwest Nursing Research Conference in St. Louis, MO, March 27-30, 2014.

Gilmore-Bykovkyi, A., Hardin, H., \& Swann, M. (2014). Emerging Scholars Luncheon. Conference programming presentation at the Midwest Nursing Research Conference in St. Louis, MO, March 27-30, 2014.

Hardin, H. (2013). Trust of Health Care among Adolescents: An Integrative Review. Midwest Nursing Research Society conference: Chicago, IL.

Hardin, H., Randall, B., \& Myers, J. (2012). Testing Rotenberg's Framework of Interpersonal Trust among Adolescents Using Structural Equation Modeling. Midwest Nursing Research Society conference: Dearborn, MI.

Hardin, H., Blankenship, B., Kaur, G. \& LaJoie, S. (2011). Utility analysis of HPV vaccine mandate for public school entry. Sigma Theta Tau International 2011 Research Congress: Cancun, Mexico. 
Hardin, H., Blankenship, B., Kaur, G. \& LaJoie, S. (2011). Utility analysis of HPV vaccine mandate for public school entry. Midwest Nursing Research Society:

Columbus, $\mathrm{OH}$

Hardin, H. \& McKillip, C. (Producers). (2010). The role of nurse as scientist. (Still media and audio podcast). Council for the Advancement of Nursing Science \& American Academy of Nursing State of the Science Congress: Washington, D.C. National podcast competition winner. \$1725 award.

Hardin, H. \& McKillip, C. (Producers). (2010). The role of nurse as scientist. (Still media and audio podcast). Midwest regional podcast competition winner. Midwest Nursing Research Society conference, Kansas City, MO. \$1000 award.

Abusalem, S. \& Hardin, H. (2010). Predictors of home health nurses' change in practice after experiencing care errors. Southern Nursing Research Society: Austin, TX.

Lehna, C. \& Hardin, H. (2010). The biochemical response to stress in children: A review of the evidence. Southern Nursing Research Society: Austin, TX.

Abusalem, S. \& Hardin, H. (2009). Predictors of home health nurses' change in practice after experiencing care errors. Research Louisville, Louisville, KY.

Lehna, C. \& Hardin, H. (2009). The biochemical response to stress in children: A review of the evidence. Research Louisville, Louisville, KY.

\section{Grant Funding}

University of Louisville Graduate Student Council Travel Award for travel expenses associated with presenting student programming at the 2014 Midwest Nursing Research Society conference in St. Louis, MO. \$250.

Dissertation research grant, Rural Nurses Organization, 2013. \$500.

University of Louisville Graduate Student Council Travel Award for travel expenses associated with presenting a research poster at the 2013 Midwest Nursing Research Society conference in Chicago, IL. \$250.

Ruth Craddock Award for travel expenses associated with presenting a research poster at the 2012 Midwest Nursing Research Society conference at Dearborn, MI. \$500.

University of Louisville Graduate Student Council Travel Award for travel expenses associated with presenting a research poster at the 2012 Midwest Nursing Research Society conference in Dearborn, MI. \$250. 
Sigma Theta Tau International Edith Anderson Leadership Education Award for travel expenses associated with presenting a research poster at the 2011 Sigma Theta Tau International Research Congress in Cancun, Mexico. $\mathbf{\$ 7 5 0 .}$

Ruth Craddock Award for travel expenses associated with presenting a research poster at the 2011 Sigma Theta Tau International Research Congress in Cancun, Mexico. \$600.

University of Louisville International Center, Graduate Student Travel Award for travel expenses associated with presenting a research poster at the 2011 Sigma Theta Tau International Research Congress in Cancun, Mexico. \$500.

Ruth Craddock Award for travel expenses associated with presenting a research poster at the 2011 Midwest Nursing Research Society at Columbus, OH. $\mathbf{\$ 6 0 0 .}$

Club Programming Committee Grant for organizing a professional mentoring workshop at the University of Louisville School of Nursing, Louisville, KY, 2011. \$175.

Ruth Craddock Award for travel expenses associated with presenting a podcast at the 2010 Midwest Nursing Research Society conference at Kansas City, MO. \$500.

University of Louisville Graduate Student Council Travel Award for travel expenses associated with presenting a podcast at the 2011 Midwest Nursing Research Society conference at Kansas City, MO. $\$ \mathbf{3 0 0}$.

Ruth Craddock Award to present a research poster at the 2010 Southern Nursing Research Society conference at Austin, TX. \$600.

Celeste M. Nichols Professional Development Award from the University of Louisville Women's Center, Louisville, KY, 2009. \$500.

\section{Teaching Experience}

\section{Fall 2014}

NURS 364 Therapeutic Nursing Interventions, clinical faculty, 14 of 14 class meetings, 10 students, Trilogy Rehabilitation Center clinical site, University of Louisville, School of Nursing, Louisville, KY.

\section{Spring 2012}

NURS 461 Childbearing Family Nursing, clinical faculty, six of 14 class meetings, 20 students, Teenage Parent Program (TAPP) clinical site, University of Louisville School of Nursing, Louisville, KY.

NURS 374 Research \& Evidence Based Practice, teaching assistant, four of 14 class meetings, 60 students, University of Louisville School of Nursing Louisville, KY. Developed online course content. 
NURS 472 Transition to Practice, teaching assistant, online content moderator, online/didactic hybrid course, 60 students, University of Louisville School of Nursing, Louisville, KY.

NURS 490 Capstone Clinical Experience, clinical preceptor at Orange County WIC, one student, 45 hours, Vincennes University School of Nursing, Vincennes, IN.

\section{Fall 2011}

NURS 472 Transition to Practice, teaching assistant, online content moderator, online/didactic hybrid course, six of 10 class meetings, 60 students, University of Louisville School of Nursing, Louisville, KY.

NURS 374 Research \& Evidence Based Practice, teaching assistant, four of 14 class meetings, 60 students, University of Louisville School of Nursing, Louisville, KY.

NURS 314 Health Assessment Clinical, clinical instructor, one of 6 class meetings, 16 students, Spalding University School of Nursing, Louisville, KY.

\section{Summer 2011}

NURS 314 Health Assessment Clinical, clinical instructor, five of six class meetings, 25 students, Spalding University School of Nursing, Louisville, KY.

NURS 304 Foundations Clinical, clinical instructor, six of six class meetings, 22 students, Spalding University School of Nursing, Louisville, KY.

NURS 301 Nursing Success Clinical, clinical instructor, teaching medication administration and professional competencies, five of six class meetings, 25 students, Spalding University School of Nursing, Louisville, KY.

\section{Leadership \& Service}

Co-Chair of the Emerging Scholars Committee, Midwest Nursing Research Society, 2011-2014.

Member of the Membership Committee, Midwest Nursing Research Society, 2012-2014.

President of the Association of Graduate Nursing Students, University of Louisville, Louisville, KY, 2009-2011.

Chairperson of the Awareness Washington County CenterPeace Park Fundraiser, Salem, IN, 2010-2013.

Doctoral nursing student representative to the Graduate Student Council, University of Louisville School of Interdisciplinary and Graduate Studies, Louisville, KY, 2008-2011. 
Doctoral student representative to the Graduate Academic Affairs Committee, University of Louisville School of Nursing, Louisville, KY, 2008-2010.

Volunteer immunization provider at the Washington County Public Health Office H1N1 Immunization Clinic, Salem, IN, 11/2009

Volunteer clinical leader \& immunization provider for the Louisville Metro Department of Public Health \& University of Louisville drive-through H1N1 Immunization Clinic at UofL Cardinal Stadium, Louisville, KY, 10/2009.

\section{Professional Memberships}

Midwest Nursing Research Society, 2010-present.

National Rural Health Association, 2013-present.

Sigma Theta Tau International Honor Society, Iota Zeta Chapter, University of Louisville, 2009-present.

American Nurses Association, Indiana Nurses Association, 2009-2012.

Southern Nursing Research Society, 2009-2011.

Council for Advancement of Nursing Science, 2010-2011.

\section{Professional Development}

Colson, S. (2012). Biological Nurturing. Workshop of the Indiana Women, Infants \& Children program at the Monon Community Center in Carmel, IN, November 1, 2012.

Sturtevant, D. (2012). Participant-Centered Education. Workshop of the Indiana Women, Infants \& Children program at French Lick, IN, September 27, 2012.

Lactation Training Five-Day Course. (2012). International Lactation Consultant Association. Indianapolis, Indiana. April 30-May 4, 2012.

Delphi Center. (2012). Celebration of Teaching \& Learning. University of Louisville. Louisville, Kentucky. February 9, 2012.

Prevost, S (2011). Research Abstracts and Grant Writing: Basic Strategies for Success. Workshop at the 2011 Sigma Theta Tau International Research Congress. Cancun, Mexico. July 13, 2011. 
Nurse in Washington Internship. (2011). Internship on Capitol Hill in Washington, DC, March 13-15, 2011.

Conn, V., Kilanowski, J., Artinian, N., Biordi, D. \& Talleferro, D. (2010). Launching a successful career: Notes for early career faculty and doctoral students. Workshop at the 2010 Midwest Nursing Research Society conference, Kansas City, MO.

Bogucka, R., Harper, G. \& McKay, B. (2010). Authorship: Your rights and responsibilities. Workshop at the 2010 Southern Nursing Research Society Conference, Austin, TX. 